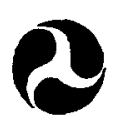

U.S. Deportment of Transporiation

National Highway

Traffic Safety Administration

\title{
Alcohol Limits for Drivers: A Report on the Effects of Alcohol and Expected Institutional Responses to New Limits
}

Report To Congress

February 1991 


\section{TABLE OF CONTENTS}

EXECUTIVE SUMMARY

Page

CHAPTER I INTRODUCTION

Preface

Study Approach

Expert Panel

Scope of Report

\section{SECTION I}

LITERATURE REVIEW

$\begin{array}{lll}\text { CHAPTER II THE EFFECTS OF ALCOHOL ON BEHAVIOR } & 8\end{array}$

Background

Physiological Effects

Laboratory Studies of Driving-Related Skills $\quad 12$

Neuromuscular

Vision

Tracking

Time-sharing and Attention

Attitude and Mood

Low BACs

Laboratory Studies

Simulator Studies

Closed Course Studies

Summary

CHAPTER III ALCOHOL CRASH PROBLEM

Epidemiological Research

Crash Outcome

Crash Characteristics

Driver Characteristics

Confidence Limits and Statistical Significance

Estimated Risk Using Similar Drivers as Controls

Crash Responsibility 


\section{EXECUTIVE SUMMARY}

This is the first of two reports in response to a congressional mandate to study the alcohol concentration at which a driver should be considered under the influence. Relevant findings from the work to date, as well as initial conclusions and recommendations, are presented.

This report is based on a review of scientific literature on the influence of $\mathrm{BAC}^{\mathrm{l}}$ on driver performance and crashes, a review of existing legislation on BAC limits, and data collected on expected institutional response to alternative BAC limits - 0.08 , 0.04 , and 0.00 for the general driving public. The final report will take the information developed in all phases of this project and integrate present conclusions and recommendations regarding the setting of specific BAC limits.

It should be understood, however, that specific BAC limits have already been established for drivers of commercial motor vehicles (generally those that are greater than 26,000 pounds gross vehicle weight rating, those that carry 16 or more persons, or those that are placarded for hazardous materials). These drivers are prohibited from driving with any amount of alcohol in their systems and are subject to stiff disqualification requirements if they are convicted of driving with a BAC of 0.04 percent or above. These penalties were mandated by the Commercial Motor Vehicle Safety Act of 1986 (CMVSA). Because various institutional considerations are different for these drivers from those for drivers of smaller vehicles, this report focuses only on the general driving public.

\section{SCIENTIFIC LITERATURE ON ALCOHOL EFFECTS}

The major findings regarding the effects of BAC on driver performance and crashes may be summarized as follows:

A. The scientific literature clearly documents the negative effects of alcohol on driver performance. Performance of driving-related tasks decreases at BACs

\footnotetext{
'In this report, BAC refers to either blood alcohol concentration, stated as grams per 100 milliliters of blood or breath alcohol concentration, stated as grams per 210 liters of breath. Issues related to measurement by blood or breath are treated elsewhere in this report.
} 
above zero. As BAC increases, the effects are greater, more functions are degraded, and more people show the effects.

B. Substantial data show that the probability of a crash increases with increases in BAC, especially for more severe crashes. The more alcohol in a driver, the greater the risk of a crash. The exact nature of the increase in crash risk due to alcohol cannot be stated quantitatively with certainty. However, when groups of drivers with similar characteristics are compared, the risk for all groups is greater for any measurable BAC and the risk increases as BACs rise.

C. There is no threshold for alcohol effects on performance or increase in crash risk. Although the effects of alcohol on impairment and crash risk appear more dramatically above 0.05 or 0.08 ; for some drivers, any measurable alcohol puts them at increased risk. One cannot specify a BAC level above which all drivers are dangerous and below which they are safe or at "normal" risk.

D. The overwhelming weight of evidence indicates alcohol is a major causal factor in traffic crashes. The observed performance decrements in laboratory tasks, together with the over-representation of alcohol in crashes, is scientific evidence that fully supports efforts to reduce the BACs of drivers on the road as a means to reduce highway crashes and their costs.

\section{INSTITUTIONAL RESPONSE TO CHANGES IN BAC LIMITS}

\section{A. Summary of BAC Limits Laws}

A variety of laws in the United States specify a BAC limit for driving by the general driving public; most specify 0.10 as the limit. The variations are important because they result in differences not only in the limit itself but also in how the limit is implemented.

There are basically two types of laws that specify BAC limits. "Per se" laws make it illegal by (or in) the act itself to drive if one's BAC level is over a specified BAC limit. "Presumptive"2 laws say that if an individual is driving over a given BAC it is presumed (or taken for granted) that the driver is impaired, but the presumption is open to refutation in court.

\footnotetext{
"In this report, the term "presumptive" refers to both presumptive and prima facie laws which are similar but not identical.
} 
Forty-five states and the District of Columbia have per se legislation. Twenty-five of these jurisdictions also have presumptive laws. Five states have only presumptive laws specifying an illegal BAC. The laws in some states also presume drivers to be unimpaired if their BAC is 0.05 or below.

Seven states and the District of Columbia have two-tiered BAC legislation in which there are two illegal BAC levels. Exceeding the lower level constitutes a less serious offense with lesser penalties.

Most jurisdictions have a $0.10 \mathrm{BAC}$ limit. Forty-one have a per se limit of 0.10 . Five states have only a presumptive limit of 0.10 . Four states have an 0.08 presumptive limit. One has a 0.12 per se limit and a 0.10 presumptive limit. In response to requirements under the CMVSA of 1986 , over 40 states have adopted a 0.04 per se limit for commercial drivers.

\section{B. Institutional Response to Change}

The nature and extent of change in the BACs of drivers on the road that would result from a change in the legal BAC limit is not clear. The BAC of drinking drivers is influenced by the interaction of complex educational, administrative, and legal systems $^{3}$. It is important to know how the institutions that deal with drinking drivers would react to changes in BAC limits for two reasons: (1) how the limits would be applied would influence future driver behavior and hence determine the actual impact of a lower BAC limit; (2) the effects on the system are part of the costs and benefits of any proposed change.

The following preliminary findings are based on an initial study of expected institutional responses to a near term change in BAC limits:

1. The establishment of 0.08 limit would likely result in: some increase in the number of cases throughout the system (detection through treatment), an increase in convictions just above 0.10 , short-lived attention from the media, and calls for better techniques to provide police with the basis for reasonable suspicion to stop and probable cause to arrest drivers at $0.08-0.10$. Institutions could adapt to a BAC limit of 0.08 with a minimum of problems.

2. The establishment of still lower limits such as 0.04 or 0.00 would likely result

${ }^{3}$ Referred to below as "the system." 
in widespread and continuing attention from the media, the public and public officials concerning the effects of low BACs. A number of problems would limit the number of cases successfully prosecuted at the new lower levels: difficulties in gaining a basis for reasonable suspicion or probable cause, official hesitancy in enforcing what they may perceive as an unpopular law or one without strong evidence, concerns about overloading the court system with "less important" cases. However there would be some increase in cases and successful prosecutions near and above the previous limit (e.g., 0.10). A larger increase in case load may occur as technology is developed for better detection. Institutions would have great difficulty in effectively implementing a BAC limit of 0.04 or 0.00 for the general driving public without additional changes. ${ }^{4}$

\section{RECOMMENDATIONS}

1. There should be a major public education effort to inform the motoring public of the dangers of driving at low BAC levels, and specifically that there is no "safe" level or amount that an individual can assume will not impair one's driving performance and increase the risk of a crash.

2. All states should have "per se" laws that refer to the BAC of drivers.

3. All states should repeal laws that create a presumption that a driver is not under the influence at any BAC above zero.

4. All states should include alcohol concentration as measured by breath (expressed as grams of alcohol/210 liters of breath) in their statutory definitions. While blood measurement may also be used, breath alcohol as a measure by itself, without reference to blood, should be established as a fully acceptable and complete indication of alcohol concentration.

5. Until a final recommendation is developed, a 0.08 per se limit, as measured by breath, should be adopted by jurisdictions considering a lowering of the legal limit for the general driving public.

6. Further consideration should be given to a multilevel system of administrative,

\footnotetext{
${ }^{4}$ This report deals with BAC limits with respect to the general driving public and does not address populations such as commercial truck drivers who are subject to a state and federally enforced 0:04 BAC limit.
} 
civil and criminal penalties or restrictions for drivers who have a BAC as measured in breath at 0.08 and below.

\section{FINAL REPORT}

Future work on this project will cover BAC limits as they influence driver decision making and the BACs of drivers on the road. It will also carry out recommendation 6 preceding as it considers further the potential problems associated with lowering BAC limits and the actions that seem to be needed for effective implementation of lower BAC limits for the general driving public. The final report will integrate the information developed in all phases of this project, identify the issues and present conclusions and recommendations regarding the setting of specific BAC limits. The final report will be submitted in December 1991. 


\section{CHAPTER I}

\section{INTRODUCTION}

\section{PREFACE}

On behalf of the Secretary of Transportation, the National Highway Traffic Safety Administration (NHTSA) has prepared this report on the relationship between breath and blood alcohol concentration (BAC) and driving impairment. The report was undertaken in response to Section 9003 of the Anti-Drug Abuse Act of 1988 (P.L. 100-690) which directed the Secretary to:

"...conduct a study to determine the blood alcohol concentration at or above which an individual when operating any motor vehicle should be deemed to be driving while under the influence of alcohol."

An earlier study, "Zero Alcohol and Other Options: Limits for Truck and Bus Drivers" was identified by the Senate Committee as containing data that would be useful in conducting the present study, and those data have been utilized.

While data concerning the effects of alcohol on driving performance are relevant to issues concerning all drivers, there are differences between commercial drivers, and the general driving public with respect to both (a) the nature of the threat from alcohol involvement (e.g., more difficulty in driving, more damage from larger vehicles, and presence of public passengers in buses), as well as (b) the nature of the system that can be applied to control or limit alcohol in drivers (commercial drivers and vehicles are subject to various rules and regulations that do not apply to the general public). Commercial drivers are subject to a State and federally enforced 0.04 BAC limit. Other than noting at the outset that such differences exist, the present report does not treat special populations such as commercial drivers. It deals with BAC limits solely with respect to the general driving public.

\section{Background}


Blood alcohol concentration $(B A C)^{5}$ limits for drivers of vehicles are set by the individual states. Statutory limits indicate the BAC at which a driver is presumed to be impaired or the BAC level at which it is an offense to drive. Early legislation usually set rather high limits, above which virtually all drivers were severely alcohol-impaired (often $0.15 \mathrm{BAC}$ or higher). This meant that many drivers were alcohol-impaired at BAC levels well below the legal limit. As further evidence of the relation between driver BAC, impairment, and crash risk became better understood, many states lowered their BAC limits. With few exceptions, most states have adopted a 0.10 BAC limit.

The primary objective of a statutory BAC limit is to minimize alcohol-impaired driving and alcohol-related crashes, injuries, and fatalities. It is important to realize that there are alcohol-impaired drivers currently on the road with a wide range of $B A C$ levels, above and below the legal limit. The practical goal of any drunk driving policy is to reduce overall BAC levels. A statutory BAC limit is unlikely to eliminate from the road all drivers with higher BACs. But, if it can reduce their number, by shifting higher BACs to lower or zero BACs, then it will improve safety.

A BAC limit is only one component of a complex system that affects drinking and driving. Other components include the other drunk driving laws, the police and courts who enforce these laws, state and local officials who can establish and encourage anti-drunk driving programs, community or national organizations such as MADD, SADD, and RID, the media who report on and influence the public's views on alcohol use and drunk driving, health professionals who help set attitudes and practices on alcohol use, jails and treatment facilities for convicted drunk drivers, and others. All these components interact to affect the daily drinking and driving decisions of individual drivers.

Laws establishing BAC limits affect drinking and driving as the laws work through this system. We can think of the process in three steps. The more we understand about each step, the better we are able to anticipate the effects that a reduced statutory BAC limit will have on drunk driving and alcohol-related crashes.

1) A BAC limit directly affects how police enforce drunk driving laws and how courts dispose of drunk driving charges. A BAC limit also affects how the media, restaurants, taverns, individual hosts, community groups such as MADD, SADD, and RID, and others view drinking and driving. These

\footnotetext{
SIn this report BAC refers to either blood alcohol concentration, stated as grams per 100 milliliters of blood, or breath alcohol concentration, stated as grams per 210 liters of breath. Issues related to measurement by blood or breath are addressed elsewhere in this report.
} 
institutions clearly interact with each other and respond to each other's practices. For example, the courts cannot convict a driver on drunk driving charges unless the police first bring charges. On the other hand, the police will not enforce a law unless their citations are upheld in court. Prior to this study it was far from clear how these institutions would react to a new BAC limit.

2) As the system -- police, courts, media, other organizations -- responds to a BAC limit, it sends many messages to individual drivers. The enforcement and conviction level, as publicized through the media, sends messages on the chance of being apprehended and convicted of drunk driving. Media accounts of drunk driving crashes send messages on the risk of a crash. Community groups and media send messages on social norms involving drunk driving. Restaurants with designated driver programs and sports arenas with limited alcohol sales policies send messages about acceptable drinking and driving behavior. How individual drivers will interpret these messages and how they will modify their individual drinking and driving behavior is an important factor that needs to be considered.

3) If we can estimate how drinking and driving patterns might change in response to a new BAC limit, we then can estimate how driver BAC levels on the road might change and how this will affect crashes, injuries, and fatalities.

These steps clearly show important pieces of information we should know before we propose an optimal BAC limit. We have the least information about: how the system will interpret and implement a BAC limit, what messages will then be sent to individual drivers, and how drivers will act in response to these messages.

\section{STUDY APPROACH}

This study seeks to determine the BAC level at which a driver should be deemed to be driving while under the influence of alcohol. The study will examine the relationship between BAC, driving impairment and crash risk. It will also examine some of the consequences of setting a lower BAC limit for the general driving public. Information will be collected to estimate how different statutory BAC limits might affect drinking and driving behavior and alcohol-related crashes.

To accomplish this task, NHTSA developed a three-phased study. Each phase is described briefly below. 


\section{Phase I}

The purpose of the Phase I literature review was to examine existing studies assessing how driver impairment and crash risk depend on a driver's BAC. Because there have been a number of fairly exhaustive reviews of the literature in this area, there was no need to duplicate previous efforts. Instead, we relied on these previous reviews to prepare an overview of what research can tell us about this topic. Specifically, we used the recent Transportation Research Board study [Zero Alcohol and Other Options: Limits for Truck and Bus Drivers, Special Report 216, 1987], our own two most recent State of the Knowledge Reports ("Alcohol and Highway Safety 1978: A Review of the State of Knowledge," R. K. Jones and K. B. Joscelyn, 1978, and "Alcohol and Highway Safety 1984: A Review of the State of Knowledge," NHTSA, 1985) and a recent report prepared for NHTSA on the effects of low BACs ("Effects of Low Doses of Alcohol on Driving-Related Skills: A Review of the Evidence," Moskowitz, H. and Robinson C. D., 1988).

As these review articles only covered the literature up to about 1983 , we conducted a literature search to identify any recently published research. This literature search was conducted by a contractor engaged to review the alcohol and highway safety literature in preparation for a 1989 updated edition of our State of Knowledge Report.

\section{Phase II}

In Phase II information was sought that would allow us to estimate how selected lower BAC limits will affect the institutions dealing with drinking and driving. To do this, we conducted four regional workshops involving the various institutions that deal with drinking and driving -- police, courts, state and local officials, community organizations, media, and others. At the workshops we sought to learn how these different parties currently respond to the statutory BAC limit and how they believe they would respond to a new limit. We felt that it was important to have all parties available to discuss the issues at the same time, since what each does depends heavily on what the others do. The workshop results were reviewed by a panel of experts and project staff. An assessment of what would occur in the system under three alternate BAC limits $(0.08,0.04$ and 0.00$)$ for the general driving public was developed.

\section{Phase III}

In Phase III, which is currently in progress, we will study the effects on drinking and 
driving behavior of system changes in response to reduced BAC limits. Here we will investigate how drivers currently make drinking and driving decisions, and how the current system of laws and information affects these decisions. Then we will assess what changes may occur in response to a new BAC limit. This means we need information on how drivers think and act. We will gather this information through a statistically representative survey of drivers. The survey will assess:

- The basis for drivers' drinking and driving decisions.

- Drivers' understanding of BAC limits.

- Drivers' attitudes concerning alcohol impairment, and their methods for assessing impairment in themselves and others.

- Drivers' perceptions of their crash and injury risk when driving at different impairment levels.

- Drivers' perceptions of their likelihood of being stopped by police, and receiving sanctions when driving at different impairment levels.

- Drivers' reactions to changes in BAC limits.

The survey also will gather information on drivers' actual drinking and driving behavior. From the survey data and other available research, we will assess how driver decisions and actions are affected by the current BAC limits and how they may be influenced by different limits.

\section{EXPERT PANEL}

NHTSA assembled a panel of experts in all areas affecting drinking and driving to provide balance, oversight, and objectivity to our study. The panel included members of the Transportation Research Board standing Committee on Drugs and Alcohol, the committee that prepared the TRB "Zero Alcohol" study, and other internationally recognized experts in the field. The panel was assembled for the purpose of obtaining the advice of the individual members. They were asked to make recommendations concerning each phase of the study, to recommend individuals to participate in the regional workshops, to review and assess each phase's results, and to indicate the conclusions that could be drawn. The twenty-one members of the panel are shown below. Appendix A provides additional information about each panelist. 


\section{Expert Panel Members}

Wayne Andersen, Supervising Judge, Circuit Court in Cook County, IL Richard D. Blomberg, President, Dunlap and Associates, Norwalk, CT B.J, Campbell, Director, Highway Safety Research Center, Chapel Hill, NC Dora Goldstein, Stanford University, Palo Alto, CA

Harold Holder, Prevention Research Center, Berkeley, CA

Paul Hurst, Wellington, New Zealand

Richard Jessor, Institute of Behavioral Science, University of Colorado

Hans Laurell, Swedish Road Safety Office, Borlange, Sweden

Adrian K. Lund, Insurance Institute for Highway Safety, Arlington, VA

Larry G. Majerus, R.L. Polk and Co., Detroit, MI

Kimball I. Maull, University of Tennessee Medical Center, Knoxville, TN

Herbert Moskowitz, University of California, Los Angeles, CA

Laimutis A. Nargelanas, Illinois State Police, Springfield, IL

Olga J. Pendleton, Texas Transportation Institute, College Station, TX

M. Bud Perrine, Vermont Alcohol Research Center, Burlington, VT

Robert H. Reeder, Northwestern University Traffic Inst., Evanston, IL

Kaliste Saloom, Jr., Judge, Lafayette, LA

Larry N. Thompson, Department of Public Safety, Phoenix, AZ

Chauncy Veatch III, Dep't of Alcohol \& Drug Abuse Pgs, Sacramento, CA

Robert Voas, National Public Services Research Institute, Landover, MD

\section{SCOPE OF REPORT}

This report presents the results of the first two phases of the study of BAC limits for the general driving public. In addition to this introduction, the report has two technical sections and recommendations based on findings to date. The first technical section covers the scientific evidence regarding $\mathrm{BAC}$, driver performance and crash risk. The second technical section covers BAC laws and institutional response to alternate BAC limits. Based on the work and findings reported in earlier sections, and recognizing that this study is not complete, initial recommendations are made. 
SECTION I

\section{LITERATURE REVIEW}




\section{CHAPTER II}

\section{THE EFFECTS OF ALCOHOL ON BEHAVIOR}

In this chapter the effects of alcohol on behavior and, more specifically, driving-related behavior, are reviewed. There is extensive literature available on this topic. No other drug has been the subject of more attention and research than alcohol. As a result, quite a lot is known about the pharmacology (absorption, distribution and elimination) of alcohol and its effects on vision, attention, cognitive, emotional and psychomotor behavior.

No other aspect of driving-related behavior has been subjected to as much study and investigation or is as well understood as the topic of alcohol use and driving. Risk-taking, speeding, fatigue, restraint usage are all poorly understood in comparison to the wealth of information available about the effects of alcohol on driving-related skill and crash risk. As in most areas of human behavior, there are gaps in knowledge and understanding of how alcohol affects behavior and precisely what effects are likely to occur on an individual basis.

However, there can be no question regarding the generally debilitating effects of alcohol on human performance. While there are some studies that have not shown measurable decrements in performance, there are almost none that have shown improved performance (with the exception of some behaviors that may show improvement for some populations, typically heavy drinkers, at low doses of alcohol). That alcohol generally impairs performance is no longer an issue. The extent or magnitude of the impairment produced by alcohol (especially at low doses), and perhaps how it affects driving, are the major remaining issues of relevance to highway safety.

\section{BACKGROUND}

Basic research on the effects of alcohol on driving behavior is designed to assess the nature and extent of the impairment of driving-related skills and the potential increase in the likelihood of traffic crashes due to the use of alcohol. Several different research approaches have been used to measure the effects of alcohol. These include laboratory studies using behavioral tests or test batteries, driving in automobile simulators, and driving in actual vehicles (often instrumented to record various 
aspects of the driver's behavior).

The study of the effects of alcohol on driving-related skills has produced a large and diverse literature. There have been numerous reports of alcohol produced impairment on laboratory tasks. Considerably fewer studies have been conducted using driving simulators or actual driving behavior in a car on a closed course.

Thus, there is a wealth of evidence that driving-related skills are adversely effected by alcohol, though the ability to translate much of this information into specific predictions regarding individual driving performance is limited. The more important reasons for this include the wide range of methods used to measure behavior in the laboratory and field, the lack of agreement on what skills are essential to safe driving or related to crash risk, individual differences in behavior and response to alcohol, and the current limited ability to relate performance in the laboratory to real world driving.

For many decades, behavioral scientists have attempted to define the parameters relevant to safe operation of a motor vehicle and to relate these parameters to crash occurrence risk. No consensus in this area has been reached. It is therefore difficult to speak of laboratory tasks which actually measure critical car driving skills. Laboratory tasks that measure manual dexterity, reaction time, tracking ability, etc., are certainly related in some general sense to the skills required to operate a motor vehicle. Many of these tasks have some surface validity, that is, they appear rationally to involve skills we think are important to safe driving. However, given the large individual differences that exist in these skills between normal people, it is often difficult to specify how performance differences produced by alcohol on these tasks relate to driving ability and crash risk. Thus, observed changes in performance on the tasks traditionally used in the laboratory to investigate the effect of alcohol have not been related in any direct way to actual driving ability. Certainly substantial decrements in performance on these simple tasks can be inferred to imply a likely effect on driving performance. Going beyond the simple inference of impaired driving ability, to quantifying the effect, is not possible.

The ability to operate a motor vehicle is so well established in most of us that we take this skill for granted and fail to realize the complexity of the task. Many variables enter into our ability to drive and they interact in subtle ways. Some factors that are important are relatively obvious; for example, coordination skills, reaction time, and perceptual ability. Other considerations are less obvious but may be equally important; for example, subjective factors such as risk-taking, emotional states (anger, fear, stress, hostility, etc.), and personality style (relaxed, tense) play a role in how we drive. Some simple variables like fatigue, physical and mental health, degree of 
hunger, distraction (by the radio, smoking, conversation, thinking) are extremely difficult to define in operational terms. As a result, we find that the driving task is not as well understood as one might hope, in spite of the many studies that have been conducted to define it. This is important only to the extent that it limits our ability to generalize from laboratory studies to real world driving.

A major problem encountered in interpreting the significance of studies designed to measure the effects of alcohol on driving behavior stems from the artificiality of the research environment. To a lesser or greater extent, the subject performs a task only somewhat similar to real world driving. Subjects participating in research studies are well aware that their behavior is being observed and measured. They undoubtedly assume (correctly) that precautions have been taken for their protection. These and other factors resulting from the research environment will alter the subject's behavior in many subtle ways that sometimes make it difficult to interpret experimental behavior in terms of real world behavior (Sanders, 1986). It is not possible at this time to estimate the extent of this effect.

Experimental research on the effects of alcohol can be conceptualized as spanning a continuum ranging from an assessment of physiological functioning (i.e., effects on the circulatory, respiratory, or nervous system), to basic psychophysical functions (i.e., sensory, perceptual, motor, or simple cognitive), to simple behavioral effects, to effects on driving-related skills, to simulated driving, and finally to actual driving performance. The further removed one gets from actual driving, of course, the more tenuous any inferences become.

Our concern in this review is not just to describe the effects of alcohol on behavior, but to the extent possible, relate amount of alcohol (BAC level) to the degree of impairment. In the rest of this chapter, we briefly summarize past research findings on the effects of alcohol as they relate to driving ability. With this in mind, a brief review of the physiological effects of alcohol is provided, followed by an overview of the effects of alcohol in the laboratory on simple behavioral processes (visual, perceptual, attention, and psychomotor) that are often treated as measuring driving-related skills, on simulated driving behavior (using driving simulators), on-the-road and closed course studies of driving, and finally the topic of individual differences is reviewed.

Literally hundreds of studies have been conducted on the effects of alcohol on simple behavioral processes as measured in the laboratory, in simulated driving and in instrumented vehicles. A number of excellent reviews of this literature have been published over the last couple of decades (Carpenter, 1962; Moskowitz, 1973; Perrine, 1973; Mitchell, 1985; Moskowitz and Robinson, 1988). In addition, two 
state of the knowledge reports on alcohol and highway safety have summarized the results of much of this literature as it pertains to the driving task (Jones and Joscelyn, 1978; DOT, 1985). The overview of the effects of alcohol presented below is based on these prior reviews.

\section{Physiological Effects}

The physiological effects of alcohol can be characterized as either acute (short-term) or chronic (long-term). Because of the focus of this report on the relationship between alcohol use and driving, primarily acute effects will be discussed. This is not to diminish the serious health implications of chronic long-term abuse of alcohol. The process of tolerance to the effects of alcohol is one exception to this. Two types of tolerance have been reliably observed (Donelson, et al., 1987). Chronic tolerance refers to the finding that people who regularly drink alcohol typically show less behavioral effects for a given amount of alcohol ingested than do infrequent drinkers. Acute tolerance refers to the fact that alcohol appears to produce the strongest effect during the period of time it is being absorbed, with a marked reduction in effect during the post-absorptive (elimination) phase. This phenomenon in which behavior shows a greater influence from alcohol when the BAC is rising is known as the Mellanby effect (TRB, 1987).

The physiological effects of alcohol can be classified as various forms of impairment of different physiological systems. Alcohol depresses the functioning of the central nervous system, causes temporary swelling of the liver, increases urinary output, increases heart rate and blood pressure, and irritation of the lining of the stomach (Jones and Joscelyn, 1978). Other observed effects of alcohol include an increase in nystagmus (rapid involuntary movements of the eyes from side-to-side), a reduction in pain sensitivity, and reduced sense of taste and smell (Jones and Joscelyn, 1978). If extreme amounts of alcohol are ingested, coma may result, terminating in death due to disruption of the respiratory system (Jones and Joscelyn, 1978).

One recent development on the effects of alcohol has been the accumulating evidence that alcohol use appears to be associated with a worse prognosis for severe injuries and longer recovery times for victims of traffic crashes (Waller, P.F., Stewart, J.R. \& Hansen, A.R., 1986). Persons who had been drinking prior to involvement in a crash are more likely to suffer serious injury or death than are drivers who were not drinking.

The effect of alcohol on the central nervous system is of primary concern because it is the depressant effect on the brain which results in the behavioral, emotional and 
cognitive changes that are believed to result in driving impairment. As was mentioned in the introduction to this chapter, the mechanism by which alcohol affects the brain is not well understood at this time (HHS, 1990). While it is not necessary to know how alcohol produces impairment of driving ability in order to establish that it does, our ability to predict the effects of alcohol beyond those that have been carefully measured is limited by the lack of detailed understanding of the mechanism whereby it produces its effect.

In the next several sections of this chapter what is known about the effects of alcohol, at various BAC levels, on driving-related behavior is reviewed. First, laboratory studies of the effects of alcohol on basic behavioral processes are summarized, followed by studies of driving-related behavior using driving simulators, and finally research involving subjects driving actual vehicles on a closed course.

\section{LABORATORY STUDIES OF DRIVING-RELATED SKILLS}

The U.S. Department of Transportation (DOT), in a 1978 review of the state of knowledge on alcohol and highway safety, classified laboratory investigations of the effects of alcohol in terms of the behavioral processes studied (U.S. DOT, 1978). The various studies reviewed were grouped into the following categories:

- Interactions of nerves and muscles, such as those that would occur in moving the steering wheel of an automobile.

- The purely sensory aspects of vision, such as the ability to read a highway sign under given conditions.

- Tracking - the ability to maintain an index at some predetermined or moving position, as might be required to keep an automobile on a roadway.

- Time-sharing - the ability to perform two or more activities intermittently, such as keeping an automobile on the road while monitoring the speedometer to maintain a legal speed.

- Attention - such as the ability to maintain concentration on the roadway ahead while driving.

- Attitude or mood changes, such as the willingness to take greater risks in 
driving.

A brief review of the major effects of alcohol on these categories of behavior is presented below (Jones \& Joscelyn, 1978; U.S. DOT, 1985; Mitchell, 1985).

Neuromuscular - One of the earliest effects of alcohol to be measured in the laboratory was the effect on coordination and body sway. The classical technique used in studying neuromuscular effects is the Romberg test, which measures the ability to stand upright without swaying. Several studies using this technique have found that all the individuals tested exhibited a significant amount of swaying at BACs over 0.10. Many were affected at much lower BACs (e.g., 0.075), and the BAC at which their swaying began to increase significantly was between 0.04 and 0.05 (Alknana, et al., 1978; Franks, et al., 1976; Fregly, Bergstedt, and Graybiel, 1976, Goldberg, 1943; Indestrom and Cadeniu, 1968).

Some studies have indicated that experienced drinkers can, if motivated, overcome these impairing tendencies at BACs as high as 0.20 (Laves, 1955; Prag, 1953). However, more recent work with a variation of the Romberg test adopted for use by police to detect impairment in drinking drivers has suggested that a standardized administration and scoring procedure will result in a reliable discrimination of drivers whose BAC is above 0.10 (Tharp, et al., 1981; Anderson, Schweitz, \& Snyder, 1983).

Vision - Considerable research has been conducted on the influence of alcohol on vision. It indicates that vision per se is not greatly affected by alcohol at BACs of less than 0.10 , but above that, it becomes impaired in most persons (Honneger, Kampschulte, and Klein, 1970; Mortimer, 1963; Newman and Fletcher, 1941). Visual acuity appears relatively unaffected by alcohol (Wallgreen \& Barry, 1970). The perception of objects in motion, however, appears to be consistently impaired at relatively low BACs. For example, the ability to distinguish between close, but separated moving objects was shown to be degraded at BACs as low as 0.02 (Mac Arthur and Sekuler, 1982).

Studies of the effect of alcohol on other aspects of vision such as peripheral vision, length of fixation, glare recovery, show little or no impairment at low BACs, but increasing impairment at BACs above 0.08 (Mortimer, 1963; Moskowitz, 1974; Adams, et al., 1976). Nystagmus (small, lateral jerking movements of the eye) has been shown to increase with BAC level (Tharp, 1981). 
Tracking - Many studies have found that the ability to follow a simple moving object does not appear to be significantly impaired by alcohol even at BACs up to 0.10 (Chiles and Jennings, 1969; Newman, 1949). These types of tasks (pursuit rotor and other simple tracking tasks) primarily measure eye-to-hand coordination. Some studies have reported small reductions in performance in pursuit rotor tasks (Valeriote et al., 1979). More complex tasks involving tracking (especially those involving a subsidiary task requiring time-sharing or divided attention) often show evidence of impairment at relatively low BACs. For example, laboratory studies of pursuit tracking, where individuals are asked to maintain an index on a moving target, demonstrate that decreased performance can result from BACs in the 0.05 to 0.10 range (Mortimer, 1963; Binder, 1971; Richter and Hobi, 1975).

Time-sharing and Attention - Impairments in time-shared tasks, at BACs as low as 0.04 , were reported among airplane pilots in a study of alcohol effects on flying (Billings and Wick, 1972). Other studies of divided attention have shown similar results (Gruner, Ludwig, and Domer, 1964).

The ability to divide attention between two tasks may be an important factor in crashes, since driving involves a division of attention between keeping the vehicle on the roadway and watching for other traffic (Moskowitz, 1974). Studies have shown that impairment of the ability to divide attention between two tasks is detectable at BACs between 0.05 and 0.08 (Burns and Moskowitz, 1980; Moskowitz and DePry, 1968). Some tests for alcohol impairment make use of this inability of some drinkers to divide their attention between two tasks (Tharp, et al., 1981).

Attitude and Mood - Studies of the effect of alcohol on mood and emotion have shown that quite disparate effects can be produced (Wallgreen and Barry, 1970; Warren and Raynes, 1972; Kelley, et al., 1971). Some individuals are stimulated by alcohol and become exhilarated, cheerful, and friendly; but others are depressed and become quiet, relaxed, sleepy, and unable to think clearly.

Other studies of more complex behavior have indicated that risk-taking may be increased at moderate BACs for introverts and light drinkers (Coldwell, et al., 1958; Cutter, et al., 1973; Goodwin, et al., 1973). Moreover, low doses of alcohol have been observed to improve the performance of heavy drinkers and alcoholics on intellectual tasks while having the opposite effect on light drinkers (Mellow, 1972; Wallgreen and Barry, 1970).

It should be noted in a number of studies that have included more than one or two 
BAC levels, the measurable effect of alcohol has been found to increase almost linearly with increasing BAC (Evans, 1974; Drew, et al., 1959; Landauer and Howat, 1983; Moskowitz, 1985).

\section{LOW BACs}

In a recent review of the literature on the effects of alcohol on driving-related behavior, Moskowitz and Robinson (1988) examined the state of knowledge regarding the BAC at which impairment begins for driving-related behaviors. While not exhaustive, Moskowitz and Robinson reviewed a sample of approximately 400 studies. They found that the majority of these studies used either improper or inadequate methods or lacked sufficient details to make it possible to determine whether proper procedures were employed. As a result, 178 studies provided the basis for their analysis of BAC levels and impairment.

The Moskowitz and Robinson review covered laboratory studies focusing on such areas of skilled performance relating to the driving task as reaction time, ability to follow or track a moving object, mental functions, visual functions, and psychomotor performance, as well as exploring the effects of alcohol more directly on measures of driving-related performance in a simulator or in actual driving situations. The findings from the laboratory studies reviewed by Moskowitz and Robinson are discussed briefly below:

\section{Laboratory Studies}

Moskowitz and Robinson reported that there are a substantial number of studies that found little or no effect of alcohol on reaction time. However, the results from a majority of the studies reviewed suggested that reaction time can be affected by alcohol at BAC levels as low as 0.04. Simple reaction times (where the subject attempts to detect a stimulus and respond as quickly as possible) appear to be less affected by lower BACs than do complex reaction times (where the subject must discriminate between stimuli and respond appropriately as quickly as possible).

Moskowitz found that a few of the studies indicated that an individual's ability to follow or track a moving object can be somewhat impaired at BACs as low as 0.02 . However, most of the studies reported substantially decreased performance only at BACs of 0.05 or greater. Moskowitz suggested that impairment was found in some studies at lower BAC levels when the tracking task was more demanding (i.e., 
requiring attention to two or more things). Thus, the evidence is not clear that at BACs below 0.05 tracking ability is reliably impaired, especially in less demanding tasks. It should be noted that relatively few studies have employed BACs below this level.

Information processing skills appear to be impaired at somewhat higher BAC levels, starting at about 0.08 . There is some evidence that central information processing suffers significant degradation by BACs of 0.05 , or less.

Paying attention while driving is accepted as an important component of the driving task. Concentrated attention (the ability to focus on one thing) appears to be the least sensitive area to alcohol impairment, with no study finding impairment below 0.05 . Research on vigilance (the ability to attend to or detect an event over a long period of time) has found little reliable evidence to indicate impairment occurring at BACs below 0.08. Most studies examining divided attention (the ability to attend to more than one thing at a time) found impairment at quite low BACs. In one study, impairment was detected at a BAC of 0.02 , and a majority of the studies found impairment at or below 0.08 .

Regarding visual capabilities, the laboratory evidence suggests that low or moderate doses of alcohol do not produce impairment of such visual functions as acuity, darkness adaptation, or peripheral vision. The evidence is less clear regarding glare recovery with contradictory results having been reported. However, dynamic visual acuity (the ability to see detail in an object in motion) clearly suffers at BAC levels below 0.05 . Control over eye movements and the ability to merge two images into one also show impairment at BAC levels below 0.05 . Alcohol also appears to increase the duration of fixations and hence reducing the number of eye movements (Moskowitz, Ziedman \& Sharma, 1976). Given the importance of vision to the driving task, impaired eye movements may be critical to safety.

Psychomotor performance is a term referring to the ability to make fine, highly controlled muscular movements, or to coordinate the movement of a number of the limbs simultaneously. Studies indicate that BACs of 0.05 or more impair tasks which require skilled motor performance and coordination.

In summary, the Moskowitz and Robinson review of laboratory research on the effects of alcohol on driving-related skills indicates there is evidence (from a large number of studies) that by a BAC of 0.05 there is some impairment of major components of driver performance. Relatively few of the studies looked at BACs below 0.04. As a result, there were a much smaller number of studies that found clearly impairing effects for BACs below 0.04, so that conclusions about behavioral 
impairment at these BACs are less certain than at 0.05 . The evidence indicates that alcohol does not uniformly impair all aspects of performance. Some behaviors are apparently more sensitive to the effects of alcohol than others. For example, there were studies showing impairment of tracking and divided attention performance can occur at BACs as low as 0.02 , while other aspects of performance showed relatively little impairment at BACs below 0.05 (e.g., simple reaction time, concentrated attention, information processing).

The most serious shortcoming of all these laboratory studies is the lack of any clear relationship between the behavior studied in the laboratory and driving. It is difficult to understand, for example, exactly how the results of a simple pursuit rotor task, reaction time test or an experiment in sorting playing cards conducted in a laboratory setting pertain to the tasks that must be performed in driving an automobile on a busy interstate highway at night. Without an explicit relationship, it cannot be said how an observed impairment affects the probability of having an automobile crash.

A laboratory study may report a statistically significant decrement in the average performance by a group of subjects dosed on alcohol that may amount to a very small actual decrease in performance. The extent to which the probability of getting involved in a crash would increase as a result of such a change in driving ability is impossible to infer. The most that can be said from this type of research is that some behavior studied in the laboratory is consistently and significantly impaired in most individuals.

As most of these studies report their results in terms of group averages, it is not clear whether differences in performance are the result of a small decrease in performance by most subjects or a large decrease in performance by a few subjects. Many persons, especially people who do not drink frequently, have shown impairment at much lower BACs than is usually found with more frequent heavy drinkers. Some studies have found that only a relatively few of the heaviest drinkers appear to show signs of impairment on simple tasks at low BACs. Moskowitz, et al. (1979) has suggested that the threshold at which the effects of alcohol occur does not differ between light and heavy drinkers. However, for the heavier drinkers the effects are less apparent at each BAC level.

\section{Simulator Studies}

In order to study the effects of alcohol on behaviors more closely related to real driving, some researchers have tried to more closely approximate the actual driving task by use of driving simulators. Comparatively fewer studies have been conducted 
to investigate the effects of alcohol using driving simulators than laboratory studies measuring more basic behavioral processes.

Many of these researchers employed somewhat crude simulators that lack any strong sense of realism. Early simulators were typically deficient in terms of the car dynamics or the visual scene presented to the driver. These simulators typically did not provide any feedback response to movements made by the drivers. For example, movements of the steering wheel or accelerator pedal did not result in corresponding changes in the visual scene. Often, the vehicle was nothing more than a driver training apparatus with a steering wheel, gear shift lever, turn signal lever, accelerator and brake pedals.

However, in comparison to on-the-road studies which involve subjects driving actual vehicles, research employing simulated driving has several real advantages. These advantages include the ability to administer higher doses of alcohol than might be risked if the subject was actually going to be operating a real vehicle, allowing for a standardized set of experiences to occur in exactly the same fashion for each subject, and allowing "dangerous" situations to occur (e.g., crashes can occur in a simulator without any risk to the subject or others).

Use of a simulator allows the researcher to introduce a variety of events during the "drive" that might prove difficult or impossible to employ during an actual driving session. For example, passing tasks can be programmed into the trip the subject takes, wind gusts may occur requiring corrective movements to keep the vehicle on the roadway, or obstacles (e.g., a large box) can appear suddenly in the roadway to test the subject's ability to respond quickly to unexpected events.

The results of driving simulator studies have been characterized as inconsistent and even contradictory at times (U.S. DOT, 1985; Moskowitz and Robinson, 1988). One reviewer observed that "there appears to be no driving behavior which the effects of alcohol have been reported more than twice with complete consistency" (Heimstra and Struckman, 1974). While comparisons among simulator studies are difficult, Moskowitz has concluded that they do reliably demonstrate reduced driver performance when sufficient demands are placed on the subjects (Moskowitz and Robinson, 1988). That is to say, few impairing effects are found due to alcohol when the simulated driving task is relatively easy, although studies that employ a demanding task typically do report decreased performance due to alcohol dosing. A few illustrative examples of research using driving simulators are presented below.

Landauer and Milner (1971) found that moderate doses of alcohol impaired performance of complex, concurrent tasks, more than simple tasks. Allen, et al. 
(1982) reported that a targeted dose of 0.10 BAC produced a consistent impairing effect on steering and speed control behavior.

Two fairly recent research programs have examined the effects of alcohol on simulated driving behavior in which an interactive simulator with relatively realistic car dynamics was used. Smiley, et al. (1985) described a study in which subjects sat in a cut down car cab and viewed a simplified roadway scene close to life size. The simulation was interactive in that the subject's use of the steering wheel, accelerator and brake pedal caused corresponding changes in the visual scene. The simulator had fairly realistic car dynamics (the simulator had the touch and feel of a real vehicle with appropriate feedback from the visual scene to control movements made by the subject). The visual presentation was, however, only a caricature of the real world. In addition, the simulator lacked any kinesthetic feedback (e.g., the cab was not mounted on a motorized platform to provide a sense of movement).

A number of different tasks were presented to the subjects during their "drive." These included curve following, controlling the car in wind gusts, following a lead car that was moving at a variable speed while maintaining a constant distance, route sign following, emergency decision making (making a stop or swerve decision after the sudden appearance of an obstacle), and passing a car between obstacles. In addition, in order to simulate the demands on the driver to attend to other traffic, pedestrians, etc., a peripheral light cancellation task was included. Red and green lights were presented on the right and left sides of the car which had to be turned off by pressing the appropriate foot pedal. Subjects drove a 45 minute simulator run of approximately 24 miles.

According to Smiley, this study did show significant effects of alcohol (subjects dosed to 0.055 and $0.11 \mathrm{BAC}$ ) on car control variables. As would be expected, the higher alcohol dose was associated with more significant effects than was the lower dose. Variability of speed and lateral position increased during curve following and during simulated wind gusts. Also, car following distance was more variable. Negative effects on decision making, similar to those found in earlier studies, were also found. Subjects were more likely to crash during the sudden appearance of an obstacle.

Smiley, et al. (1985) used the same simulator and driving tasks (with different subjects) to examine the effects of alcohol at BAC levels of 0.05 and 0.08 on simulated driving behavior. They report that negative changes in performance were detected primarily at the higher doses administered to the subjects. Alcohol impaired psychomotor tasks such as maintaining lane position and a constant posted speed.

Stein, et al. (1983) have also looked at the effects of alcohol on simulated driving 
employing a fully interactive simulator that was similar to the one described above. Subjects were tested at 0.00 and $0.10 \mathrm{BAC}$. The subjects had full control over both steering and speed in this simulator, while following a video projected two-lane roadway. As with the Smiley simulator, the car dynamics were fairly realistic while the visual scene was relatively simple. Subjects drove a 10 mile drive that took about 15 minutes to complete.

A variety of events were encountered during the driving scenario including wind gusts, winding roads, lane changes both in emergency and non-emergency conditions, obstacles and isolated curves. A secondary task of sign detection and recognition was required during tracking. The primary measures of safety were simulated crashes (hitting obstacles, running off the roadway by a full car width) and speeding tickets (speed checks at predetermined points during the drive).

The results revealed that alcohol was associated with significantly increased crashes and incidents of speeding. The crashes were primarily caused by an increase in driving speed, steering control variability and reaction time. Overall, driver steering and speed control deteriorated as a function of increasing BAC. Response speed and accuracy also decreased with increased BAC.

Stein and Allen (1986) conducted a similar study using the same simulator with subjects dosed to $0.00,0.10$, and 0.15 . This study involved testing subjects twice at $0.10 \mathrm{BAC}$, once when their BAC was ascending and again when it was descending. The simulated drive included a risk perception situation involving a traffic light programmed to turn from green, to yellow and then red as the subject approached the intersection.

The results showed a significant effect due to alcohol, with increased speeding and accidents occurring under the alcohol conditions. No differences in performance were found between $0.10 \mathrm{BAC}$ ascending and descending conditions. The signal light task indicated that alcohol did not increase the subjects' willingness to take risks, although the objective risks they took appeared to increase due to the deterioration in perceptual abilities.

In summary, studies of the effects of alcohol on simulated driving behavior have found changes in such performance variables as steering errors, gear changing, braking response time, tracking, vehicle position, lane tracking, speed maintenance, reaction time, distance judgements, and acceleration. In almost all cases, these changes in performance were detected at BACs at, or above, 0.05 .

Perhaps because it has been generally accepted for several decades that alcohol, at 
least at relatively high BACs, impairs driving ability, there have been very few recent simulator studies conducted on the effects of alcohol on driving ability. Earlier research was motivated by an interest in establishing the impairing effects of alcohol and thus tended to use relatively high BAC levels. Attempts to more clearly delineate a threshold for impairment have not occurred using this research approach.

\section{Closed Course Studies}

Some studies have measured actual driving performance of subjects who drive a vehicle through a prescribed route on a closed course. Use of a closed course (parking lot, test track, etc.) allows the roadway environment to be made much safer (no hazardous obstacles like parked cars, sign posts, embankments or ditches) and there is no unpredictable risk from other drivers. On the other hand, the driving environment typically encountered on a closed course is much less perceptually rich than that found under real world conditions, and thus does not present as realistic a scenario.

Performance in studies of driving behavior can be measured by simple observation, in which trained raters record specific aspects of the driver's behavior, or by use of an instrumented vehicle that automatically measures and records the driver's performance. There has been a tendency for researchers to use trained observers, rather than instrumented vehicles, undoubtedly as a result of the reduced costs. Unfortunately, many published studies have failed to provide any indication that the observer's ratings were reliable or valid measurements of the subjects' driving behavior.

When vehicles are instrumented, it is not uncommon that so many different variables are recorded that one almost always finds significant changes on a few (as would be expected by chance alone). Interpreting these observed changes, in the face of many variables which show no effects from the alcohol used, then becomes very problematic. Certainly, some changes in behavior are not necessarily indications that the driver's behavior is more hazardous.

The appeal of closed course studies is the apparent face validity of the task for measuring the effects of alcohol on driving behavior. In this type of study subjects drive real vehicles, sometimes on real streets, and very occasionally in the midst of real traffic. However, there are many reasons some scientists consider this research approach as much a simulation of driving as any other. Some of the more obvious reasons include: 
- Considerable care is always taken to prevent harm to the driver.

- The driver is under constant observation (either by one or more observers seated in the vehicle, or by unusual equipment in the vehicle to record the driver's behavior).

- The driver is aware he or she is part of a study and not completely responsible for his or her own behavior (the subject has been given alcohol as part of an experiment; the observer riding with the driver often has a second brake pedal or ignition key; the subject is often instructed not to converse with the observer or listen to the radio, eat, drink, smoke, etc. while driving).

- The route to be driven is not of the driver's choice. The motivation is not at all similar to when a driver is actually out driving for some purpose but rather concerns the fact that he or she is performing a task in which his or her behavior is being recorded.

- The driver is often instructed to perform an artificial secondary task, to simulate the divided attention often present in real world driving (for example, mental arithmetic).

An important consideration in the design of an on-the-road study is that the driving task be representative of normal driving behavior, and perhaps more importantly, representative of the types of situations in which crashes are most likely to occur (Smiley, 1986b). It is possible that the deleterious effects of alcohol may only be clearly evident in the unusual situations that often precede an accident occurring and not necessarily during routine driving tasks. Thus, a closed-course study in which the driving task involves a repetitive course delineated with cones, perhaps requiring following a lead car at a set distance, or passing situations, may not measure the real world situations and behaviors that precede accidents. Some situations, for example crashes involving single vehicles that run off the road, may be very difficult to simulate in a test environment.

Previous research on the behavioral causes of crashes has repeatedly found that judgmental and attention factors predominate over what may be termed inappropriate vehicle control maneuvers. Factors such as inattention, excessive speed, and improper lookout (Treat et al., 1979) are more often associated with accidents than are inappropriate responses to environmental and situational occurrences. The implications of this are that small difficulties in maintaining lane position, cornering, 
judging gaps or closing speed are not the typical events occurring prior to accidents. Rather, the failure to quickly notice and respond to events, or to anticipate events, occur much more frequently prior to accidents. These latter situations are the ones that should be measured, if at all possible.

The final consideration in designing an on-the-road study is the selection of which behaviors to measure. These should have some clear relevance to safe driving or conversely be related to the causes of crashes. They should be reliably measured, with relatively low variance. There is a tendency by researchers to treat any change in performance as indicative of impairment, though this is not always the case. Until the relevance for safe driving of many behaviors that are measured in these studies is better understood, small statistically significant changes are not necessarily meaningful. For example, one behavior frequently measured in these studies is "steering wheel reversals," or changes in the direction the steering wheel is turned. It is not clear whether an increase in the number of steering wheel reversals is an indication of poorer or better performance.

In summary, it is fair to say that despite the obvious appeal of measuring the effects of drugs on driving behavior in an on-the-road approach, this methodology is still very much at a developmental stage. The driving tasks employed are frequently highly artificial and do not appear to represent normal driving. Ideally, we would like to better understand why crashes occur so that the situations and circumstances that typically precede accidents could be reflected in the driving tasks employed in these studies. Likewise, the measurement of driving behavior needs to become much more informed and sophisticated so that behaviors that are clearly relevant to the occurrence of crashes are measured.

A few closed course studies on the effects of alcohol on driving performance are briefly described below in order to illustrate some of the problems one faces in interpreting this type of research. Many of these studies involved administration of alcohol as well as other drugs.

Hansteen, et al. (1976) had sixteen subjects repeatedly drive a 1.1 mile course while drug free and after dosing with alcohol (to a BAC of 0.07). The subjects drove the course immediately after dosing and again three hours later. The course was laid out with poles and cones. The course involved some slow speed forward and backward maneuvers and higher speed straight and curved sections. Subjects were instructed to drive the course as quickly as possible. The study found that the alcohol treatment resulted in more cones being hit in the slalom portion of the course when compared to the drug-free trials. 
Casswell (1977) studied the effects of alcohol (target BAC of 0.10 ) in a driving task involving more normal maneuvers than often found in studies of this type. They included such events as driving through narrow spaces, around a hairpin turn, passing, and responding to road signs and traffic signals. A secondary task required the subjects to respond to an auditory signal as quickly as possible while on the closed course. Thirteen subjects drove the course during three treatment sessions.

The results indicated that, under the effects of alcohol, fine steering wheel reversals decreased from the no alcohol condition, while lateral positioning became more variable. Speed also increased under the effects of alcohol. The author suggested that alcohol appeared to result in the subjects driving faster and making less of an effort at vehicle control.

A similar closed course study by Attwood, et al. (1981) had eight subjects perform a variety of driving tasks during a 25 minute drive including speed maintenance at 60 and $80 \mathrm{kph}$ and following a lead car moving at a variable speed. Subjects drove an instrumented vehicle and no secondary task was used to distract the subjects or increase the information processing load. Subjects drove the course after target dose of $0.00,0.04$ and $0.08 \mathrm{BAC}$.

The results of this study revealed few obvious effects due to the administration. The small changes in behavior reported (car following and speed maintenance) were subtle effects which the author admits would not be readily detected through observation.

A relatively large scale closed course study of the effects of alcohol and marijuana on driving performance was reported recently by Biasotti, et al. (1986). Approximately 80 male subjects received either alcohol (target dose of $0.08 \mathrm{BAC}$ ), marijuana, alcohol and marijuana, or no drugs. They subsequently drove over a test course four times at one hour intervals. The driving course included a variety of tasks including a chicane (series of tight turns of opposite direction), forced lane change, emergency stop, sign and route following, turning, maintaining a constant speed with the speedometer covered, and gauging the width of narrow gaps. A variety of different driver behavior measures were made that included computerized vehicle measures (speed, accelerator reversals, brake presses, steering control, and lateral placement), subjective judgments by in-car raters and other observers, impairment ratings by police officers in a following car, and self assessment.

Out of several hundred variables that were analyzed, a number showed significant effects due to alcohol. Subjects touched more cones during the chicane task and they also drove slower in this task. When the subjects were instructed to drive at a predetermined speed, they drove faster with the speedometer covered than uncovered. 
The more subjective measures showed that the subjects given alcohol were rated as driving through the chicane less smoothly, stopping less accurately, and having poorer overall driving quality. The self assessments and officer ratings also correlated well with the drug treatments. For example, the officers in a car following the subjects indicated that they thought the driver was impaired about 50 percent of the time for the subjects receiving alcohol and 15 percent of the time for sober drivers.

Smiley, et al. (1986) examined the effects of alcohol (0.08 BAC - the Canadian limit), marijuana alone and combined with alcohol $(0.05)$ on driving an instrumented car in a closed course study. Smiley had subjects perform various driving tasks including curve following, following a lead car, route navigation, obstacle avoidance, and decision making. The subjects performed an unrelated visual discrimination task while driving. The results indicated that the alcohol treatment led to higher speeds on both some straight and curved roadway sections.

Stein and Allen (1986) in a study of the effects of alcohol on risk-taking had fourteen subjects drive on a closed course in an instrumented vehicle. The drive was designed to parallel the simulator study described in the previous section. The driving task required the subjects to perform speed and lane position control tasks, negotiate curves, and obey signal lights. A similar pattern of results was obtained in the closed course as was found in the simulator study. Increases in speeding, failure to stay in lane, and stop for red lights were observed. Alcohol did not affect response time during the braking task (for red lights).

Louwerens, et al. (1987) conducted a study in the Netherlands involving subjects driving an instrumented vehicle on over $25 \mathrm{kms}$ of secondary road (which was closed to other traffic). Subjects were instructed to maintain a constant speed $(90 \mathrm{~km} / \mathrm{hr})$ and to keep the vehicle in the center of the right hand lane. Subjects were dosed to four BAC levels: $0.00,0.025,0.06,0.085$, and 0.122 . The results showed that speed control was not affected by alcohol level. Lateral position was correlated with BAC, with increasing variability in position found as BAC increased at the 0.06 level and higher. Women subjects appeared to be more affected than men at each BAC level greater than 0.025 .

Kearney and Guppy (1988) conducted an experiment on the effects of alcohol on speed perception. They had twenty-four male subjects drive a closed course at both 0.00 and 0.095 BAC. Subjects were instructed to drive at a constant speed of $30 \mathrm{mph}$ and then to reduce speed to $20 \mathrm{mph}$ under two conditions: using their speedometer and with the speedometer covered. They found no effect due to alcohol on the subjects' performance. Significantly higher speeds were found when the subjects were deprived of access to their speedometers. 
In summary, this research employing subjects driving cars on closed courses has shown changes in performance on such variables as steering wheel reversals, lateral positioning, and speed. These changes in performance were found in some of the studies at BAC of 0.05 and 0.06 .

\section{SUMMARY}

The research reviewed in this chapter on the physiological and behavioral effects of alcohol in laboratory, simulator and closed course studies has shown that alcohol impairs a wide variety of skills that appear important to safe driving. The great diversity of methods and procedures used in these experiments, the different subjects and behaviors, tasks, and skills studied, leave no question that alcohol produces a wide range of performance deficits.

The laboratory studies have shown that alcohol can lead to reduced performance in such measures as reaction time, the ability to track moving objects, information processing, divided attention, dynamic visual acuity, eye movements and psychomotor performance (coordination and skilled movement). Simulator and closed course studies have demonstrated performance decrements on such driving-related skills as car following, steering, lane position, speed maintenance, risk-taking (higher speeds in entering curves), emergency responses, braking response time, and driver decision making.

Some studies have reported effects due to alcohol at very low BACs. Clearly, as $\mathrm{BAC}$ rises above zero, the effects of alcohol become more pronounced. In addition, as BAC rises, it appears that a greater percentage of subjects show the effects of alcohol and performance decrements are found on a greater variety of tasks and skills. It is obvious that the BAC level at which all people would be noticeably impaired (to an observer) would be well above that at which some people would be impaired as indicated by objective performance measures.

It is not possible to relate specific performance decrements as shown in these experiments to actual crash risk. At the same time, there appears to be no level at which all drivers should be considered as unaffected by alcohol. The impaired performance shown in these experiments certainly does not lead to less crash risk and undoubtedly produces some real (even if unquantifiable) increase in crash risk. While people have the capacity to compensate for impairment due to various factors (including alcohol), it is unlikely that compensation can do more than reduce the performance deficits, not eliminate them. 
In conclusion, viewing the effects of alcohol as having a threshold appears to be inappropriate. Rather, the effects of alcohol on driving-related behavior are better thought of as representing a continuum. Even at very low BACs some people will show evidence of decreased performance. The higher the BAC, the greater the performance decrement and the larger the percentage of people who will show signs of impairment.

In terms of driving-related behavior, this review has found ample evidence that many persons show impaired performance at BACs at or below 0.05 . Whether the degree of impairment at these low BACs alone is sufficient to increase crash risk can not be determined by this type of research alone. This topic will be addressed in the next chapter. 


\section{CHAPTER II}

\section{ALCOHOL CRASH PROBLEM}

\section{EPIDEMIOLOGICAL RESEARCH}

Investigators interested in the role of alcohol in causing crashes have tried to study this issue by looking directly at the actual involvement of alcohol in crashes. Early studies of this type documented the incidence of alcohol positive drivers among those drivers involved in crashes (Jones and Joscelyn, 1978). These early studies (e.g., Waller, et al., 1970; Neilson, 1969; Perrine, et al., 1970; Filkins, et al., 1970) showed that a large percentage of crash involved drivers had been drinking and that many had relatively high BAC levels (i.e., 0.10 and higher).

For example, a number of studies of fatally injured drivers conducted in the 1960s (reviewed by Jones and Joscelyn, 1978) found that 40 percent to 55 percent of all fatally injured drivers tested had BACs of 0.10 or more (see Table 1). These same studies showed that between approximately 50 percent to nearly 70 percent of the fatally injured drivers had positive BACs $(0.02$ or greater). The percentage of drivers with BACs of 0.10 or higher differed depending on whether the driver was involved in a single-vehicle or multiple vehicle crash. A much larger percentage (55 percent to 65 percent) of drivers involved in single vehicle crashes had BACs of 0.10 or higher. For drivers involved in multi-vehicle crashes, 25 percent to 50 percent were found to have BACs of 0.10 or higher. The corresponding percentages of alcohol positive drivers were approximately 60 percent to 70 percent for drivers in single vehicle crashes, and 30 percent to 55 percent for drivers in multiple vehicle crashes.

The few studies of injury crashes showed a smaller percentage, ranging from 9 percent to 13 percent, of injured drivers had BACs of 0.10 or more. Approximately 20 percent of the injured drivers in these studies had positive BACs. The only rigorous study of non-injury crashes (property damage only) conducted in the U.S. found only about 5 percent of these drivers had BACs of 0.10 or higher, with approximately 15 percent of the drivers having a positive BAC.

A series of roadside surveys were conducted to obtain BAC information on non-crash involved drivers. Some of these studies collected data throughout the day and night, others were restricted to weekends and/or nighttime hours. These roadside surveys revealed that from 1 percent to 6 percent of the non-crash involved drivers had BACs of 0.10 or higher. Approximately 12 percent to 16 percent of these drivers had 
positive BACs.

These early studies were useful in showing the potential magnitude of the alcohol crash problem. Alcohol was frequently found among crash involved drivers, and to a much greater extent than among the general driving public. However, the use of alcohol by drivers involved in crashes does not prove that it "caused" the crash or was necessarily related to the occurrence of the crash. Traffic crashes are caused by many different factors and circumstances.

Table 3.1

Estimated Percentages of Drivers with BACs Exceeding Given Values

\begin{tabular}{lrr} 
& \multicolumn{2}{c}{ BAC } \\
Drivers Sampled & \multicolumn{1}{c}{$\mathbf{0 . 0 2}+$} & $\mathbf{0 . 1 0 +}$ \\
\hline Fatally Injured Driver & $50-70 \%$ & $40-55 \%$ \\
Single-Vehicle & $65-70 \%$ & $55-65 \%$ \\
Multiple-Vehicle & $30-60 \%$ & $25-50 \%$ \\
Injured Drivers & $20 \%$ & $9-13 \%$ \\
Property Damage & $15 \%$ & $5 \%$ \\
Non-Crash Involved & $12-16 \%$ & $1-6 \%$
\end{tabular}

(adapted by Compton from Jones and Joscelyn, 1978)

Certainly in some crashes, one of the contributing factors may be alcohol. It is conceivable that a driver who has had alcohol to drink may be involved in or unable to avoid a crash regardless of the drinking. The contribution of alcohol to crashes in which a driver had been drinking is not shown by mere presence alone.

One way of investigating the role of alcohol in crashes is to compare the frequency of alcohol use between crash involved drivers and similarly at risk non-crash involved drivers. If drivers who are under the influence of alcohol are over-represented among the crash involved drivers, then alcohol can be presumed to play a role in the occurrence of the crashes. For example, if alcohol were unrelated to crash occurrence, one would expect (due to chance) to find the same percentage of crash involved drivers having used alcohol as is found in similarly at risk drivers on the road. If one found that 10 percent of crash involved drivers had used alcohol and 10 percent of the drivers on the road at the same time and places had used alcohol, then one would infer that alcohol use did not contribute to the occurrence of crashes. However, if one found that 55 percent of crash involved drivers had used alcohol, but 
only 10 percent of similarly at risk non-crash involved drivers had used alcohol, then one would infer that alcohol use was contributing to the occurrence of crashes.

Thus, in this approach, the BAC levels of crash and non-crash involved drivers are compared. This type of study requires that BAC data be collected from a group of crash involved drivers and a group of drivers stopped at the same or similar locations, time of day, day of week, etc. Interpretation of the results of a study like this is based on the assumption that the comparison or exposure group represents similar drivers with similar crash risk with the exception of any differences produced by the alcohol use. If this assumption is not true then the results produced by this approach may be subject to error. For example, if the group of crash involved drivers are predominantly male, young, and heavy drinkers, while the comparison group of noncrash involved drivers are less predominantly male, older and less frequent drinkers, then any differences in BAC levels found between the groups may relate less to the relative crash risk at different $\mathrm{BAC}$ levels than to these other differences between groups or to other risk factors associated with these groups.

This method, traditionally referred to in epidemiological research as a retrospective case-control study, can yield valid inferences if proper methodology and statistical analysis techniques are employed. The problems faced in using sound methodology, however, are daunting. Classical scientific methods such as experimental control, randomization, and matching others are seldom feasible. Controlling for all significant risk factors, than the one being studied, is critical to the methodological soundness of this approach.

It has become accepted in studies of this type to present the results in terms of "relative probability of a crash." This method, refined by Hurst (1970), enables one to calculate the probability of being involved in a crash at a certain BAC level, relative to the probability of crash involvement at a zero (or lowest measured) BAC level.

In the hypothetical example used above, alcohol was over-represented in the crash involved group by a factor of 5.5 ( 55 percent of the crash involved drivers divided by 10 percent of the non-crash involved drivers). The risk of a crash for the drivers with a BAC equal to zero would be .5 ( 45 percent of the crash involved drivers divided by 90 percent of the non-crash involved drivers). The relative risk of crash involvement of these two groups (actually the "odds" ratio) would be approximately 11 (5.5 divided by .5). Thus, in this hypothetical example, drivers with positive BACs are 11 times more likely to be involved in a crash relative to drivers who had not been drinking. 
Since BAC varies continuously, the relative risk of crash involvement can theoretically be calculated across the range of BAC levels, producing a relative risk curve. In actual practice, relative risk curves are generated based on a number of discrete points or BAC ranges. In this fashion, the extent to which drivers with various BAC levels are over-represented (or under-represented) in crashes can be displayed. It should be noted that in epidemiological research calculation of relative risk is traditionally associated with cohort designs (where two groups of subjects, one exposed and one not exposed to the suspected causal agent, are followed to determine the outcome incidence) while the odds ratio is used with case-control designs (typically retrospective where "case" and control groups have different outcomes and are checked for the presence of the causal agent).

These two measures of association between an outcome and a risk factor are similar, though theoretically distinct, and under certain circumstances the odds ratio closely approximates the relative risk measure. Technically speaking, research on the effects of alcohol on crash risk have used case-control designs and calculated an odds ratio rather than relative risk. However, for consistency, this report will use the term relative risk, when in fact an odds ratio is what has been calculated.

There have been relatively few case-control studies performed in the United States or in other countries that have compared the BAC levels of drivers involved in crashes with a comparison group of drivers not involved in crashes. These studies have been extensively reviewed elsewhere (DOT, 1978; U. S. DOT, 1985; Perrine, 1975; Hurst, 1985; TRB, 1987). The general procedure used in these studies is to identify a group of drivers who were involved in a crash for whom BAC measurements are available and then to obtain BAC measurements from drivers on the same roads at the same times, days of the week, locations, etc. Typically, police officers are used to stop traffic at the designated times and locations and researchers ask the driver to provide a BAC sample. Cooperation rates of approximately 90 percent are not unusual.

Figure 1 (from Hurst, 1985) shows the general relationship between BAC and relative risk of crash involvement for fatal and nonfatal crashes. This figure represents relative risk curves from seven studies. These studies are described briefly below (from Donelson, et al., 1987):

- Evanston, Illinois (1938) - Holcomb (1938). Study included 270 injured drivers and 1,750 non-crash involved drivers using the same roads (stopped and tested at all hours and days of the week but not matched by time and place). 
- Toronto, Ontario (1951 - 1952) - Lucas et al. (1955). Study included 423 crash involved drivers and 2,015 non-crash involved drivers (stopped and tested at night (6:30 PM to 10:30 PM), Monday through Saturday).

- Manhattan, New York (1959 - 1960) - McCarroll and Haddon (1961). Study included 34 fatally injured drivers and 222 non-crash involved drivers (stopped and tested at the times and places of fatal crashes).

- Grand Rapids, Michigan (1962 - 1963) - Borkenstein, et al. (1964). Study included 5,985 drivers involved in all types of crashes (300 fatal or injury crashes) and 7,590 non-crash involved drivers (stopped and tested at the times and places of the crashes, i.e., all hours and days of the week).

- Vermont (1967 - 1969) - Perrine, et al. (1971). Study included 106 fatally injured drivers and 1,125 non-crash involved drivers (stopped and tested at the times and places of the fatal crashes).

- Huntsville, Alabama (1974 - 1975) - Farris, et al. (1977). The study included 615 injured drivers and 806 non-crash involved drivers (stopped at the times and places of crashes).

- $\quad$ Adelaide, South Australia (1979) - McLean, et al. (1980). The study included 299 injured drivers and 1,196 non-crash involved drivers (stopped and tested at the times and places of crashes).

Figure 1 shows that the relative risk estimates from these studies increases with BAC level. There is little difference in relative risk for drivers with BAC levels between zero and 0.05 (at most 1.5 times). There appears to be an increase in relative risk at BACs between 0.05 and 0.10 (the estimates of relative risk for drivers with a BAC at 0.10 ranges from 1.5 times to 12 times the risk of drivers with a zero $\mathrm{BAC}$ ), with the rate of increase in relative risk accelerating above 0.10 (at a $\mathrm{BAC}$ of 0.15 the range is 2 to 20 times the relative risk of drivers at zero BAC). For the most part, all of these curves share the same general shape with some increase in relative crash risk between zero and 0.05 , followed by a more rapid increase in risk around 0.08 to 0.10 .

Hurst (1973) has noted that the relative risk values for the same BAC range differ between studies and there are sizable differences in slope and acceleration of slope. Several factors have been hypothesized to account for these differences. These include the fact that some studies included only fatal crashes, some injury crashes, and some all types of crashes (i.e., property damage as well as injury producing); the 
inclusion of drivers of different ages, with varying drinking experience, varying driving experience; some studies were conducted only in the evening hours (when alcohol-related crash risk appears greater) while others were conducted throughout the day; and the choice of location (urban versus rural).

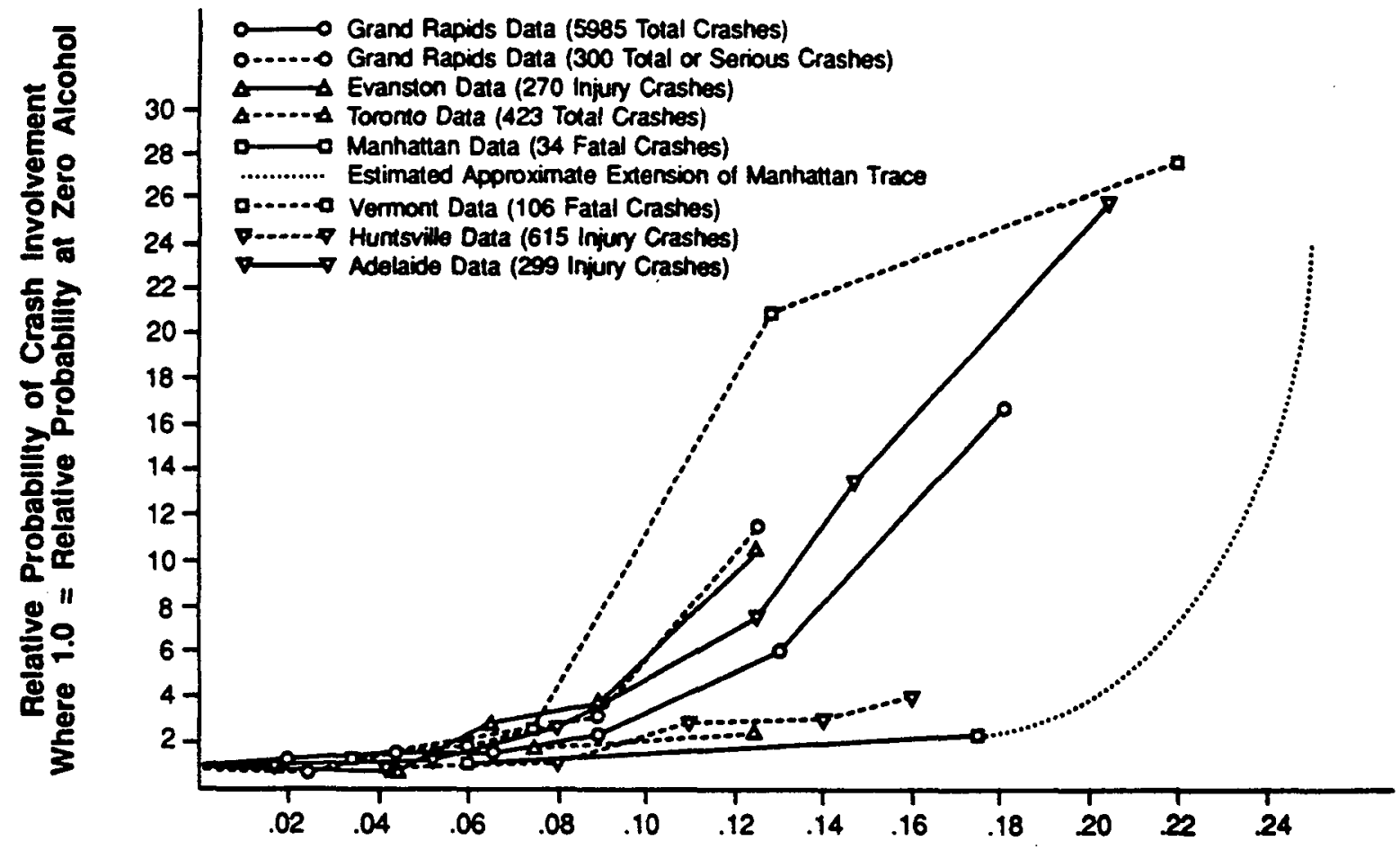

BAC \% WN

Figure 1. Relative Probabllity of Crash Involvement as a Function of BAC

More detailed analyses of the drivers in these studies have examined the possible relationship between a number of variables and relative crash risk estimates. It should be noted that the following analyses examined each factor separately, without consideration of their possible interactive effects. In addition, it is possible that other factors not considered or measured could have accounted for the following findings. For example, an effect of age on relative risk may be due more to driving experience than chronological age per se.

Donelson (1987) has categorized these variables into those relating to (1) crash outcomes; (2) crash characteristics; and (3) driver characteristics. 


\section{Crash Outcome}

Crash Severity: As was mentioned previously, relative risk estimates differ substantially depending on the severity of the crash. The relative risk estimates associated with different crash outcomes increase with the severity of the outcome, with the lowest relative risk found with property damage only crashes, higher risk with injury producing crashes, and the highest relative risk found in crashes resulting in a fatality to the driver. The differences in relative risk due to crash severity, if any, are small at BACs below 0.08 , becoming very pronounced at the higher BACs (i.e., over 0.10).

\section{Crash Characteristics}

Collision-Type: In the Grand Rapids study, higher relative risk estimates were found for drivers involved in single-vehicle crashes than for drivers involved in multiple-vehicle crashes.

Day of Week: Donelson has reported that at high BACs (i.e., over 0.08), relative risk increases from Wednesday to Saturday nights.

Time of Day: There is some evidence that relative risk does change with time of day. In the Ontario study drivers having BACs over 0.08 had higher relative risk estimates during the later nighttime hours.

\section{Driver Characteristics}

Age: A number of studies have shown that age appears to be strongly related to relative risk of crash involvement. For example, in the Grand Rapids study relative risk was found to differ by age even for non-drinking drivers. At zero BAC $(0.00-.009)$ drivers $16-24$ years of age were found to have an increased crash risk relative to the average non-drinking driver. Older drivers (25 years old and over) were found to have a reduced risk of crash.

In general, the youngest drivers appear to have a higher relative crash risk than do older drivers at any BAC, while older drivers have increased crash risk at higher BACs.

Gender: While males appear to be over-represented in crashes, their relative risk does not appear to differ from that of females at the lower BAC levels. In 
the Grand Rapids study, females with BACs at 0.08 had a higher relative risk than did males with a BAC of 0.08. Similarly, the Ontario study found little difference in crash risk between males and females at BACs below 0.08. At higher BACs (i.e., above 0.10) there appeared to be greater risk for females.

Marital Status: In the Grand Rapids study, little difference was found in relative crash risk of single, married, and separated or divorced drivers at BACs below 0.08. At the higher BACs, married drivers had a lower relative risk. However, this finding may be confounded by driver age, and until further information is available about marital status, no firm conclusions can be reached.

Occupation: Here again, reports of a relationship between occupational status and relative crash risk may be confounded by age and sex, so that unambiguous conclusions are not possible. The Grand Rapids study appeared to find that lower occupational status (unskilled) drivers had higher relative crash risk than did higher occupational status drivers (white collar and professional). The Vermont study attempted to control for age in examining occupational status and found no significant differences.

Driving Experience: The Grand Rapids study suggests that based on self-reported annual mileage, low mileage drivers (less than 5,000 per year) had a higher relative crash risk than higher mileage drivers did at BACs in the 0.05 -0.08 range. The high mileage drivers' relative crash risk was increased only at BACs above 0.10 .

Drinking Experience: Considerable attention has been paid to this variable with a number of studies examining self-reporting drinking frequency. Hurst has reexamined the data from the Grand Rapids and Vermont studies as a function of self reported drinking frequency and found that relative crash risk estimates have a strong inverse relationship to drinking frequency. In other words, the more frequent drinkers have a lower relative crash risk at any BAC level than do less frequent drinkers.

In summary, these detailed analyses have shown that many variables are related to relative crash risk estimates. These include crash severity, collision type, day of week, time of day, driver age, gender, marital status, and driving experience. Because of the nature of the data sets and methods used, it is possible that these apparent relationships result from confounding by other factors not measured. However, the evidence for increased relative crash risk at higher BACs (i.e., over 0.10 ) is fairly consistent, despite the fact that it differs between groups based on these 
factors. The evidence for increased relative crash risk at lower BACs is more variable and less certain.

TRB (1987) in their discussion of this epidemiological research and these relative crash risk estimates suggested that the effect of alcohol at low BACs was masked by other variables in these studies due to the heterogeneity of the control groups (i.e., they are composed of very different types of drivers) and the lack of perfect comparability between the crash and non-crash involved drivers. They point out that the data points in Figure 1 are based on groups of drivers of different ages with varying experience with alcohol and driving.

TRB cites the example of the Grand Rapids study in which there was a lack of comparability between the drivers involved in crashes and the control drivers in terms of their frequency of consuming alcohol. This lack of comparability is noted as the reason for the apparent improvement in crash risk at low BACs in the Grand Rapids study and the general understatement of crash risk at low BACs. In the Grand Rapids study, drivers with BACs in the range of 0.00 to 0.05 have a slightly lower relative risk than drivers with a zero BAC. This apparent effect has often been referred to as the "Grand Rapids dip".

TRB offers the following explanation:

"Hurst (1973) noted that the control group had a higher proportion of drivers who were regular consumers of alcohol. Their apparently greater tolerance for alcohol had made them safer drivers at low BACs than the drivers involved in crashes, presumably because the later had less experience as drinkers. Hurst recalculated the relative risk of crash involvement in the Grand Rapids data based on the drivers' self-reported frequency of alcohol consumption (Figure 3-2). He drew three conclusions from the results. First, drivers with experience as drinkers are less likely to be involved in crashes than light and moderate drinkers at comparable BACs. Second, regardless of the tolerance for alcohol, the risk of crash involvement increases with BAC. Third, the curves greatly underestimate the risk for the average driver at any BAC; they only demonstrate the relative hazard to drivers who regularly drink and drive. The curvilinear relationship between relative risk of crash involvement and BAC is therefore partially caused by the comparison of drivers with varying degrees of experience as drinkers and experience driving under the influence of alcohol. When experience with alcohol is controlled for, the risk of crash involvement increases with BAC without evidence of a threshold effect." (TRB, 1987, pg. 52). 
It is interesting to note in Figure 3-2 that the regular drinkers (those who drink at least once a week) have a lower relative risk of crash involvement at zero BAC than do all the drivers taken together as a group. The crash risk of the daily drinker at a BAC of about 0.08 was approximately the same as that of all the drivers at zero $B A C$. If nothing else, this finding illustrates some of the problems that occur when the comparison group of drivers are not similar to the crash involved drivers. If each drinking frequency group had been compared to similar non-crash involved drivers in calculating their relative risk, then each group's risk at zero BAC would have been equal to one. That it is not suggests other factors are involved that have not been accounted for.

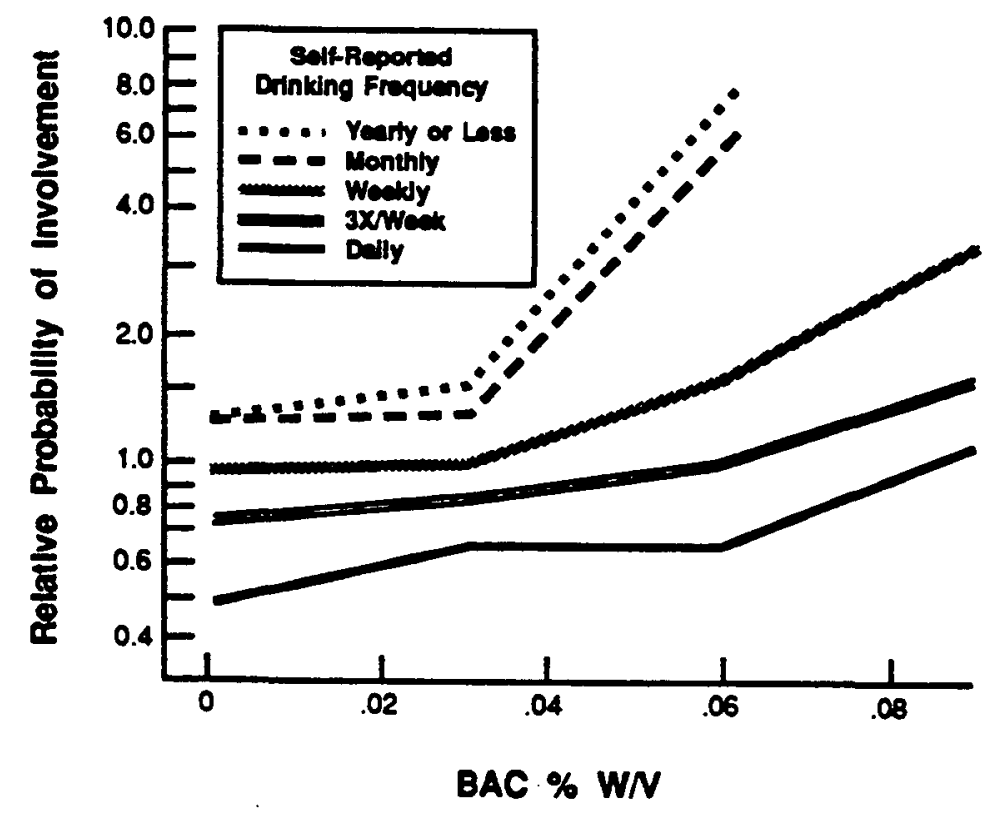

Figure 2. Relative Probability of Crash Involvement by Self-Reported Drinking Frequency

This explanation of the Grand Rapids dip (improvement at low BACs) is undoubtedly incomplete as it considers only the role of drinking frequency and not all of the other factors that appear to effect relative risk estimates (e.g., age, sex, type of crash, etc.). Other authors, who have examined other factors, have also found that the apparent decrease at moderate BACs is eliminated (Moskowitz and Bums, 1985). 
One way of attempting to deal with the problem of the heterogeneity of the non-crash involved drivers is to control for the effects of the factors known to affect relative risk estimates in selecting the comparison group of drivers to include in the analysis. Of course, there may be equally important or more important factors that have not been measured.

Donelson (1987) has pointed out that the relative crash risk estimates discussed above were all based on comparing the crash risk of various groups of drivers to all the drivers in the study at a zero BAC. Another, and probably more appropriate, way of calculating relative crash risk is to compare drinking drivers to similar drivers (e.g., age, sex, driving and drinking experience, etc.) at a zero BAC. Ideally, one would like to compare a group of drivers at various BACs to themselves at zero BAC, but this is impossible. The alternative is to use only drivers having specific characteristics in the comparison group. For example, in calculating the relative crash risk of drivers in a certain age group, only drivers in that same age group who have a zero BAC would be included in the comparison group. Thus, if one were to calculate the relative risk for young (16-24 years old) males at various BAC levels, they would be compared to only similar young males not involved in crashes.

Donelson, using data from two studies conducted in Ontario, employed this procedure to calculate relative risk estimates for drivers grouped according to several different variables, including: age, gender, day of week, and time of day (Donelson, et al., 1987). These studies were not strictly case-control studies. In both studies, BAC data from nighttime roadside surveys in Ontario (conducted in 1974 and 1979), were used along with the distribution of BACs among Ontario drivers fatally injured during nighttime hours (from 1973-1982 and from 1973-1985, respectively). The two samples were matched according to general nighttime hours, day of week, and vehicle type, but not the actual crash time and places. Of course, as the crash and non-crash involved drivers came from very different time periods, an unknown bias may have resulted.

The results of this analysis indicated that at BACs over 0.08 , younger drivers (16-20 years old) had generally higher estimated relative crash risk than did older drivers, except at the very highest BACs (over 0.16) where middle-aged drivers (25-34 years old) had the highest estimated relative risk. At BACs over 0.08 , females had higher estimated relative crash risk, again except at the highest BAC level (over 0.16) where males had higher relative risk.

In general, Donelson reported finding little statistically significant difference in estimated relative risk using the Ontario data for any group of drivers at BACs of 0.05 or below, when compared to similar drivers at zero BAC. A statistically 
significant increased estimated relative risk was found for almost every group at BACs above 0.08 , when compared to similar drivers at zero BAC. Whether the lack of a statistically significant effect at BACs below 0.08 is an artifact of Doneison's statistical procedure (using 95 percent confidence limits), or non case-control data set (with crash and non-crash involved drivers coming from different years), is unknown.

\section{Confidence Limits and Statistical Significance}

Relative risk curves indicate the general relationship between BAC level and estimated risk of crash involvement. Without further analysis, however, they do not indicate the significance of absolute differences between the relative risk of drivers at specific BAC levels in comparison to drivers at zero BAC. For example, what is one to make of a finding that drivers at $0.04 \mathrm{BAC}$ have a relative risk 1.2 times that of drivers at zero BAC? One could say that a twenty per cent increase in relative risk is a substantial and unacceptable increase. On the other hand, some might argue that after considering all possible sources of error (due to various forms of confounding, measurement error, variability in the phenomena under study), that such a small numeric difference does not represent a significant difference.

In epidemiological research, statistical methods have been developed to estimate confidence limits for relative risk calculations. These methods can be used, for example, to approximate the 95 per cent confidence limits (e.g., the range within which a relative risk estimate may fall by chance alone 95 times out of 100). Hence they can be used as a form of test for statistical significance for the relative risk (or odds ratio). Unfortunately, these methods have not been applied to the research discussed above, with the exception of analyses conducted by Allsop (1966) and Donelson (1987).

Allsop (1966) reanalyzed the Borkenstein Grand Rapids data and calculated 95 percent confidence limits as a means of determining whether the estimated relative risk of drivers at various BACs differ from the drivers at zero (or less than $0.00 \mathrm{BAC}$ ). His results showed that the relative crash risk for drivers below $0.08 \mathrm{BAC}$ was not significantly different from the zero BAC drivers.

In his report, Donelson also re-analyzed the Grand Rapids data, as well as the Huntsville, Vermont, Adelaide and Ontario data to include the calculation of 95 percent confidence limits as a test of significance of the relative risk estimates. This analysis showed that a statistically significant increase in risk was shown only at BACs at or above 0.08 in the Grand Rapids study, above 0.03 in the Huntsville study, above 0.05 in the Adelaide study, above 0.08 in the Vermont study, and above 
0.00 and 0.05 in the Ontario studies (1974 and 1979 , respectively).

\section{Estimated Relative Risk Using Similar Drivers As Controls}

A recent study of the relationship of $\mathrm{BAC}$ and relative crash risk was reported by Zador (1990). Zador used a procedure similar to Donelson's in comparing data on fatally injured drivers taken from the Fatal Accident Reporting System (FARS) with data from a 1986 roadside survey that collected BAC information from drivers. The FARS is a computerized data base containing virtually all motor vehicle fatalities in the United States as reported by the state governments to the National Highway Traffic Safety Administration.

The non-crash involved driver BAC data came from a roadside survey conducted in 34 communities in the U.S. BACs were obtained from drivers stopped on the road only during the hours from 10 p.m. to 3 a.m., on just Friday and Saturday nights. Driver fatalities from similar vehicle types, on similar roadway types, during the same two days and time periods, that occurred in 29 States (which collect BAC data on at least 80 percent of fatally injured drivers) during 1985 and 1986 were extracted from the FARS data base.

Fatally injured drivers with unknown BACs were eliminated from the analysis (the percentage of cases eliminated was not reported). Thus, this study used crash and non-crash involved drivers from different States on similar, but different roads. To what extent these two groups of drivers represent populations with similar crash risk independent of BAC level is unknown.

The Zador study focused on the joint effects of driver age and gender on estimated relative risk as a function of $\mathrm{BAC}$ in single-vehicle crashes. A loglinear modeling technique was used to analyze the crash rates. Zador emphasized single-vehicle crashes in his analysis because the contribution of alcohol to increased risk is more straightforward than in multi-vehicle crashes. In multi-vehicle crashes the contribution of alcohol to crash risk depends on the BACs of all drivers involved in the crash, information which is not obtained often enough to produce an unbiased sample for study.

The results of this study supported previous findings that the estimated relative crash risk increased with increasing driver BAC. This was true overall and within each of six driver age and sex groups studied (see Table 2). Male drivers had higher estimated relative crash risk at the lowest BAC level $(0.02-0.04)$ and the highest BAC level $(0.15+)$, though the absolute differences were small. Females had significantly 
higher crash risk at the two middle BAC ranges (0.05-0.09 and 0.10-0.14).

Table 3.2

Model Based Within Group Relative Driver Fatality Risk Estimates By Sex, Age and BAC in Single Vehicle Crashes ${ }^{6}$

\begin{tabular}{lccccc} 
& & \multicolumn{4}{c}{ BAC } \\
Sex & Age & $\mathbf{0 . 0 2 - 0 . 0 4}$ & $\mathbf{0 . 0 5 - 0 . 0 9}$ & $\mathbf{0 . 1 0 - 0 . 1 4}$ & $\mathbf{0 . 1 5 +}$ \\
\hline Male & $25+$ & 1.2 & 8.6 & 39.7 & 607.1 \\
& $21-24$ & 2.5 & 11.8 & 135.2 & 600.7 \\
& $16-20$ & 1.2 & 18.3 & 30.4 & 349.0 \\
Female & $25+$ & 0.8 & 25.5 & 118.5 & 546.5 \\
& $21-24$ & 1.6 & 35.1 & 403.8 & 540.8 \\
& $16-21$ & 0.8 & 54.4 & 90.8 & 314.2
\end{tabular}

(adapted from Zador, 1989)

Age had a less clear effect upon estimated relative crash risk. At the lowest BAC range $(0.02-0.04)$ the $21-24$ years old drivers had the highest relative risk with the older (25+ years old) and younger (16-20 years old) drivers having lower relative risk. Drivers with BACs between 0.05-0.09 showed the highest relative risk at the lowest age with the risk decreasing with increasing age. At the next higher BAC range (0.10-0.14), drivers between the ages of 21-24 years old had the highest risk, followed by drivers $25+$ years old, with drivers $16-20$ years old having the least relative risk for this BAC range. At the highest BACs $(0.15+)$, the older drivers had significantly higher relative risk than did the youngest drivers (16-20 years old).

\section{Crash Responsibility}

One other method that has been used to explore the role of alcohol in crashes is to compare drivers judged as responsible (partly or wholly) for their crashes with drivers judged not to be responsible for their crashes (i.e., they were innocent victims of the responsible driver). The logic behind this approach is fairly simple. If alcohol use is related to crashes then one would expect drinking drivers to drive dangerously and cause crashes. Thus, BAC, relative risk, and crash responsibility should be related.

${ }^{6}$ Relative to crash risk at $\mathrm{BAC} \leq 0.01$ 
The major shortcoming of this approach is the difficulty in establishing driver responsibility for a crash. The definition of responsibility used in this context is different from the legal concept of responsibility (which usually involves some sort of illegal or irresponsible action). The assignment of responsibility for a crash almost always involves some subjective judgement by the rater.

A number of studies in which driver responsibility has been determined (see DOT, 1985 ) have compared the BAC levels of responsible and nonresponsible crash involved drivers. All found some relationship between responsibility and BAC. In general, the higher the BAC level, the more drivers were rated responsible (Terhune, 1982; Terhune, 1983).

Another use of responsibility judgements has been to calculate relative risk curves for crash involved drivers judged responsible for their crashes compared to crash involved drivers judged not responsible for their crashes. For example, Figure 3-3 shows data from the Grand Rapids study plotted by whether the driver was or was not judged responsible. The relative risk for responsible drivers rises with BAC level, whereas the crash risk for nonresponsible drivers remains relatively flat as BAC increases. This, and other studies reviewed, that have used responsibility judgements to compare the relative risk of crash involvement for drivers judged responsible and not responsible, all had severe problems with the underlying data sets, methods of determining responsibility, sample sizes, etc., such that these analyses may be considered descriptive, and useful for generating hypotheses, but not for proving hypotheses (i.e., not evidence that alcohol causes crashes).

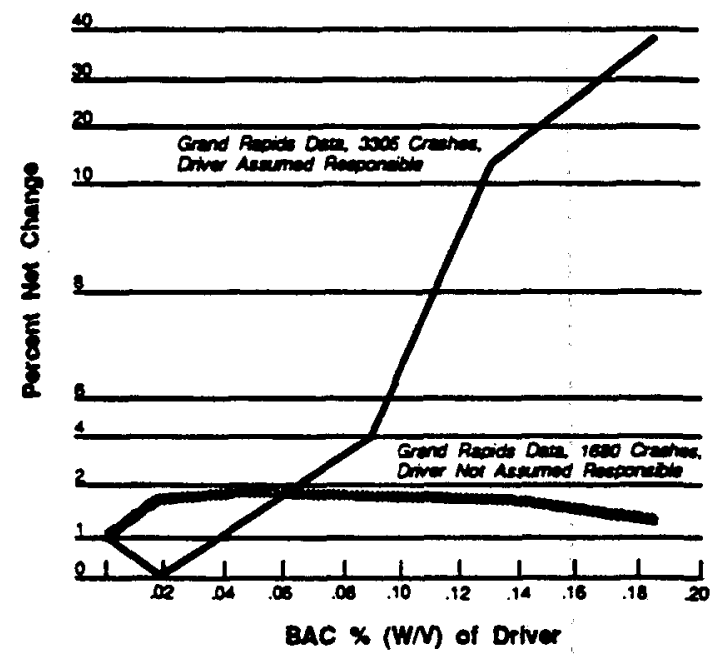

Fioure 3. Rolative Crash Probablity for Drivere Aceumed Recponsiblo and Those Not Aseumed Reaponalble is a Function of BAC, where 1.0 = Rolattve Probability at Znro Aleohol 
Some researchers have attempted to use the differences in responsibility for a crash to develop control or comparison group data where it was not possible to conduct roadside surveys of drivers at times and places of crashes. This approach is based on the assumption that nonresponsible drivers involved in crashes would be the same as drivers using the road but not crash involved. In this view, nonresponsible drivers are presumed to be involved in crashes purely by chance, and therefore are a random sample of drivers using the roads at the same times and places as the responsible drivers. This method of developing a control sample has been labeled "induced exposure." This approach is fraught with potential problems (lack of control for many other factors) so that its usefulness is limited to very special situations.

\section{SUMMARY}

This chapter has reviewed the evidence for the involvement of alcohol in crashes and the relationship between BAC and estimated crash risk. There is no question that alcohol is over-represented in crashes. The available evidence indicates clearly that a greater percentage of crash involved drivers have positive BACs than one finds in non-crash involved drivers.

The available evidence indicates that a larger percentage of drivers have been using alcohol in more severe crashes. Fatal crashes show the highest percentage of drivers with positive BACs, with non-fatal injury crashes somewhat lower and property damage only crashes, even lower. Information about alcohol use in non-fatal crashes is of much poorer quantity and quality. Testing of crash involved drivers is not conducted regularly or systematically in non-fatal crashes. Thus, our knowledge and understanding of the involvement of alcohol in these crashes is limited. There are plausible hypotheses as to why alcohol may contribute to a greater extent to the occurrence of fatal or injury crashes than to property damage crashes, but there is no direct evidence to support any of these theories.

Unfortunately, data about the presence of alcohol in crash involved drivers can only suggest the magnitude of the potential contribution of alcohol in contributing to the occurrence of crashes. It can not tell us the extent to which alcohol caused or actually contributed significantly to the occurrence of these crashes.

The few epidemiological studies that have tried to estimate the relationship between BAC and probability of being involved in a crash have consistently shown that estimated relative risk increases with BAC level. Moreover, the shapes of the estimated overall relative risk curves derived from all of these studies are generally 
quite similar, despite the use of different data sets involving different drivers on different types of roads in different places, times and years.

It should be noted that many other factors besides BAC level have also been shown to relate to estimated relative risk, including crash outcome (property damage, injury, or fatal crash), type of crash (single versus multiple vehicle), time of day, and day of week. Also, relative risk clearly differs depending on the driver's age, gender, driving experience, and drinking experience. These other factors can increase or decrease estimated relative risk in the absence of alcohol. Relative risk estimates, while highly correlated with $\mathrm{BAC}$, can be mitigated or enhanced by these other factors.

All of these studies suffer from various methodological and analytical shortcomings that limit, or at least require some caution in, the drawing of firm conclusions about the precise relationship between BAC and estimated relative risk. While one can not know for sure that the apparent relationship of BAC to estimated crash risk is actually revealing a true effect of $\mathrm{BAC}$, or is due to some co-variate that has not been controlled for in the design of the studies or adjusted for during the analyses, the weight of the evidence is rather overwhelming that alcohol contributes to the occurrence of crashes. No evidence is available to support an argument that alternative co-variates are responsible for these results.

Thus, there is convincing evidence that alcohol contributes to the occurrence of crashes and that as BAC increases the risk of involvement increases, apparently rather dramatically at high BACs. Unfortunately, the available evidence does not permit quantification of the percent of the population that can be considered at significantly increased risk at each BAC.

There is no question that there is strong evidence that all groups of drivers appear to have higher estimated relative risk at BACs of 0.08 and above. While the evidence for increased crash risk for all drivers at very low BACs is not as strong as it is at higher BACs, it appears clear that all drivers, when compared to similar drivers at zero $\mathrm{BAC}$, show increasing risk as $\mathrm{BAC}$ increases.

Given that all drivers do not have the same relative risk at zero BAC and that groups of drivers do not show the same rate of increase in relative risk as BAC increases, there does not appear to be sufficient evidence to support the concept of a threshold for the impairing effects of alcohol. A threshold implies that all drivers are dangerous above this level and all safe below it. The available evidence argues for the effects of alcohol to be viewed as a continuum with crash risk increasing with BAC, possibly at different rates for different groups. 


\section{CHAPTER IV}

\section{CONCLUSIONS}

The two previous chapters have examined the scientific evidence regarding the effects of alcohol on driver performance and the relationship between BAC level and crashes. Each provides useful and important information, and each has its particular limitations for drawing conclusions. Because each approaches the issue with different methods and data, when the two are combined and found to point in the same direction, much greater confidence can be placed in the conclusions. The following presents the conclusions drawn from the material in the previous two chapters:

There is no threshold for alcohol impairment. Any amount of alcohol can impair performance of some people on some tasks that are related to driving. The greater the amount of alcohol, the greater the degree of impairment on a given task and the more functions (or different kinds of tasks) that are impaired. However, the relationship between performance decrements due to alcohol found in experimental situations and the risk of a crash can not be quantified.

Studies of alcohol presence in crashes compared to alcohol in similar situations not involved in crashes, show that the more alcohol in a driver, the greater the risk of a crash. However, the available data do not permit an accurate quantification of the increase over the BAC range for the risk due to alcohol or the increased risk to be expected in a given individual. Commonly used alcohol risk curves appear to underestimate the risk for some groups and overestimate the risk for other groups at given BAC levels.

In case comparison field studies, an observed correlation between alcohol level and crash risk may not be due solely to alcohol related performance decrements, but rather to other factors that correlate with alcohol use. For example, there may be people who take risks and these people also may be more likely to drink heavily. It is not possible, based on field studies alone, to determine the contribution of each of these two factors to crash risk.

For both experimental and field studies, there is the matter of individual and group differences which limit generalizations to the whole population regarding performance or impairment at a given BAC level. (For example, there are individual differences in initial or base level performance, differences in reaction to alcohol due to factors 
such as age, sex, drinking history, learning adaptation etc.).

These limitations do not permit the firm and precise conclusions that would quantify the relationship between alcohol levels and increased crash risk in a way that would lead to unequivocal decisions about acceptable and unacceptable BACs. Nevertheless, the broad pattern of results from the laboratory studies and epidemiological studies are consistent.

In summary, there is a substantial body of laboratory and epidemiological data confirming that alcohol impairment is a major factor in motor vehicle crashes. Although impairment and crash risk increase much more dramatically above 0.08 , there is no BAC below which alcohol is not expected to impair driving ability to some degree. While precise quantification is not possible, it is clear that the greater the alcohol, the greater the danger, and that a reduction in driver BACs will result in a significant highway safety benefit. 
SECTION II

LEGISLATIVE AND INSTITUTIONAL RESPONSES 


\section{CHAPTER V}

\section{BAC LIMITS AND LEGISLATION}

\section{DESCRIPTION OF LAWS AFFECTING THE GENERAL DRIVING PUBLIC}

Drinking and driving laws in the U.S. and many foreign countries allow use of Blood or Breath Alcohol Concentration (BAC) as either presumptive or per se evidence of impairment or intoxication. Under a presumptive ${ }^{7}$ law the accused is presumed to be impaired when his or her BAC is at the established limit. The accused, however, is allowed to submit evidence that he or she was not impaired at the prescribed limit. The prosecutor is also allowed to present evidence that the driver was impaired even though his or her BAC was less than the presumptive limit. With a per se law, it is an offense to drive with a BAC greater than a specified amount. A defendant will be convicted on the basis of a chemical test alone. The defendant's degree of impairment is not a factor.

In this country nineteen states have only per se limits of 0.10 . Another sixteen jurisdictions have both per se and presumptive limits of 0.10 . Five states have only presumptive or prima facie laws (See Table 1). A few states, California, Maine, Oregon, and Utah have moved to a lower per se limit of 0.08 . Vermont has recently (Jan., 1990) enacted a law making driving with a BAC of 0.08 a civil offense. In total, 46 jurisdictions have set 0.10 as the highest legal limit, four have 0.08 , and one has 0.12 .

State sanctions for a first offense frequently include a fine ranging from $\$ 50$ to $\$ 500$ and/or imprisonment up to 72 hours. Twenty-four states and the District of Columbia impose license suspension or revocation for driving over the legal limit. There is little difference in penalties between states with 0.10 and $0.08 \mathrm{BAC}$ as their limit. Several states have adopted two-tier BAC legisiation. Under this system there are two illegal BAC limits (a lower and an upper limit), and different sanctions associated with each limit. Most of these states have a per se level of 0.10 as the higher limit and a presumptive level of 0.08 or 0.05 as the lower limit. Exceeding the lower level constitutes a less serious offense with lesser penalties (NHTSA, 1990). (See Appendix B for further information on States' BAC limits and sanctions.)

\footnotetext{
7n this report, the term "presumptive" refers to both presumptive and prima facie laws which are similar, though not identical. A presumptive evidence law directs that a deduction be made based on the presentation of particular facts, although in some cases, the law permits the rebuttal of the presumption. A prima facie law provides that the presentation of particular facts is sufficient to make the case of the party introducing those facts into evidence, but it does not, as a matter of law, go so far as to create a presumption.
} 
Table 5.1

BAC Limits in the U.S.

\begin{tabular}{|c|c|c|c|c|c|c|c|}
\hline & \multirow[b]{2}{*}{.10} & & \multicolumn{5}{|c|}{ 2-tiered limits } \\
\hline & & .08 & $\begin{array}{l}.12 \\
.10\end{array}$ & $\begin{array}{l}.10 \\
.08\end{array}$ & $\begin{array}{l}.10 \\
.07\end{array}$ & $\begin{array}{l}.10 \\
.05\end{array}$ & Total \\
\hline $\begin{array}{l}\text { Per Se } \\
\text { only }\end{array}$ & 19 & 2 & - & - & - & - & 21 \\
\hline $\begin{array}{l}\text { Presumptive } \\
\text { only }\end{array}$ & 4 & - & - & - & 1 & -. & 5 \\
\hline $\begin{array}{l}\text { Per Se and } \\
\text { Presumptive }\end{array}$ & 16 & 2 & 1 & 1 & 2 & 3 & 25 \\
\hline Total & 39 & 4 & 1 & 1 & 3 & 3 & $51^{9}$ \\
\hline
\end{tabular}

The following material describes the BAC laws in various foreign countries. The information is not comprehensive and is limited mainly to European countries and a few other developed nations. It is based on the most recent information available.

For countries specifying single BAC limits, the legal level ranges from 0.02 (Sweden) to 0.10 (New Zealand) -- levels typically equal to, or below, those in the U.S. A few countries, such as Finland and Denmark, have adopted multi-tiered ( $2-5$ tiers) legislation. The lower limits begin at 0.05 or 0.08 and the upper limits begin at 0.10 to 0.25 . Some countries permit roadside breath testing as evidence of impairment or intoxication. In Australia, random breath testing is allowed at police roadside checkpoints.

Sanctions imposed on drivers with illegal BACs in foreign countries include fines, imprisonment, and license suspension similar to the penalties received in the U.S. (See Appendix C for more detailed information on foreign BAC laws and sanctions.)

\section{EVALUATION OF LOW BAC LAWS}

Scientific evaluation of any drinking and driving law is difficult. Evaluation of lower legal BAC levels is no exception. Studies attempting to discern differences in crash or fatality rates after law implementation have to deal with many problems.

${ }^{8}$ In states with two levels the higher limit is per se with the lower level presumptive

Tncludes the District of Columbia 
Extraneous variables such as degree of enforcement and introduction of other legislative changes serve to confound any effects of the lower limit. In addition, the analysis of data depends on accurate and consistent record keeping. During the course of a legal change in BAC limit, police or court recording practices may also change. Thus, any real change due to the lower limit may be masked by differences attributable to the reporting system. The choice of which outcome variable to study is also important. Crash data, distribution of BAC levels (crash, arrest, and on-road), and self-reported behavior change, are all potential candidates, but each addresses different aspects of the problem. Partly for these reasons, evaluations of changes in legal BAC limits, both in this country and abroad, are scarce. Caution should be exercised in interpreting the results of these studies because of cultural, political, and economic differences between countries as well as the limited ability to isolate effects of lower BAC limits from other effects on fatal crash statistics.

As far as the U.S. is concerned, few studies have evaluated the effect of lower BAC levels. Personke (1984) examined the effect of 0.08 limits in Oregon and Utah. In 1983 Oregon lowered their limit from 0.10 to 0.08 and Utah moved from a presumptive level of 0.08 to a per se level of 0.08 . Although the data from Oregon are confounded by other enforcement activities occurring at the same time, an informal survey of police indicated that the lower BAC level makes the officer's job easier; they still arrest essentially the same drivers but can feel more comfortable that the arrest will be a good one in the courts. Because Utah's BAC level did not change, and residents were not aware of the meaning of the change to a per se law, that study did not provide relevant evaluative material.

In another study, paired crash data from Oregon and Utah (both 0.08) were compared with data from Washington (0.10) and Colorado (then 0.15). Analyses of single vehicle night-time driver fatalities in all four states were carried out. The study identified no significant statistical differences in fatality rates between the 0.08 states paired with their similar 0.10 or higher states. There was, however, an indication that some degree of positive impact occurred in favor of the 0.08 states. The 0.08 states generally maintained a lower incidence of alcohol fatalities than the non-0.08 states (Johnson, 1988). NHTSA has initiated a study to assess the impact of the recently enacted $0.08 \mathrm{BAC}$ law in California. The study will determine the extent to which the new law affects: 1) people's drinking and driving behavior and the occurrence of alcohol-related fatal crashes, and (2) organizations which deal with drinking and driving behavior. The results of this study should be available by August 1991.

As far as research to determine the effect of lowering the BAC limit in foreign countries is concerned, evaluation studies have been conducted in Great Britain and 
Australia. Ross (1981) used time-series analysis to study the effect on drinking and driving of the British Road Safety Act of 1967 which established a per se limit of 0.08 (previously there was no specified limit). His data noted a significant decrease in road casualties in the months immediately after inception of the legislation. In addition, for the years immediately prior to the 1967 law, 25 percent of the drivers killed in England and Wales had illegal BACs. In the corresponding period between 1967 and 1968, only 15 percent of fatally injured drivers had a BAC above the limit (Ross, 1979). Although the law appeared to have an immediate effect, the effect dissipated within a few years -- the initial decrease in casualties has disappeared. Ross believes that the initial decrease in casualties was due to public perception of increased risk of arrest and threat of severe punishment. According to Ross, this effect abated when the public realized they had overestimated the certainty of punishment under the new law (Ross, 1981).

In 1982, Queensland, Australia lowered the legal BAC from 0.08 to 0.05 . Smith (1988) conducted an evaluation of the lower limit using crash data. Night-time crashes were compared to daytime crashes for three years prior to and after 0.05 implementation. There was a 11.3 percent reduction in night-time injury crashes involving admission to a hospital. The BAC distribution of all drivers and motorcyclists involved in crashes in Queensland during the three-year period was significantly different from that of the before period. There was no significant difference, however, in fatal crashes in Queensland before and after the law change or in the control state of Western Australia.

\section{INSTITUTIONAL POSITIONS REGARDING LOWER BAC LIMITS}

A number of national organizations have recommended that states adopt a BAC of 0.08 per se or lower.

The National Safety Council (NSC) has recommended a BAC of 0.08 citing evidence that drivers are impaired at 0.08 and that with a $\mathrm{BAC}$ of 0.08 and higher, the rate of injury accidents increases significantly. The NSC believes a limit of 0.08 would enlighten the nation to the increasing problem of the alcohol-impaired driver in both vehicle crashes and fatalities.

The National Commission Against Drunk Driving (NCADD) has revised its proposal on state BAC limits. The Commission originally recommended a per se limit of 0.10 and a presumptive limit of 0.08 . After consideration of evidence concerning the effects of relatively low levels of alcohol, the Commission has revised its 
recommendation to a per se limit of 0.08 and a presumptive limit of 0.05 .

In June 1985 the American Medical Association (AMA) endorsed a limit of 0.05 BAC per se as the legal limit. The AMA also urged all states to adopt administrative suspension or revocation of driver licenses after Driving Under the Influence (DUI) conviction and mandatory revocation after a specified number of repeat offenses. The AMA cited evidence that alcohol causes deterioration of driving skills beginning at 0.05 and that there is significant alcohol involvement in injury-causing road crashes beginning at 0.05 .

The Surgeon General has advocated making driving with a BAC of 0.08 illegal. The Surgeon General cited evidence that there is measurable impairment in operating a motor vehicle (e.g., divided attention tasks) beginning in most drivers at or below 0.05 and that all drivers are impaired at 0.08 .

In November 1987 the Association for the Advancement of Automotive Medicine (AAAM) encouraged states to adopt 0.05 as presumptive evidence of driving impairment and 0.08 as the per se limit. The AAAM cited evidence that there is measurable impairment in operating a motor vehicle beginning in most drivers at or below 0.05 and that all drivers are impaired at 0.08 .

Within the U.S. and abroad there is a trend towards lower BAC limits. In January 1990, California joined Oregon, Utah, and Maine in setting the limit at 0.08, while Vermont established 0.08 as a civil offense. Commercial drivers in the U.S. are now subject to a state and federally enforced 0.04 limit. $^{10}$ Sweden recently $(7 / 90)$ lowered their legal BAC to 0.02. In Australia there is a move by the Federal government to establish a national BAC of 0.05 . Currently all states and territories in Australia, except two, have set the maximum permissible BAC at 0.05 . The remaining states have BAC levels of 0.08 .

\footnotetext{
${ }^{10}$ The Commercial Motor Vehicle Safety Act of 1986 and the Federal Motor Vehicle Safety Rules issued pursuant to that law set a per se BAC standard of 0.04 for commercial motor vehicle drivers, the same standard applied to commercial operators of all forms of transportation under federal safety regulation. Commercial motor vehicles are defined for purposes of the Act as those over 26,000 pounds gross vehicle weight rating, those equipped to carry 15 or more people and those carrying hazardous materials. While some states have already enacted the $0.04 \mathrm{BAC}$ for commercial motor vehicle drivers and all states are required to do so by 1991, no data are yet available on the effectiveness of the 0.04 BAC standard for this special population of drivers.
} 


\section{CHAPTER VI}

\section{INSTITUTIONAL RESPONSE TO CHANGES}

The nature and extent of changes in the BACs of drivers on the road that would result from a change in the legal BAC limit for the general driving public is not clear. BAC limits are implemented through a complex educational, administrative and legal system. It is important to know how the institutions that deal with drinking drivers would react to changes in BAC limits because:

1. How the limits would be implemented would influence future driver behavior and hence determine the actual impact of a lower BAC limit for the general driving public;

2. The effects on the system are part of the costs and benefits of any proposed change.

The second phase of the study involved assessing the impact of various alternate BAC levels on the major agencies and institutions that interact with drinking-impaired drivers. These agencies and institutions include law enforcement agencies, the court system, departments of motor vehicles, treatment centers, legislatures, activist groups, the media and the hospitality and alcoholic beverage industry.

A review of the literature found only very limited information on the subject, primarily arrest and conviction rates in Oregon and Utah. Input from selected invitees from the relevant agencies and institutions was secured through a series of workshops conducted by a contractor. NHTSA selected the workshop participants through a process of referral and recommendation by people in the relevant fields. The workshop participants considered changes at BAC levels of $0.00,0.04$, and 0.08 . Information provided by the workshop participants was reviewed and analyzed by the expert panel and project staff to develop this section of the report.

Four workshops were held across the country during a three-week period:

Reston, Virginia

San Francisco, California

Kansas City, Missouri

Atlanta, Georgia
April 11, 1990

April 18, 1990

April 25, 1990

April 27, 1990 
The workshop participants were selected to provide information on how their "type" of organization -- not necessarily their own specific organization -- would react as a result of changes in the BAC limits for the general driving public. It was their expectations of operational changes that were sought -- not their opinions on the goodness or the wisdom of the change, or whether the public would agree or object to the new limit.

The workshop addressed participants' expectations of changes to the types of agencies and institutions they represented at each of three proposed BAC levels. A copy of the workshop agenda is provided in Appendix D.

All participants provided information prior to the workshops regarding their expectations at each of the three proposed BAC levels. A cumulative set of the responses for all the members of a particular workshop was provided to each participant prior to that workshop. This advance information stimulated ideas and enabled workshop discussion to progress quickly. At the conclusion of each workshop, participants again completed similar reply forms. This last set of information provided documentation of the participants' expectations after having the benefit of the workshop discussion.

The workshop moderator instructed participants (see Appendix E) to think in terms of the type of agency or institution they represented rather than their specific agency or institution. The moderator also encouraged participants to assert their best opinion and not conform to a group opinion. The discussion process was not a consensus process.

In total, 77 participants attended the workshops. A list of participants at each workshop is provided in Appendix F. Participants represented each of the pre-selected categories of agencies and institutions dealing with alcohol-impaired drivers and included some of the most prominent people in their fields. They included state legislators, judges, attorneys, chiefs of police, heads of departments of motor vehicles, directors of treatment centers, directors of activist groups, authors, police officers, and reporters.

Participants often came from a combination of backgrounds. One prosecutor had been a legislator; an administrator in a department of motor vehicles had been with a law enforcement agency; a beverage distributor had been a police officer; and a parole officer had worked with the inventor of the breath tester. This depth of experience provided the workshops with a wealth of insight.

No assumptions were made as to whether the limit was a per se level (offense defined 
solely by BAC level) or a presumptive level (impairment presumed to be present but is rebuttable). No assumptions were made as to the availability of funding to enforce the new level. The discussions addressed adult drivers with operators' licenses. Participants frequently discussed different BAC levels for people under the age of 21 and for commercial drivers, but these issues go beyond the scope of this report.

\section{DESCRIPTION OF EXPECTED INSTITUTIONAL RESPONSES BY BAC LEVEL}

This portion of the report provides information about expected institutional responses at each of the three BAC limits considered at the workshops. For each BAC level, the first part presents the expectations of the participants by type of institution. The second part - headed analysis and conclusions - incorporates expert panel input, integrates data from different institutions, and summarizes expected institutional response to the alternate BAC limit for the general driving public.

\section{Workshop Participant Expectations at a BAC Level of 0.08}

At a BAC level of 0.08 , the changes that would occur would be determined by how far this level is from the current level in a given jurisdiction. Several jurisdictions are at 0.08 percent $\mathrm{BAC}$ level already. Participants from jurisdictions with BAC levels higher than this level generally felt that while there would be resistance to this level, agencies could manage effective enforcement.

Expected Institutional Responses:

- Law Enforcement Agencies: Law enforcement agencies expected they would need more officers, and that officers would need more training. Probable cause would likely remain an issue at a BAC level of 0.08 . There was concern expressed that police would have increased discretion in determining whom to arrest and whom to prosecute.

- The Court System: Plea bargaining, challenges to the evidence, and requests for jury trials were expected to increase.

- Departments of Motor Vehicles: Departments of motor vehicles were expected to experience increased administrative hearings, processing requirements, and information exchange demands. 
- Treatment Facilities: Treatment personnel thought that additional treatment centers would be required.

- Legislatures: Legislators expected they would have to consider additional legislation to bolster support for police enforcement.

- Activist Groups: Activist groups would expect minimal change to their activities at this level. They would continue to focus on public education and victim support.

- The Hospitality and Alcoholic Beverage Industry: The Hospitality and Alcoholic Beverage Industry felt it would begin to feel a decrease in consumption. These industries would then expect to become increasingly involved in sellers' and servers' training and might increasingly promote designated drivers and related safe driving programs.

- The Media. Minimal change was expected in the activities of the media. The media would be expected to continue coverage in about the same fashion as at the current time.

Analysis and Conclusions:

Officials in affected institutions expect a greater work load and the need for more resources. However, they do not expect the increase to be great. Limited experience in States that have adopted this level seems to indicate that the system would adapt with minimal changes. Enforcement officials point out the need for new scoring systems for tests of impairment that had been designed with a 0.10 limit, in order to detect those between 0.08 and 0.10 . Drivers with a 0.10 to 0.12 BAC would no longer be considered as marginal cases and more would be prosecuted and convicted. Cases in the 0.08 to 0.10 would be more difficult to prosecute and convict where the law required observed evidence of impairment. The number of cases referred to alcohol treatment would increase, with some increase in those in the earlier stages of alcoholism. There would be relatively little impact on media coverage or activist group activity. Alcohol beverage service industry use of server training and designated driver and ride service programs would probably increase. 


\section{Workshop Participant Expectations at a BAC Level of $0.04^{11}$}

At a level of 0.04 , officials in affected institutions expect that the staffing, training, workload, and resource demands that were anticipated at a level of 0.08 would be exacerbated. Participants believed that the general public might not be fully supportive of a law at this level and noted the difficulty in enforcing a law without broad public support.

Expected Institutional Responses:

- Law Enforcement Agencies: Because obvious signs of impairment do not exist at a level of 0.04 , participants foresaw problems with probable cause. Police would no longer have the benefit of the Standardized Field Sobriety Test since it had been validated for higher BAC levels, unless it or a new test is validated for lower limits. One participant projected a need for a breath test device in every officer's car. Another projected an increase in the number of false arrest charges. Concern was expressed that there would be too much discretionary power for the police.

- The Court System: Participants felt that both judges and prosecutors would exercise greater discretion in determining which cases got prosecuted because the court would not be able to handle all cases. While arrests were expected to increase at the .04 level, participants believed that dismissals and acquittals would also increase. Defense attorneys said they would challenge most low BAC level arrests on the basis of probable cause and would bring an array of experts to testify that impairment does not exist. Less plea bargaining might occur at this level because drivers would request jury trials. Defense attorneys might file a class action suit on the basis of civil rights violations. They expected they would defend against more charges of driving without a license' and without insurance and would spend more time challenging prior convictions and getting restricted licenses. They might also attempt to delay pleas so that defendants can complete Driving While Impaired/Intoxicated (DWI) school and thus get a restricted permit. One participant foresaw more people going to jail for

\footnotetext{
"This report deals with BAC limits with respect to the general driving public and does not address populations such as commercial truck drivers who are subject to a state and federally enforced 0.04 BAC limit.
} 
driving on a suspended license than for DWI.

- Departments of Motor Vehicles: Participants agreed in their expectations that all functions at departments of motor vehicles would be backlogged.

- Treatment Facilities: Treatment facilities would expect to begin to see clients who did not have an alcohol problem. If so, they would have to revise their programs to take a more informational and preventive stance. Their success rates might increase.

- Legislatures: Legislators expected that revisions to legislation would be required in many states. A participant from one state, for example, reported that his state currently has legislation that dictates that a BAC level of less than 0.05 is prima facia evidence that a driver is sober. Legislatures could also begin to hear legislation to repeal the 0.04 level.

- Activist Groups: Activist groups would closely monitor other groups' efforts to repeal the 0.04 level.

- The Hospitality and Alcoholic Beverage Industry: Participants from the industry felt that it would be fighting economic hardships on all fronts. The industry, they believe, would have to absorb the costs of sellers' and servers' training on a wholesale basis, the costs of transportation for customers, and the costs of skyrocketing liability insurance while simultaneously experiencing a decrease in consumption. One participant commented that alcohol carry-out establishments, however, might experience an increase in sales. It was expected that the alcoholic beverage industry would make efforts to change its image and would promote designated driver programs.

- The Media: The media would cover new arrest statistics, sellers' and servers' training, and unique programs to transport customers home. It would also begin to cover questionable cases, hardship stories of individual drivers and groups advocating a repeal of the law.

- Insurance: Participants expected increases in automobile insurance rates for those convicted of DWI and in the number of unlicensed and uninsured drivers. 


\section{Analysis and Conclusions:}

Officials in affected institutions expect that this level for the general driving public could result in a heavy load which could overwhelm the system. At the same time, there are significant problems in enforcement that would limit the ability of enforcement agencies to detect and convict DWIs at levels below 0.08 . The main problem anticipated is the lack of reasonable suspicion to stop a driver or probable cause to arrest and test a driver because of the lack of obvious signs of impairment at the lower BAC levels and limitations of current methods of enforcement. Unless the statute is a per se law, this would also present problems in convicting drivers at 0.04 . There is concern about the potential for too much police officer discretion in enforcement, and a recognition for the need for revised detection and testing procedures for enforcement at levels below 0.10 or 0.08 . An administrative per se law with civil penalties (license suspension, fine) for offenses under 0.10 or 0.08 would eliminate court problems, but the DMV would see an increase in processing load.

The system might adapt to the 0.04 level by (a) development and use of new or modified techniques to permit detection and prosecution of cases between 0.04 and 0.10 (b) by use of administrative per se laws to implement such a level without large increases in court loads, and (c) prosecutorial discretion in weak cases.

Until and unless new techniques are developed and applied to provide police officers with reasonable suspicion and probable cause to investigate drivers who are likely to be between 0.04 and 0.08 , it appears that most stops and arrests for violations at these levels would be made in conjunction with other traffic incidents (violations and crashes). Thus the increase in case loads due to cases at 0.04 to 0.08 would be limited to situations where an officer previously may not have arrested a driver for another infraction alone. There would also be an increase, perhaps more substantial, in arrests and convictions at the 0.08 to 0.15 level, since these would no longer be considered marginal cases.

\section{Workshop Participant Expectations at a BAC Level of 0.00}

A BAC level of 0.00 would eliminate the problems of determining the exact BAC level since any alcohol at all would be prohibited. Nonetheless, participants expected considerable resistance.

Expected Institutional Responses. Participants predicted that the staffing, training, workload, and resource demands cited at the higher limits would persist, and be at a 
crisis level, at a BAC of 0.00 .

- Law Enforcement Agencies: At a BAC level of 0.00, the problems of enforcement personnel would be considerably eased since probable cause would no longer be an issue. Discretionary enforcement continued to be a concern of participants as well as increased charges of false arrest.

- The Court System: At a BAC level of 0.00, participants predicted the court backlog would begin to ease. The system would be streamlined since the issue of impairment would be moot. From a legal standpoint, participants felt that this is a better situation than the higher BAC levels. Penalties would have to be kept lenient so that defendants would not be able to request a jury trial. Defense attorneys would be handling more cases of BAC from controversial sources (e.g., communion wine, rum cakes) and would more frequently be using doctor's and employer's testimony as evidence. One participant predicted that juries might acquit cases as a waste of time.

- Departments of Motor Vehicles: Departments of motor vehicles might be overwhelmed with processing and tracking the increases of suspended; restricted, and revoked licenses.

- Treatment Facilities: A zero tolerance level would eliminate altogether the need for treatment programs to educate clients on the impairment associated with the different BAC levels.

- Legislatures: Legislatures are expected to be dealing with legislation both to facilitate enforcement at this level and to repeal this level. Numerous appropriation and tax bills would be considered as means of financing enforcement. Legislatures would be asked to pass legislation to permit the revocation of the driving license for refusal to take a breath test.

- Activist Groups: Activist groups expected to be immersed in monitoring and containing anti-BAC legislation.

- The Hospitality and Alcoholic Beverage Industry: On-premise drinking establishments were expected to be in dire economic straits. Many might shut down. Carry-out liquor establishments might have less difficulty. One participant forecast the growth of "illegal social clubs" 
where people would not be subjected to servers' intervention.

- The Media: Participants felt that a level of 0.00 would be considerably easier for the public to understand since the law would simply be: "No drinking and driving." This is a less difficult concept than "No drinking over 0.04 and driving" or "No drinking over 0.08 and driving." The media felt it would focus on hardship stories and would document efforts to have the law repealed.

- Other Impacts: Participants expected increases in automobile insurance rates for those convicted of DWI and in the number of unlicensed and uninsured drivers. Participants speculated that people convicted of DWI would not serve any jail time due to the incapacity of the prison system. Participants were concerned that the public would ignore and flaunt the law, which would then diminish respect for other laws.

Analysis and Conclusions:

At this level, some enforcement problems that exist for an 0.04 law are reduced because the odor of alcohol can provide reasonable suspicion to investigate and probable cause to arrest. Drivers who were stopped for whatever reason might be detected, but present day techniques do not enable police to detect drinkers at low BACs who are riding by in their cars. At the same time, enforcement officials are concerned about the number of cases and a lack of public support.

\section{SUMMARY AND CONCLUSIONS}

If BAC limits were changed to $0.08,0.04$ or 0.00 for the general driving public without other changes in the system, or without a significant effort to educate personnel in all phases of the system, we would expect the following institutional or system responses:

The establishment of 0.08 limit would likely result in: some increase in the number of cases throughout the system (from detection through treatment), an increase in convictions just above 0.10 , short lived attention from the media, and calls for better techniques to provide police with the basis for reasonable suspicion to stop and probable cause to arrest drivers at $0.08-0.10$. Institutions could adopt a BAC limit of 0.08 with a minimum of problems. 
The establishment of still lower limits such as 0.04 or 0.00 would likely result in widespread and continuing attention from the media, the public and public officials concerning the effects of low BACs. A number of problems would limit the number of cases successfully prosecuted at the new lower levels: difficulties in gaining a basis for reasonable suspicion or probable cause, hesitancy of local officials to enforce what they perceive as an unpopular law or one without strong evidence and concerns about overloading the court system with "less important" cases. However there would be some increase in cases and successful prosecutions near and above the previous limit (e.g., $0.10)$. A larger increase in case load may occur as technology for better detection is developed or gains legal acceptance. Institutions would have great difficulty in effectively implementing a BAC limit of 0.04 or 0.00 for the general driving public, without additional changes ${ }^{12}$.

The establishment of significantly lower limits (e.g., 0.04 or 0.00 ), without other changes, would exacerbate many present problems in the system that deals with DWI and could lead to difficulties in the proper and efficient handling of cases. However, ways to overcome these problems are in use in some jurisdictions and additional steps have been suggested.

Statutory changes are a clear solution to one problem in DWI enforcement that exists today and would be exacerbated with lower BAC limits. The problem is legal challenges to breath test evidence on two technical grounds:

Defense attorneys will sometimes attempt to discredit BACs measured with breath tests, arguing that the BAC limit is stated as blood alcohol concentration and that the transformation from breath to blood is a matter of scientific dispute. However, the preponderance of recent evidence on the effects of low BACs is based on BAC as measured by breath, justifying the modification of statutes to protect against this argument. (See Appendix G.)

\footnotetext{
${ }^{12}$ This report deals with BAC limits with respect to the general driving public and does not address populations such as commercial truck drivers who are subject to a state and federally enforced 0.04 BAC limit. Federal rules for commercial motor vehicle drivers issued under the Commercial Motor Vehicle Safety Act of 1986 provide that such a driver found driving with any detectable BAC will be put out of service for 24 hours. Canada has a similar rule. While U.S. commercial motor vehicle drivers have heretofore been prohibited from driving while impaired and from drinking alcohol within 4 hours of going on duty, the out of service regulation is new and will not be mandatory for all states until 1992. No data on the effectiveness of the rule in the states where it is already in force are yet available. The willingness of states to impose a $0.00 \mathrm{BAC}$ standard on this specialized population of drivers should not be construed as extending to the general driving public.
} 
A second legal argument is used when the defendant is charged under a "presumptive" law. In this situation, a BAC of 0.10 presumes DWI but this presumption may be refuted by other evidence. The defense will argue that the absence of observable signs of intoxication indicates the client was not impaired. There is no scientific evidence that the lack of visible signs of intoxication means an individual is not impaired in the faculties required for driving. (See Appendix H.) BAC is the best measure and it should be used in "per se" statutes that make an offense of driving above a given BAC per se.

While the above solutions would be helpful, they deal with only one issue relating to breath test evidence. Some of the other possible solutions are:

- Education of the public and officials regarding the evidence about lower BACs in relation to highway safety.

- A multi-level system defining "per se" BAC ranges with differential treatment of drivers who violate each limit.

- Use of administrative and civil penalties for some violations of lower limits.

- Different enforcement approaches for different levels (e.g. secondary enforcement ${ }^{13}$.

- Phase-in of lower limits over time and segments of the population (e.g., restricted licenses for new drivers, previous offenders).

- Development of new detection techniques consistent with individual rights.

- Coordination of legal and administrative actions (e.g., license suspensions) for drinking driving offenses within and among jurisdictions.

\footnotetext{
${ }^{13}$ Secondary enforcement is when a citation is issued for a violation only after the motorist has been stopped for a separate violation.
} 
SECTION III

\section{RECOMMENDATIONS AND FUTURE WORK}




\section{RECOMMENDATIONS}

Based on the work and findings reported in earlier sections, and recognizing that this study is not yet complete, the following recommendations are made:

1. There should be public education regarding the dangers of low BACs, and specifically that there is no "safe" level or amount that an individual can assume that will not impair one's driving performance and increase the risk of a crash.

2. All states should have "per se" laws that refer to the BAC of drivers.

3. All states should repeal laws that create a presumption that a driver is not under the influence at any BAC above zero.

4. All states should include alcohol concentration as measured by breath (expressed as grams of alcohol/210 liters of breath) in their statutory definitions. While blood measurement may also be used, breath alcohol as a measure by itself, without reference to blood, should be established as a fully acceptable and complete indication of alcohol concentration. (See Appendix G.)

5. Until a final recommendation is developed, a 0.08 per se limit, as measured by breath, should be adopted by jurisdictions considering a lowering of the legal limit for the general driving public.

6. Further consideration should be given to a multilevel system of administrative, civil and criminal penalties or restrictions for drivers who have a BAC as measured in breath at 0.08 and below.

\section{FUTURE WORK}

Future work on this project will cover BAC limits as they influence driver decision making and the BACs of drivers on the road. It will also carry out recommendation 6 above as it considers further the potential problems associated with lowering BAC limits and the actions that seem to be needed for effective implementation of alternate BAC limits. The final report will integrate the information developed in all phases of this project, identify the issues, and present conclusions and recommendations regarding the setting of specific BAC limits for the general driving public. The final report will be submitted in December 1991. 


\section{REFERENCES}

Adams, A.J.; Brown, B. and Flom, M.C., 1976, Alcohol-Induced Changes in Contract Sensitivity Following High-Intensity Light Exposure, Perception \& Psychophysics, Vol. 19 (3), pp. 219-225.

Alkana, R.L.; Yess, C.J.; Humphries, J.C.; Willingham, T.A.; Parker, E.S.; and Noble, E.P., 1978, Platform-Balance Measure of Alcohol-Induced Motor Impairment, In: Seixas, F.A. (Ed.), Currents in Alcoholism: Vol. III, New York, NY, Grune and Stratton, pp. 467-478.

Allen, R.W.; Stein, A.C.; and Hogue, J.R., 1982, The Effects of Alcohol and Marijuana on Driver Control Behavior in a Driving Simulator: Phase I, National Highway Traffic Safety Administration Technical Report No. DOT HS 806 414, May 1982. Available from the National Technical Information Service, Springfield, VA 22161.

Allsop, R.E., 1966, Alcohol and Road Accidents: A Discussion of the Grand Rapids Study, Road Research Laboratory, Ministry of Transport, RRL Report No. 6.

Anderson, T.E., Schweitz, R.M., and Snyder, M.B., 1983, Field Evaluation of a Behavioral Test Battery for DWI, National Highway Traffic Safety Administration Report No. DOT HS 806 475, September 1983, U.S. Department of Transportation. Available from NTIS, Springfield, VA 22161.

Attwood, D.A.; Williams, R.D; and Madill, H.D., 1980, Effects of Moderate Blood Alcohol Concentration on Closed-Course Driving Performance, Joumal of Studies on Alcohol, Vol. 41, pp. 623-634.

Attwood, D.; Williams,R.; McBurney, L; and Frecker, R., 1981 "Cannabis, Alcohol And Driving: Effects on Selected Closed Course Tasks," In Alcohol. Drugs and Traffic Safety, edited by Golberg, L., Vol. III., Almqvist and Wiksell, Stockholm.

Biasotti, A. A.; Boland, P.; Mallory, C.; Peck, R; and Reeve, V.C., 1986 "Marijuana and Alcohol Performance Study - A Final Report," CA/OTS Project \# 087902, Sacramento, CA: California Department of Justice, September 1986. 
Billings, C.E. and Wick, R.L., 1972, Effects of Alcohol on Pilot Performance During Instrument Flight, Federal Aviation Administration, Technical Report No. FAA-AM-72-4, 74.

Binder, A., 1971, An Experimental Approach to Driver Evaluation Using Alcohol Drinkers and Marihuana Smokers, Accident Analysis and Prevention, Vol. 3, pp. 237-256.

Borkenstein, R.F., Crowther, R.f., Shumate, R.P., Zeil, W.B. and Zylman, R., 1964, The Role of the Drinking Driver in Traffic Accidents, Bloomington, IN, Indiana University, Department of Police Administration.

Burns, M. and Moskowitz, H., 1980, Methods for Estimating Expected Blood Alcohol Concentration, Final Report on Contract No. DOT-HS-8-01999, available from the National Highway Traffic Safety Administration, 400 Seventh Street, S.W., Washington, DC 20590.

Carpenter, J.A., 1962, Effects of Alcohol on Some Psychological Processes: A Critical Review with Special Reference to Automobile Driving Skill, Quarterly Journal of Studies on Alcohol, Vol. 23, pp. 274-314.

Casswell, S., 1977, "Cannabis and Alcohol: Effects On Closed Course Driving Behavior", In Proceedings of the Seventh International Conference on Alcohol, Drugs and Traffic Safety, edited by Johnson, I., Melbourne, Australia.

Chiles, W.D. \& Jennings, A.E., 1969, Effects of Alcohol on Complex Performance, Report No. AM 69-14, Federal Aviation Administration, Office of Aviation Medicine, Civil Aeromedical Institute, Oklahoma City.

Coldwell, B.B., Penner, D.W.; Smith, H.W.; Lucas, G.H.W.; Rodgers, R.F.; and Darroch, F., 1958, Effect of Ingestion of Distilled Spirits on Automobile Driving Skill, Quarterly Journal of Studies on Alcohol, Vol. 19, pp. 590-616.

Compton, R.P., Use of Controlled Substances and Highway Safety: A Report to Congress, National Highway Traffic Safety Administration Report No. 807 261. Available from the National Technical Information Service, Springfield, VA 22161.

Cutter, H.S.G.; Green, L.R.; and Harford, T.C., 1973, Levels of Risk Taken by Extroverted and Introverted Alcoholics as a Function of Drinking Whiskey, 
British Joumal of Social \& Clinical Psychology, Vol. 12, pp 83-89.

Damkot, D.K.; Toussie, S.R.; Akley, N.R.; Geller, H.A.; and Whitmore, D.G., 1977, On-The-Road Driving Behavior and Breath Alcohol Concentration, National Highway Traffic Safety Administration Technical Report No. DOT HS 802 264. Available from the NTIS, Springfield, VA 22161.

Donelson, A.C.; Beirness, J.R.; Mayhew, D.R.; and Simpson, H.M., 1987, Blood Alcohol Concentration (BAC) Limits In Impaired-Driving Laws: Their History, Scientific Basis, and Effectiveness, Report from the Traffic Injury Research Foundation of Canada, Ottawa, Ontario.

Donelson, A.C.; Beirness, J.R.; and Simpson, H.M., 1988, Beverage Alcohol Concentration and Traffic Safety, Report from the Traffic Injury Research Foundation of Canada, Ottawa, Ontario.

Drew, G.C.; Colquhoun, W.P.; and Long, H.A., 1959, Effect of Small Doses of Alcohol on a Skill Resembling Driving, Her Majesty's Stationery Office, London.

Dubowski. K.M., 1976, Human Pharmacokinetics of Ethanol. I. Peak Blood Concentrations and Elimination in Male and Female Subjects, Alcohol Technical Report, No. 5, pp. 55-63.

Dubowski. K.M., 1984, Absorption. Distribution and Elimination of Alcohol: Highway Safety Aspects, In: Turner, T.B., Borkenstein,R.F., Jones, R.K. \& Santora, P.B. (Eds.) Alcohol and Highway Safety. Proceedings of the North American Conference on Alcohol and Highway Safety, Baltimore, MD, June 1984.

Evans, M.A.; Martz, R.; Rodda, B.E.; Kiplinger, G.F.; and Forney, R.B., Quantitative Relationship Between Blood Alcohol Concentration and Psychomotor Performance, Clinical Pharmacology and Therapeutics, Vol. 15, pp. 253-260.

Farris, R.; Malone, T.B.; and Kirkpatrick, M., 1977, A Comparison of Alcohol Involvement in Exposed and Injured Drivers, National Highway Traffic Safety Administration Report No. DOT HS 802 555. Available from the National Technical Information Service, Springfield, VA 22161. 
Farris, R.; Malone, T.B.; and Lilliefors, H., 1976, A Comparison of Alcohol Involvement in Exposed and Injured Drivers. Phases I and II, National Highway Traffic Safety Administration Report No. DOT HS 801826 , available from the National Technical Information Service, Springfield, VA 22161.

Federal Office of Road Safety, 1990, The Case for a 0.05 Blood Alcohol Concentration Limit. Canberra, Australian Capital Territory.

Filkins, L.D.; Clark, C.D.; Rosenblatt, C.A.; Carlson, W.L.; Kerlan, M.W.; and Manson, H., 1970, Alcohol Abuse and Traffic Safety: A Study of Fatalities, DWI Offenders, Alcoholics and Court-Related Treatment Approaches, U.S. Department of Transportation, National Highway Traffic Safety Bureau, Contract Nos. FH-11-6555 and FH-11-7129.

Franks, H.M.; Hensley, V.R.; Hensley, W.J.; Starmer, G.A.; and Teo, R.K.C., 1976, The Relationship Between Alcohol Dosage and Performance Decrement in Humans, Joumal of Studies on Alcohol, Vol. 37(3), pp. 284-297.

Fregley, A.R.; Bergstedt, M.; and Graybiel, A., 1967, Relationships Between Blood Alcohol, Positional Alcohol Nystagmus and Postural Equilibrium, Quarterly Joumal of Studies on Alcohol, Vol. 28, pp. 11-21.

Goldberg, L., 1943, Quantitative Studies on Alcohol Tolerance in Man, Acta Physiologica Scandanavia, No. 16(5), pp. 1-128.

Goodwin, D.W.; Powell, B.; and Stein, J., 1973, Behavioral Tolerance to Alcohol in Moderate Drinkers, American Journal of Psychiatry, Vol. 122, pp. 93-94.

Gruner, O.; Ludwig, O. and Domer, H., 1964, Zur abhangigkeit alkoholbedingter aufmerksamkeitsstorungen vom blutalkoholvert bei neidrigen konzentation, Blutalkohol, Vol. 3, pp. 445- 452.

Hansteen, R.S.; Miller, R.D. and Lonero, L., 1976, "Effects of Cannabis and Alcohol On Automobile Driving and Psychomotor Tracking," Annals of the New York Academy of Sciences, Vol. 282, pp. 240-456.

Heimstra, N. and Struckman, D., 1974, The Effects of Alcohol on Performance in Driving Simulators, paper presented at the OECD Conference on Alcohol and 
Road Safety, Washington, D.C., 1972, as cited in H. Moskowitz, Alcohol Influences Upon Sensory Motor Functions, Visual Perception, and Attention, in Alcohol, Drugs and Driving, Perrine, M.W. (Ed.), National Highway Traffic Safety Administration, Technical Report No. DOT HS 801096.

Holcomb, R.L., 1938, Alcohol In Relation to Traffic Accidents, Joumal of the American Medical Association, Vol. 103, pp. 739-741.

Honneger, H.; Kampschulte, R. and Klein, H., 1970, Alcohol Disturbance of Visual Acuity for Moving Objects, Blutalkohol, Vol. 7, pp. 31-44.

Huntley, M.S., 1973, Alcohol Influences Upon Closed-Course Driving Performance, Journal of Safety Research, Vol. 5, pp. 149-164.

Huntley, M.S., 1974, Alcohol Influences Upon Closed-Course Driving Performance, In M.W. Perrine (Ed.) Alcohol, Drugs and Driving, NHTSA Report No. DOT HS 801096.

Hurst, P. M., 1973, Epidemiological Aspects of Alcohol in Driver Crashes and Citations, Journal of Safety Research, Vol. 5 (3), pp. 130-148.

Hurst, P. M., 1985, Blood Alcohol Limits and Deterrence: Is There A Rational Basis for Choice?, Alcohol, Drugs and Driving, Vol. 1 (1-2), pp. 121-130.

Indestrom, C.M. \& Cadenius, B., 1968, Time Relations of the Effects of Alcohol Compared to Placebo, Psychopharmacologia, Vol. 13, pp. 189-200.

Jones, R.K. \& Joscelyn, K.B., 1978, Alcohol and Highway Safety 1978: A Review of the State of the Knowledge, National Highway Traffic Safety Administration, Report No. DOT HS 803 714, U.S. Department of Transportation, Washington, D.C., January 1978, available from NTIS, Springfield, VA 22161.

Johnson, J., 1988, Evaluation of States with .08 BAC Level Illegal Per Se. NHTSA memo, Sept. 13, 1988.

Kearney, S.A. and Guppy, A., 1988, The Effects of Alcohol on Speed Perception In a Closed-Course Driving Situation, Journal of Studies on Alcohol, Vol. 49(4), pp. 340-345. 
Kelley, M., Myrsten, A.L. and Goldberg, L., 1971, Intravenous Vitamins In Acute Alcoholic Intoxication: Effects on Physiological and Psychological Functions, British Journal of Addiction, Vol. 66, pp. 19-30.

Landauer, A.A. \& Howat, P., 1983, Low and Moderate Alcohol Doses, Psychomotor Performance and Perceived Drowsiness, Ergonomics, Vol. 26 (7), pp. 647-657.

Landauer, A.A. \& Milner, G., 1971, Desipramine and Impramine, Alone and Together with Alcohol in Relation to Driving Safely, Phamakopsychiatric Neuro-Psychopharmakologie, Vol. 4, pp. 265-275.

Landauer, A.A.; Milner, G.; and Patman, J. 1969, Alcohol and Amitriptyline Effects on Skills Related to Driving Behavior, Science, Vol. 163, pp. 1467-1468.

Laurell, H., 1977, Effects of Small Doses of Alcohol on Driver Performance in Emergency Traffic Situations, Journal of Accident Analysis and Prevention, Vol. 9, pp 191-201.

Laves, W., 1965, Measure and Number in Medical Expert Testimony on Ability to Drive, Medizinische Klinik, Vol. 50, pp. 9-12.

Louwerens, J.W.; Gloerich, A.B.M.; d. Vries, G.; Brookhuis, K.A.; and O'Hanlon, J.F., 1987, The Relationship Between Driver's Blood Alcohol Concentration (BAC) and Actual Driving Performance During High Speed Travel, In:

Noordzij, P.C. and Roszbach, R. (Eds.), Alcohol, Drugs and Traffic Safety T86, Elsevier Science Publishers B.V.

Lucas, G.W.H.; Kalow, W.; McColl, J.D.; Griffith, B.A.; and Smith, H.W., 1955, Quantitative Studies of the Relationship Between Alcohol Levels and Motor Vehicle Accidents, In: Proceedings of the Second International Conference on Alcohol and Road Traffic, Toronto, Garden City Press Cooperative.

Lund, A.K. \& Wolfe, J.W., 1990, Changes in the Incidence of Alcohol-Impaired Driving in the United States, 1973-1986, Joumal of Studies on Alcohol (in press).

MacArthur, R.D. and Sekuler, R., 1982, Alcohol and Motion Perception, Perception \& Psychophysics, Vol. 31(5), pp. 502-505. 
Mayhew, D.R.; Donelson, A.C.; Beirness, J.R.; and Simpson, H.M., 1986, Youth, Alcohol and Relative Risk of Crash Involvement, Accident Analysis and Prevention, Vol. 18 (4), pp. 273-287.

McCarroll, J.R. and Haddon, W, Jr., 1962, A Controlled Study of Fatal Automobile Accidents in New York City, Journal of Chronic Diseases, Vol. 15, pp. 811-826.

McClean, A.J.; Holubowycz, O.T.; and Sandow, B.L., 1980, Alcohol and Crashes: Identification of Relevant Factors in this Association, Road Accident Research Unit, University of Adelaide, Adelaide, Australia.

Mellow, N.K., 1972, Behavioral Studies of Alcoholism, In: Kissin, B, \& Begleiter, H. (Eds.) Physiology and Behavior, Vol. 2, New York, Plenum Press.

Mitchell, M.C., 1985, Alcohol-Induced Impairment of Central Nervous System Function: Behavioral Skills Involved in Driving, Journal of Studies on Alcohòl, Vol. 10, pp. 109-116.

Mortimer, R.G., 1963, Effect of Low Blood Alcohol Concentrations in Simulated Day and Night Driving, Perceptual and Motor Skills, Vol. 17, pp.399-408.

Moskowitz, H., 1974, Alcohol Influences Upon Sensory Motor Function, Visual Perception, and Attention, In Perrine, M.W. (Ed.), Alcohol, Drugs and Driving, National Highway Traffic Safety Administration Report No. DOT HS 801160.

Moskowitz, H., 1975, Laboratory Studies on the Effects of Alcohol on Some Variables Related to Driving, Journal of Safety Research, Vol. 5, pp. 185-199.

Moskowitz, H. and Burns, M., 1973, Alcohol Effects on Information Processing Time with an Overlearned Task, Perceptual and Motor Skills, Vol. 37, pp. 835-839.

Moskowitz, H., Burns, M.; and Williams, A., 1985, Skills Performance at Low Blood Alcohol Concentrations, Journal of Studies on Alcohol, Vol. 46, pp. 482-485.

Moskowitz, H. Daily, J.; and Henderson, R., 1979, The Mellanby Effect In 
Moderate and Heavy Drinkers, In: Johnston, I.R. (ed.) The 7th International Conference of Alcohol, Drugs and Traffic Safety, Australian Publishing Service, Canberra, pp. 184-189.

Moskowitz, H. and Depry, D., 1968, The Effect of Alcohol Upon Auditory Vigilance and Divided Attention Tasks, Quarterly Journal of Studies on Alcohol, Vol. 29, pp. 54-63.

Moskowitz, H. and Robinson, C.D., 1988, Effects of Low Doses of Alcohol on Driving-Related Skills: A Review of the Evidence, National Highway Traffic Safety Administration, Report No. DOT HS 807 280, U.S. Department of Transportation, Washington, D.C., March 1988, available from NTIS, Springfield, VA 22161.

Moskowitz, H.; Ziedman, K. and Sharma, S., 1976, Visual Search Behavior While Viewing Driving Scenes Under the Influence of Alcohol and Marijuana, Human Factors, Vol. 18, pp. 417-432.

Neilson, M.W., 1975, Alcohol Involvement in Fatal Motor Vehicle Accidents: California, 1962-1968, San Francisco: California Traffic Safety Foundation.

Newman, H.W., 1949, The Effect of Altitude on Alcohol Tolerance, Quarterly Journal of Studies on Alcohol, Vol. 10, pp. 398-403.

Newman, H. and Fletcher, E., 1940, The Effect of Alcohol on Driving Skill, Joumal of the American Medical Association, Vol. 115, pp. 1600-1602.

Newman, H. and Fletcher, E., 1941, The Effect of Alcohol on Vision, American Journal of the Medical Sciences, Vol. 202, pp. 723-731.

National Highway Traffic Safety Administration, Department of Transportation, 1990, Digest of State Alcohol-Highway Safety Related Legislation, Eighth Edition.

O'Neill, B.; Williams, A.M. and Dubowski, K.M., 1983, Variability in Blood Alcohol Concentrations: Implications for Estimating Individual Results, Joumal of Studies on Alcohol, Vol. 44, pp. 222-230.

Palmer, J.W. and Tix, P.E., 1985, Minnesota Alcohol Roadside Survey, St. Cloud State University, September, 1985. 
Perrine, M.W., 1973, Alcohol Influences on Driving-Related Behavior: A Critical Review of Laboratory Studies of Neurophysiological, Neuromuscular, and Sensory Activity, Journal of Safety Research, Vol. 5(3), pp. 165-184.

Perrine, M.W., 1975, Alcohol Involvement in Highway Crashes: A Review of the Epidemiologic Evidence, Clinics in Plastic Surgery, Vol. 2(1), pp. 11-34.

Perrine, M.W.; Waller, J.W.; and Harris, L.S., 1971, Alcohol and Highway Safety: Behavioral and Medical Aspects, National Highway Traffic Safety Administration Technical Report No. DOT HS 800 599, available from the National Technical Information Service, Springfield, VA 22161.

Personke, C., 1984, "A Study of the Feasibility of Establishing Lower Blood Alcohol Content Limits in Sections of the Wisconsin Statutes related to Operating a Vehicle Intoxicated", Wisconsin: Wisconsin University.

Prag, J.J., 1953, The Chemical and the Clinical Diagnosis of "Driving Under The Influence of Alcohol" and the Use of Chemical Tests in Traffic Law Enforcement, South African Journal of Clinical Sciences, Vol. 4, pp. 289-325.

Richter, R. and Hobi, V, 1979, Die Beeintrachttigung der Fahrtuchtigket bei Blutalkoholonzentrationen um O, 5\%, Blutalkohol, Vol. 105(27), pp.884-890.

Ross, H., 1979, Blood Alcohol Concentrations among Traffic Fatalities in Inner North London: A Research Note. Medicine, Science, and Law, Vol. 19, pp. 233-244.

Ross, H., 1981, Deterring the Drinking Driver, Lexington, Massachusetts: Lexington Books.

Ross, H.; 1973, Law, Science and Accidents: The British Road Safety Act of 1967. Journal of Legal Studies, Vol. 2, pp. 1-78.

Sanders, A.F., 1986, Drugs, Driving and the Measurement of Human Performance, In: Drugs and Driving, (Eds.) J.F. O'Hanlon and J.J. de Gier, pp. 3-16, Philadelphia, PA, Taylor \& Francis, Inc.

Smiley. A.M., Moskowitz, H.M. \& Ziedman, K., 1985, Effects of Drugs on Driving: Driving Simulator Tests of Secobarbital, Diazepam, Marijuana, and Alcohol, U.S. Department of Health and Human Services, DHHS Publication 
No. (ADM) 85-1386, 1985.

Smiley, A.M. 1986a, "Marijuana: On-Road and Driving Simulator Studies," In Alcohol, Drugs and Driving, Vol. 2, No.3-4, July-December 1986, pp. 121-133.

Smiley, A.M., 1986b, Assessment of Drug Effects On Driving Performance Using On-The-Road Studies, In: Drugs and Driving, Edited by O'Hanlon, J.F. \& DeGier, J.J., Taylor and Francis, London, 1986, pp. 51-64.

Smith, D., 1988, Effect on Traffic Safety of Introducing a .05\% Blood Alcohol Level in Queensland, Australia. Medicine, Science, and Law, Vol. 28, No. 2, pp. 165-170.

Stein, A.C. and Allen, W.R., 1986, The Effects of Alcohol on Driver Decision Making and Risk Taking, In: American Association for Automotive Medicine, 30th Annual Meeting: Proceedings, October 6-8, 1986, Montreal, Quebec, Des Plains, IL, pp. 59-73.

Stein, A.C.; Allen, W.R.; Cook, M.L.; and Karl, R.L., 1983, A Simulator Study of the Combined Effect of Alcohol and Marijuana on Driving Behavior. National Highway Traffic Safety Administration Technical Report No. DOT HS 806 405, Available from the National Technical Information Service, Springfield, VA 22161.

Terhune, K. W., 1982, An Evaluation of Crash Culpability to Assess Alcohol and Drug Impairment Effects, Proceedings of the 26th Annual Meeting, American Association for Automotive Medicine, October 4-6, 1982, Ottawa, Ontario, Canada.

Terhune, K. W., 1983, An Evaluation of Responsibility Analysis for Assessing Alcohol and Drug Crash Effects, Journal of Accident Analysis \& Prevention, Vol. 15 (3), pp. 237-246.

Tharp, V., 1981, Gaze Nystagmus as a Roadside Sobriety Test, Abstracts and Reviews in Alcohol and Driving, Vol. 2(2), pp. 5-8.

Tharp, V.; Burns, M, and Moskowitz, H., 1981, Development and Field Test of Psychological Tests for DWI Arrest, NHTSA Report No. DOT HS 805864 , p. 88, available from the National Technical Information Service, Springfield, 
VA 22161 .

Tix, P.E. and Palmer, J.W., 1987, Minnesota Alcohol Roadside Survey: Summary of Reports, Mankato State University, October, 1987.

Transportation Research Board, 1987, Special Report 215: Zero Alcohol and Other Options, National Research Council, August 1987, Washington, D.C.

U.S. Department of Health and Human Services, 1990, The Seventh Special Report to the U.S. Congress on Alcohol and Health, U.S. Government Printing Office: 1990-255-307:01162, Washington, D.C.

U. S. Department of Transportation, 1968, Alcohol and Highway Safety, Report to the U.S. Congress, Washington, D.C., U.S. Government Printing Office.

U. S. Department of Transportation, 1985, Alcohol and Highway Safety 1984: A Review of the State of the Knowledge, NHTSA Report No. DOT HS 806 569, February 1985, U.S. Department of Transportation, available from the National Technical Information Service, Springfield, VA 22161.

Valeriote, C.; Tong, J.E.; and Druding, B., 1979, Ethanol, Tobacco and Laterality Effects on Simple and Complex Motor Performance, Journal of Studies on Alcohol, Vol. 40, pp. 823-830.

Wallgreen, H. and Barry, H. III, 1970, Actions of Alcohol, Amsterdam, Elsevier.

Waller, P.F.; King, E.M.; Nielson, G.; and Turkel, H.W., 1970, Alcohol and Other Factors in California Highway Fatalities, In Proceedings of the Eleventh Annual Meeting of the American Association for Automotive Medicine, Springfield, Ill., Charles C. Thomas.

Waller, P.F., Stewart, J.R. and Hansen, A.R., 1986, The Potentiating Effects of Alcohol On Driver Injury, Journal of the American Medical Association, Vol. 256 (11), pp. $1461-1466$.

Warren, G.H. and Raynes, A.E., 1972, Mood Changes During Three Conditions of Alcohol Intake, Journal of Studies on Alcohol, Vol. 33, pp. 979-989.

Wolfe, A.C., 1974, 1973 U.S. National Roadside Breathtesting Survey: Procedure and Results, Highway Safety Research Institute, May 1974. 
Wolfe, A.C., 1986, 1986 U.S. National Roadside Breathtesting Survey: Procedure and Results, Mid-America Research Institute, September, 1986.

Zador, P., 1990, Alcohol-Related Relative Risk of Fatal Driver Injuries in Relation to Driver Age and Sex, Journal of Studies of Alcohol (in press). 
APPENDIX A

BIOGRAPHICAL SKETCHES OF PANEL MEMBERS

Judge W. Anderson

Judge Anderson is the Supervising Judge of the Circuit Court in Cook County (Chicago), Illinois. He has had extensive judiciary experience in traffic court, and has spoken on alcohol and other drugs at a recent Lifesaver Conference.

\section{Richard Blomberg}

Mr. Blomberg is president of Dunlap and Associates, a research organization dealing with human factors, systems, and applied problems. He has authored numerous papers dealing with alcohol and drug-induced highway safety problems. Mr. Blomberg is an international consultant on human performance in complex task situations. He is currently on the Industrial Safety Panel for NASA.

\section{Dr. B. J. Campbell}

Dr. Campbell is the longtime Director of the Highway Safety Research Center (HSRC) of the University of North Carolina. He has played a leadership role for many years in one of the leading highway safety research institutes in the United States. Dr. Campbell has well established contacts with the highway safety community both here and abroad. Under his direction, HSRC has been active in the forefront of research on alcohol and highway safety.

\section{Dr. Dora Goldstein}

Dr. Goldstein, a medical doctor, is Professor of Pharmacology at Stanford University. She has authored numerous papers and articles dealing with alcohol tolerance and withdrawal, and a text entitled, Pharmacology of . Alcohol. Dr. Goldstein is a member of and has chaired the VA Merit Review Board on Alcoholism and Drug Dependence. 


\section{Dr. Harold Holder}

Dr. Holder, a sociologist, is with the Prevention Research Center where he has done a considerable amount of work with computer simulation models in the alcohol research area. Other interest areas include content analyses of alcohol themes and community alcohol treatment programs.

Dr. Paul Hurst

Dr. Hurst, a psychologist, is well known in the field of epidemiology. He did the classic work leading to the development of relative risk curves which describe the accident risk at various BAC levels relative to the risk associated with sober drivers. Dr. Hurst is retired, but still serves as a consultant to the New Zealand Department of Transportation in the field of alcohol and other drugs.

Dr. Richard Jessor

Dr. Jessor is Professor of Psychology and Director of the Institute of Behavioral Science at the University of Colorado. His specialty area is problem behavior in youth, with emphasis upon adolescent alcohol use. Dr. Jessor is on the Editorial Board of the joumal Alcohol. Drugs and Driving.

Mr. Hans Laurell

Mr. Laurell, research psychologist, is currently Head, Department of Analysts, in the Swedish Road Safety Administration. He is a member of the TRB committee on Alcohol, Other Drugs, and Transportation.

Dr. Adrian K. Lund

Dr. Lund is Director, Human and Environmental Factors, for the Insurance Institute for Highway Safety. Dr. Lund is a member of the TRB committee on Alcohol, Other Drugs, and Transportation.

\section{Larry G. Majerus}

Mr. Majerus was formerly the Administrator of the Montana Division of Motor Vehicles. He is currently with an automotive publishing firm in Detroit, Michigan. Mr. Majenus has been President of Region IV of the American Association of Motor Vehicle Administrators and Chairman of the 
Driver License Compact Commission. Most recently, he served on the "Zero Alcohol" committee for the National Academy of Sciences.

Dr. Kimball I. Maull

Dr. Maull, a physician, is Professor and Chairman of the Department of Surgery, University of Tennessee. He has written a number of papers on crash trauma and the relationship between alcohol abuse and vehicle crashes. Dr. Maull is past president of the American Association for Automotive Medicine and Editor-in-Chief of Advances in Trauma. He recently served as a member of the National Academy of Sciences' "Zero Alcohol" committee.

Dr. Herbert Moskowitz

Dr. Moskowitz, a psychologist, is a noted alcohol researcher. He is a Professor in the Department of Psychology and the Department of Psychiatry and Biobehavioral Sciences, University of Califormia, Los Angeles. Dr. Moskowitz is Editor of the journal Alcohol, Drugs and Driving, and President of the Southern California Research Institute. He is the coauthor of the NHTSA literature review of the effects of law BAC levels on driving impairment. Dr. Moskowitz is a member of the TRB committee on Alcohol, Other Drugs, and Transportation.

\section{Laimutis Nargelanas}

Laimutis Nargelanas, a law enforcement specialist, is currently the Assistant Deputy Director of the Division of Criminal Justice, Illinois State Police. He served as an Illinois State Trooper for five years before joining the staff of the Illinois State Police Academy. He was director of Curriculum Development before becoming the Director of Training for the State Police Department of Law Enforcement Academy in 1979. He progressed through the ranks, achieving the permanent rank of Major in 1983. Prior to his current position, he was Superintendent of the Division of State Troopers. Illinois State Police. $\mathrm{He}$ is a member of the International Association of Chiefs of Police and chairman of both the Traffic Law Enforcement and Adjudication Committees for the National Safety Council. Superintendent Nargelanas recently served as a member of the National Academy of Sciences' "Zero Alcohol" committee.

\section{Dr. Olga J. Pendleton}

Dr. Pendleton, a statistician, is a Program Manager for the Statistical Analysis and Research Program in the Texas Transportation Institute. She has written a 
number of articles relating to traffic fatalities, including the involvement of alcohol and blood alcohol concentration. Dr. Pendleton was recently a member of the National Academy of Sciences' "Zero Alcohol" committee.

Dr. M. W. Perrine

Dr. Perrine, a psychologist, is Professor at the Schools of Medicine and Public Health at Boston University and Director of the latter's Alcohol Research Unit. Dr. Perrine recently served as Chairman of the Committee on the Benefits and Costs of Alternate Federal Blood Alcohol Concentration Standards for Commercial Vehicle Operators which produced the "Zero Alcohol and Other Options" report for the National Academy of Sciences. He is also a member of the TRB committee on Alcohol, Other Drugs, and Transportation.

\section{Robert Harry Reeder}

Mr. Reeder, a lawyer, serves as the General Counsel of the Traffic Institute at Northwestern University and as Executive Director of the National Committee on Uniform Traffic Laws and Ordinances. He received his BA and JD from Washburn University. Before coming to the Traffic Institute as assistant counsel, he began his legal career as a research assistant with the Research Department of the Kansas Legislature. An expert in traffic law, Mr. Reeder has authored and co-authored several books on the subject. He has been Chairman of the National Safety Council and now serves on their Committee on Alcohol and Other Drugs. Recently, he served on the "Zero Alcohol" committee of the National Academy of Sciences.

\section{Judge Kaliste J. Saloom, Jr.}

Judge Saloom is a judge with the City and Juvenile Court of Lafayette, Louisiana. He is an expert in the traffic judiciary area.

\section{Larry N. Thompson}

Colonel Thompson is currently the Chairman of the Highway Safety Committee of the International Association of Chiefs of Police. He also holds long-standing tenure on the committee. A staunch advocate of highway safety, Colonel Thompson has promoted training in standardized field sobriety testing for all officers, and has taken a leading role in implementing the Drug Evaluation and Classification program in Arizona. Additionally, he participated in NHTSA's IPA program for many years, and currently details a 
member of his department to NHTSA's Office of Enforcement and Emergency Services (Police Traffic Services Division.

\section{Chauncey Veatch, III}

Chauncey Veatch, III is the President of the National Association of State Alcohol and Drug Abuse Directors. A rehabilitation specialist; he is currently with the Department of Alcohol and Drug Abuse Programs, Sacramento, California. Most recently, Mr. Veatch served as a member of the Treatment Panel in the Surgeon General's Workshop on Drunk Driving.

\section{Dr. Robert B. Voas}

Dr. Voas is a psychologist with the National Public Services Research Institute. He has held research positions with the U.S. Navy, NASA, Litton Industries, and the Peace Corp. For more than ten years, Dr. Voas was Chief of the Evaluation Division for the National Highway Traffic Safety Administration. Most recently, he was a member of the "Zero Alcohol" committee for the National Academy of Sciences. Dr. Voas is also a member of the TRB committee on Alcohol, Other Drugs, and Transportation. 


\section{APPENDIX B}

\section{U.S. BAC LEGISLATION}

(adapted from Digest of State Alcohol Legislation, NHTSA, 1990)

\begin{tabular}{|c|c|c|c|c|c|c|c|}
\hline & STATE & $\begin{array}{l}\text { ILLEGAL } \\
\text { PER SE } \\
\text { BAC } \\
\text { LEVEL }\end{array}$ & $\begin{array}{l}\text { PRESUMP- } \\
\text { TIVE } \\
\text { BAC LEVEL }\end{array}$ & FINES $^{\prime}$ & $\begin{array}{l}\text { IMPRISON- } \\
\text { MENT }^{\prime}\end{array}$ & $\begin{array}{l}\text { COMMUNITY } \\
\text { SERVICE } \\
\text { IN LIEU OF } \\
\text { JAIL TIME } \\
\end{array}$ & $\begin{array}{c}\text { LICENSE } \\
\text { SANCTION }\end{array}$ \\
\hline \multirow{4}{*}{$\begin{array}{l}\text { Non- } \\
.10 \\
\text { states } \\
\end{array}$} & CA & .08 & .08 & $\$ 390$ & -- & $\cdots$ & -- \\
\hline & $\mathrm{ME}$ & .08 & --- & $\$ 300$ & 48 con hrs & $\cdots$ & $S^{2}-60$ days \\
\hline & OR & .08 & .08 & $\cdots$ & $48 \mathrm{hrs}$ & $80 \mathrm{hrs}$ & $\cdots$ \\
\hline & $\mathbf{U T}$ & .08 & $\cdots$ & $\$ 50$ & 48 con hrs & $24 \mathrm{hrs}$ & S-90 days \\
\hline \multirow{2}{*}{$\begin{array}{l}\text { Two- } \\
\text { tiered } \\
\text { states }\end{array}$} & \multirow[t]{2}{*}{$\mathrm{CO}$} & .10 & $\cdots$ & $-\cdot$ & 5 days ${ }^{4}$ & $48 \mathrm{hrs}^{20}$ & \multirow[t]{2}{*}{--} \\
\hline & & -- & $>.05-.10^{7}$ & $\cdots$ & 2 days & $24 \mathrm{hrs}$ & \\
\hline & \multirow[t]{2}{*}{ DC } & .10 & -- & -- & --- & --- & \multirow[t]{2}{*}{$R^{5}-6$ mos. } \\
\hline & & $\cdots$ & $>.05^{3}$ & $\cdots$ & $\cdots$ & $\cdots$ & \\
\hline & \multirow[t]{2}{*}{ GA } & .12 & -. & -- & -- & $\cdots$ & \multirow[t]{2}{*}{---} \\
\hline & & $\cdots$ & .10 & --- & -- & --- & \\
\hline & \multirow[t]{2}{*}{ ID } & .10 & $\cdots$ & $-\cdots$ & $\cdots$ & $\cdots$ & \multirow[t]{2}{*}{--} \\
\hline & & $\cdots$ & $>.08$ & -- & -- & $\cdots$ & \\
\hline
\end{tabular}




\begin{tabular}{|c|c|c|c|c|c|c|c|}
\hline & STATE & $\begin{array}{c}\text { ILLEGAL } \\
\text { PER SE } \\
\text { BAC } \\
\text { LEVEL } \\
\end{array}$ & $\begin{array}{l}\text { PRESUMP- } \\
\text { TIVE } \\
\text { BAC LEVEL }\end{array}$ & FINES $^{\prime}$ & $\begin{array}{l}\text { IMPRISON- } \\
\text { MENT }^{1}\end{array}$ & $\begin{array}{c}\text { COMMUNITY } \\
\text { SERVICE } \\
\text { IN LIEU OF } \\
\text { JAIL TIME } \\
\end{array}$ & $\begin{array}{l}\text { LICENSE } \\
\text { SANCTION' }\end{array}$ \\
\hline & \multirow[t]{2}{*}{ MD } & \multirow[t]{2}{*}{--} & $.10^{6}$ & $\cdots$ & -- & -- & \multirow[t]{2}{*}{--} \\
\hline & & & $.07^{6}$ & --- & --- & --- & \\
\hline & \multirow[t]{2}{*}{ MI } & .10 & $\ldots$ & $\ldots$ & --- & --- & \multirow[t]{2}{*}{$\cdots$} \\
\hline & & --- & $.07-.10^{7}$ & --- & --- & -- & \\
\hline & \multirow[t]{2}{*}{ NY } & .10 & -- & $\$ 350$ & $\cdots$ & $-\cdots$ & \multirow[t]{2}{*}{---} \\
\hline & & $\ldots$ & $.07-.10^{3}$ & --- & --- & $\cdots$ & \\
\hline & \multirow[t]{2}{*}{ OK } & .10 & $\ldots$ & -- & -- & $\cdots$ & \multirow[t]{2}{*}{$-\cdots$} \\
\hline & & -.. & $>.05-.10^{8}$ & --- & -- & -- & \\
\hline \multirow{7}{*}{$\begin{array}{l}\text { Single } \\
\text { Level } \\
\text { States }\end{array}$} & $\mathbf{A L}$ & .10 & .10 & $\cdots$ & $\ldots$ & -- & S-90 days \\
\hline & $\mathrm{AK}$ & .10 & $\ldots$ & -- & 72 con hrs & --- & R-30 days \\
\hline & $A Z$ & .10 & .10 & $\$ 250$ & 24 con hrs & $8 \mathrm{hrs}$ & $S^{9}-90$ days \\
\hline & $\mathbf{A R}$ & .10 & $\cdots$ & $\$ 150$ & -- & --- & --- \\
\hline & CT & .10 & --- & --- & 48 con hrs & $100 \mathrm{hrs}$ & $S-1$ yr \\
\hline & DE & .10 & $.10^{3}$ & $\cdots$ & $\cdots$ & --- & R-90 days \\
\hline & FL & .10 & $.10^{3}$ & $\cdots$ & --- & $50 \mathrm{hrs}^{20}$ & --- \\
\hline
\end{tabular}




\begin{tabular}{|c|c|c|c|c|c|c|}
\hline STATE & $\begin{array}{l}\text { ILLEGAL } \\
\text { PER SE } \\
\text { BAC } \\
\text { LEVEL }\end{array}$ & $\begin{array}{l}\text { PRESUMP- } \\
\text { TIVE } \\
\text { BAC LEVEL }\end{array}$ & FINES ${ }^{\prime}$ & $\begin{array}{l}\text { IMPRISON- } \\
\text { MENT' }^{1}\end{array}$ & $\begin{array}{l}\text { COMMUNITY } \\
\text { SERVICE } \\
\text { IN LIEU OF } \\
\text { JAIL TIME }\end{array}$ & $\begin{array}{l}\text { LICENSE } \\
\text { SANCTION }^{\prime}\end{array}$ \\
\hline HI & .10 & $.10^{11}$ & $\begin{array}{c}\$ 150- \\
1,000^{12}\end{array}$ & $48 \mathrm{hrs}^{12}$ & $72 \mathrm{hrs}^{12}$ & S-30 days \\
\hline IL & .10 & .10 & $\ldots$ & -- & --- & $\ldots$ \\
\hline IN & .10 & $.10^{13}$ & $\ldots$ & $\ldots$ & $\ldots$ & S-30 days \\
\hline IA & .10 & -- & $\$ 500$ & $\ldots$ & $-\cdots$ & -- \\
\hline $\mathrm{KS}$ & .10 & $.10^{3}$ & -- & 48 con hrs & $100 \mathrm{hrs}$ & $S-30$ days \\
\hline KY & --- & .10 & -- & --- & --- & S-30 days \\
\hline LA & .10 & .10 & --- & 2 days & 4 days & --- \\
\hline MA & $\ldots$ & .10 & $\cdots$ & -- & $\cdots$ & S-45 days \\
\hline MN & .10 & $\cdots$ & $\cdots$ & $\cdots$ & -- & --- \\
\hline MS & .10 & --- & $\$ 200$ & -- & -- & S-30 days \\
\hline MO & .10 & -- & $\cdots$ & $\cdots$ & -- & -- \\
\hline MT & .10 & .10 & $\ldots$ & 24 con $\mathrm{hrs}^{14}$ & $\cdots$ & --- \\
\hline NE & .10 & --- & -- & $\ldots$ & -- & R-60 days \\
\hline NV & .10 & .10 & $\ldots$ & 2 days 15 & $48 \mathrm{hrs}$ & R-45 days \\
\hline NH & .10 & $.10^{3}$ & $\ldots$ & $\cdots$ & $\cdots$ & R-90 days \\
\hline $\mathrm{NJ}$ & .10 & --- & --- & --- & --- & 6 mus. $^{16}$ \\
\hline
\end{tabular}




\begin{tabular}{|c|c|c|c|c|c|c|}
\hline STATE & $\begin{array}{c}\text { ILLEGAL } \\
\text { PER SE } \\
\text { BAC } \\
\text { LEVEL } \\
\end{array}$ & $\begin{array}{l}\text { PRESUMP- } \\
\text { TIVE } \\
\text { BAC LEVEL }\end{array}$ & FINES $^{\prime}$ & $\begin{array}{l}\text { IMPRISON- } \\
\text { MENT' }^{\prime}\end{array}$ & $\begin{array}{c}\text { COMMUNITY } \\
\text { SERVICE } \\
\text { IN LIEU OF } \\
\text { JAIL TIME } \\
\end{array}$ & $\begin{array}{l}\text { LICENSE } \\
\text { SANCTION' }\end{array}$ \\
\hline NM & .10 & -- & $\cdots$ & -- & -- & -- \\
\hline NC & .10 & -- & -- & -- & -- & $\cdots$ \\
\hline ND & .10 & -- & $\$ 250$ & -- & $\cdots$ & S- 30 days \\
\hline $\mathrm{OH}$ & .10 & $\cdots$ & $\$ 150$ & -- & $\cdots$ & $\cdots$ \\
\hline PA & .10 & $\cdots$ & $\$ 300$ & $\cdots$ & $-\cdots$ & S-1 mo. \\
\hline $\mathbf{R I}$ & .10 & $\therefore$ & $\$ 100$ & --- & $-\cdots$ & $\mathrm{S}-3$ mos. \\
\hline SC & -- & $.10^{17}$ & $\$ 200$ & $48 \mathrm{hrs}$ & $48 \mathrm{hrs}$ & $\cdots$ \\
\hline SD & .10 & .10 & --- & $\cdots$ & $--\cdot$ & -- \\
\hline $\mathrm{TN}$ & $\cdots$ & .10 & $\$ 250$ & $48 \mathrm{hrs}$ & - & $\because$ \\
\hline TX & .10 & $\cdots$ & -- & -- & -- & -- \\
\hline VT & $.10^{18}$ & $.10^{19}$ & -- & -- & $\ldots$ & S-90 days \\
\hline VA & .10 & .10 & -- & $\cdots$ & $\cdots$ & $\cdots$ \\
\hline WA & .10 & $\cdots$ & $\$ 250$ & 24 con hrs & -- & S-30 days \\
\hline wV & .10 & $.10^{13}$ & $\$ 100$ & $24 \mathrm{hrs}$ & -- & $\cdots$ \\
\hline WI & .10 & $\cdots$ & $\cdots$ & $\cdots$ & -- & $S-15$ days \\
\hline WY & .10 & $\cdots$ & $\cdots$ & $\cdots$ & $\ldots$ & -.. \\
\hline
\end{tabular}




\section{APPENDIX C}

BAC LEGISLATION IN FOREIGN COUNTRIES

\begin{tabular}{|c|c|c|c|}
\hline COUNTRY & LIMIT & $\begin{array}{l}\text { SANCTIONS } \\
\text { (1st Offense) }\end{array}$ & MISC. LAWS \\
\hline Norway & .05 per se & $\begin{array}{l}\text { Imprisonment and license } \\
\text { revocation are common }\end{array}$ & $\begin{array}{l}\text { Random stops by police are } \\
\text { allowed }\end{array}$ \\
\hline \multirow[t]{2}{*}{ Sweden } & $\begin{array}{l}.02 \text { per se } \\
\text { blood }\end{array}$ & $\begin{array}{l}\text { Fines or imprisonment not more than } 6 \\
\text { mos. }\end{array}$ & \multirow[t]{2}{*}{1} \\
\hline & .15 & $\begin{array}{l}\text { Fines or imprisonment not more than } 1 \\
\text { yr. }\end{array}$ & \\
\hline Iceland & .05 & & \\
\hline \multirow[t]{2}{*}{ Finland } & .05 & & \\
\hline & .15 & & \\
\hline \multirow[t]{5}{*}{ Denmark } & $.08-.12$ & Fines \& restricted license & \\
\hline & $.121-.15$ & Fines \& 1 yr. license suspension & \\
\hline & $.151-.20$ & Fines \& 2 yrs. license suspension & \\
\hline & $.201-.25$ & 14 days in prison, 30 mos. suspension & \\
\hline & $.25+$ & 20 days in prison, 30 mos. suspension & \\
\hline
\end{tabular}




\begin{tabular}{|c|c|c|c|}
\hline COUNTRY & LIMIT & $\begin{array}{l}\text { SANCTIONS } \\
\text { (1st Offense) }\end{array}$ & MISC. LAWS \\
\hline Switzerland & .08 & $\begin{array}{l}\text { Permit automatically suspended for not } \\
\text { less than } 1 \text { yr. }\end{array}$ & \\
\hline Netherlands & .05 & $\begin{array}{l}\text { Imprisonment up to } 3 \text { mos, fines up to } \\
\text { f5, } 000 \text { (approx. } \$ 2,500 \text { ) and license } \\
\text { suspension up to } 5 \mathrm{yrs} \text {. }\end{array}$ & $\begin{array}{l}\text { A breath test may be requested if } \\
\text { alcohol consumption is suspected }\end{array}$ \\
\hline Austria & $\begin{array}{l}.08 \text { per se } \\
\text { blood }\end{array}$ & $\begin{array}{l}\text { Administrative } \\
\text { fine (or imprisonment up to } 6 \text { weeks if } \\
\text { unable to collect) }\end{array}$ & \\
\hline $\begin{array}{l}\text { Federal Republic of } \\
\text { Germany }\end{array}$ & $\begin{array}{l}.13 \text { per se } \\
\text { blood or urine }\end{array}$ & & $\begin{array}{l}\text { Breath tests are not allowed as } \\
\text { admissible evidence in court }\end{array}$ \\
\hline \multirow[t]{2}{*}{ Czechoslovakia } & .03 & $\begin{array}{l}\text { Fine up to } 500 \text { crowns \& usually license } \\
\text { suspension }\end{array}$ & \multirow[t]{2}{*}{ Breath testing is allowed } \\
\hline & .10 & $\begin{array}{l}\text { Imprisonment up to } 1 \mathrm{yr} \text {., a reformatory } \\
\text { measure, loss of license, or fine }\end{array}$ & \\
\hline \multirow[t]{2}{*}{ France } & $.08-.12$ & & \multirow{2}{*}{$\begin{array}{l}\text { Any driver can be required to take } \\
\text { a breath screening test in } \\
\text { checkpoint operations }\end{array}$} \\
\hline & $.12+$ & & \\
\hline Great Britain & $\begin{array}{l}.08 \text { per se } \\
\text { breath }\end{array}$ & $\begin{array}{l}6 \text { mos. imprisonment or } 500 \text { pounds } \\
\text { (approx. } \$ 835 \text { ) } \\
\text { or both \& mandatory license suspension }\end{array}$ & $\begin{array}{l}\text { A breath test may be requested } \\
\text { when driver is involved in a traffic } \\
\text { violation or suspected or } \\
\text { consuming alcohol }\end{array}$ \\
\hline
\end{tabular}




\begin{tabular}{|c|c|c|c|}
\hline COUNTRY & LIMIT & $\begin{array}{l}\text { SANCTIONS } \\
\text { (1st Orfense) }\end{array}$ & MISC. LAWS \\
\hline New Zealand & $\begin{array}{l}.08 \mathrm{blood} \\
500 \mathrm{ug} / \mathrm{l} \text { for } \\
\text { breath }\end{array}$ & $\begin{array}{l}\text { Min. suspension of } 6 \text { mos., fines, \& } \\
\text { possible prison sentence }\end{array}$ & Evidential breath tests are allowed \\
\hline $\begin{array}{l}\text { Australia } \\
\text { (ea. state \& } \\
\text { territory sets its } \\
\text { own BAC limit) }\end{array}$ & $\begin{array}{l}.05-.08 \text { per } \\
\text { se }\end{array}$ & & $\begin{array}{l}\text { Random breath testing is allowed } \\
\text { at road check } \\
\text { points }\end{array}$ \\
\hline Canada & .08 & $\begin{array}{l}\text { Fines up to } \$ 1,000 \text { and/or imprisonment } \\
\text { up to } 6 \text { mos. }\end{array}$ & \\
\hline Japan & .05 & $\begin{array}{l}\text { Penal servitude not to exceed } 3 \text { mos., or a } \\
\text { fine up to } 30,000 \text { yen (approx. } \$ 200 \text { ) }\end{array}$ & \\
\hline India & .09 & & \\
\hline Sri Lanka & .08 & & \\
\hline
\end{tabular}




\section{Endnotes}

1 Mandatory minimum for a DWI conviction -- 1st offense

2 Suspension

3 BAC level or levels which indicate prima facie evidence

4 Applies only to 1st illegal per se convictions.

5 Revocation

6 A restricted license may be issued for an implied consent law violation provided the defendant pleads guilty to a subsequent DWI charge.

7 The lower of the two numbers is driving while impaired; the higher is driving while under the influence.

8 License suspension for 1 year if the driver has a prior DWI offense conviction.

9 May not apply to certain offenders who have been suspended pursuant to the administrative per se law.

10 Mandatory community service regardless of whether there is a mandatory imprisonment sanction.

11 Competent evidence of DWI.

12 The court must sentence defendants to at least one of these sanctions but may sentence them to more than one such sanction.

13 This state has both prima facie and presumptive evidence laws with BAC levels of 0.10 .

14 Does not apply to illegal per se offense; this sentence only applies to "regular" DWI offenses.

15 One day imprisonment or 24 hours of community service if rehabilitation is taken.

16 The law states that the right to drive is "forfeited."

17 This BAC level is an inference of DWI.

18 Civil offense at a BAC level of 0.08 .

19 Permissive inference of a DWI offense.

20 Mandatory community service regardless of whether there is a mandatory imprisonment sanction. 


\section{SECTION III}

\section{LEGISLATIVE AND INSTITUTIONAL RESPONSES}

CHAPTER V BAC LIMITS AND LEGISLATION

Description of Laws $\quad 48$

Evaluation of BAC Laws $\quad 49$

Institutional Positions Regarding Lower BAC Limits 51

CHAPTER VI INSTITUTIONAL RESPONSE TO CHANGES

Description of Expected Institutional Responses by BAC Level

Workshop Participant Expectations at a BAC Level of 0.08

Workshop Participant Expectations at a BAC Level of 0.04

Workshop Participant Expectations at a BAC Level of 0.00

Summary and Conclusions 61

\section{SECTION III}

RECOMMENDATIONS AND FUTURE WORK

RECOMMENDATIONS AND FUTURE WORK

REFERENCES

\section{APPENDICES}

A Biographical Sketches of Panel Members

B U.S. BAC Legislation

C BAC Legislation in Foreign Countries

D Workshop Agenda

E Workshop Introduction

F List of Workshop Participants

$G$ Results Based on Breath Measures

H Relationship of Observable (Behavioral) Signs of Intoxication and Driving Impairment and Increased Crash Risk 


\section{APPENDIX D \\ WORKSHOP AGENDA}

Morning Session

8:00-8:10 Welcome and Opening Remarks

Overview of the Study

Orientation to Facilities

8:10-8:30 Introduction to Workshop Model

Objective of the Workshop

Rules of the Workshop Process

Results Expected from these Workshops

Review of Materials Previously Provided

8:30-9:30 Introduction of the Participants

9:30-9:50 Break

9:50-10:00 Review of Materials Previously Provided

10:00-12:00 Individual Presentations by Participants

Afternoon Session

12:00-1:00 Lunch

1:00-1:10 Review of Differences in Expectations within or between or among Institutions as Identified in Morning Session

1:10-1:55 $\quad 0.08$ Percent BAC Level (Open Discussion)

1:55-2:00 Note Break

2:00-2:45 0.04 Percent BAC Level (Open Discussion)

2:45-3:00 Break

3:00-3:45 0.00 Percent BAC Level (Open Discussion)

3:45-4:05 Break

4:00-5:00 Review of Workshop Accomplishments 


\section{APPENDIX E}

\section{WORKSHOP INTRODUCTION}

This appendix presents the comments made by the moderator at the workshops. These remarks were developed in advance of the workshops and were read verbatim to assure consistency.

\section{Overview of the Study}

"The workshop is part of a larger study that is being conducted by the National Highway Traffic Safety Administration to determine the blood alcohol concentration level at or above which an individual when operating any motor vehicle should be deemed to be driving while under the influence of alcohol. This study is being conducted as part of the Secretary of Transportation's responsibilities outlined in the Drunk Driving Prevention Act of 1988 (Public Law 100-690), Section 9003 - Alcohol Impairment Standards and Information Exchange. The study is being conducted in three phases. They are to determine:

1) What is the available evidence regarding the relationship between blood or breath alcohol concentration (BAC) driver impairment and crash risk? What is the current distribution of driver BAC levels on the road?

2) How would a lower BAC limit affect the institutions dealing with drinking and driving-the police, courts, jails, state and local officials, media, and others?

3) How will the institutional changes that might result from a lower BAC limit affect individual drinking and driving behavior?

"Information will be gathered from a number of sources to answer these questions. This workshop focuses on the second question, How would a lower BAC limit affect the institutions dealing with drinking and driving-the police, courts, jails, state and local officials, media, and other groups? Four Regional workshops are being held in Washington, DC, San Francisco, Kansas City and Atlanta. Approximately 25 participants will attend each workshop to discuss how different institutions currently respond to the statutory BAC limit, how you believe your type of institution would respond to a new limit, and how these actions would be sent to the public.

"Based upon these workshops and other information gathered throughout the study, NHTSA will prepare a report to Congress regarding the BAC topic. You will be 
identified as a contributor to this report. The study will be completed by December 1991. A progress report will be completed by this Fall."

\section{Introduction to Workshop Model}

"The workshop process was started when you completed the forms that were mailed to you and when you reviewed the results of this group's responses to the questions. We continue this morning with a discussion of changes in expectations that you may have experienced as a result of reading the responses of the other participants. This afternoon's session will be devoted to focussing on reactions of the system to specific changes in the BAC levels. And finally, you will again have an opportunity to write down your views about changes resulting from the BAC laws based upon information you know about your type of institution as well as information you may get from participating in the discussions."

\section{Objective of the Workshop}

"The objective of this workshop is to estimate how alternative BAC limits will affect ' the institutions dealing with drinking and driving. I will serve as the facilitator for the discussions. My firm is responsible for designing the workshop sessions, working with the National Highway Traffic Safety Administration staff, to facilitate the sessions, collect the information, and coordinate your involvement in the workshop process as participants.

"You were selected as participants, recommended by your peers to the National Highway Traffic Safety Administration, because you are knowledgeable in your field. You have hands-on experience in your professional area.

"As a participant, you have agreed to contribute information about how your "type" of institution, not necessarily your own specific institution, would react as a result of changes in the BAC limits. For example, media representatives have been invited to participate in the workshop, not as reporters, documenting the events of the day, but rather as contributors, representing all media. The workshop has been structured to give you an opportunity to listen to other participants representing other types of institutions which will be involved in the management of the BAC limits issue. This may be the first time you have heard perspectives from other professionals who may see the issue quite differently than you do. We ask you to consider these opinions and views and use this as a learning exercise to formulate statements about reactions of your type of institution to events that may or may not ever come to pass.

"There are a couple of observers here today who will not contribute actively to the sessions. They are here to listen only. They are staff of the National Highway Traffic Safety Administration and are here to listen and learn." 


\section{Rules of the Workshop Process}

"As we go through the day, l'd like you to keep some "rules" about the workshop process in mind. We are not forming a consensus statement! You are participating as an individual representing a "type" of institution. It is not necessary to sway the thinking and win over other participants to your thinking. I do ask you however to be assertive when you have information to offer that may be unique to your institutional setting - information that may not be known by one or more of the participants. There are no right answers. Responses will not be graded. As a participant you are asked to contribute to the discussions as completely as you can. As a member of a group discussion, remember to seek out opinions and ideas from all participants."

\section{Results Expected from these Workshops}

"At the end of the session today, you will each present in written form your expectations regarding changes resulting from new BAC limits. These written responses are expected to be different statements regarding the impact of changes in BAC limits. The National Highway Traffic Safety Administration does not have preconceived ideas of the outcome of this workshop. Your final statement will serve as a record of your participation, not identified with you personally, but as a representative of your "type" of institution. It is okay for you to change your mind from your earlier expectations to those you have now. "

\section{Review of Materials Previously Provided}

"As you know, we are dealing with three altemative BAC limits. A BAC limit is only one component of a complex system that affects drinking and driving. Other components include the other drunk driving laws, the police and courts who enforce these laws, state and local officials who can establish and encourage drunk driving programs, the alcohol beverage industry which can assert a profound influence on behavior through its advertising, community or national organizations such as MADD, SADD, and RID, the media which report on and influence the public's views on alcohol use and drunk driving, health professionals who help set attitudes and practices on alcohol use, jails and treatment facilities for convicted drunk drivers, and others. All these components interact to affect the daily drinking and driving decisions of individual drivers.

"Laws establishing BAC limits affect drinking and driving as they work through this system. The more we understand about each step, the better we are able to anticipate the effects that a reduced statutory BAC limit will have on drunk driving and alcohol-related crashes.

"How do different BAC limits affect the institutions dealing with drinking and driving? A BAC limit affects how police enforce drunk driving laws and how courts 
dispose of drunk driving charges. A BAC limit also affects how the media, restaurants, taverns, individual hosts, community groups, such as MADD, SADD, and RID, and others view drinking and driving. These institutions clearly interact with each other and respond to each other's practices. For example, the courts cannot convict a driver on drunk driving charges unless the police first bring charges. On the other hand, the police will not enforce a law unless their citations are upheld in court. It is far from clear how these institutions will react to a new BAC limit.

"How do different BAC limits, working through these various institutions, affect drinking and driving behavior? As the system - police, courts, media, other organizations - responds to a BAC limit, it sends many messages to individual drivers. The enforcement and conviction level, as publicized through the media, sends messages on the chance of being apprehended and convicted of drunk driving. Media accounts of drunk driving crashes send messages on the risk of a crash. Community groups and media send messages on social norms involving drunk driving. Restaurants with designated driver programs and sports arenas with limited alcohol sales policies send messages about acceptable drinking and driving behavior. We must estimate how individual drivers will interpret these messages and how they will modify their individual drinking and driving behavior." 


\section{APPENDIX F}

\section{LIST OF WORKSHOP PARTICIPANTS}

Reston, Virginia

April 11, 1990

Gill Cochran

116-B Cathedral Street

Annapolis, MD 21401

(301) 269-1552

Jean Cook

Legislative Liaison

NJ MADD

13 Clark Road

Barrington, NJ 08007

(609) 546-5566 (Chapter)

\section{H.A. Divine}

Director

School of Hotel, Restaurant \& Institutional Management

Penn State University

118 Henderson Building University Park, PA 16802

(814) 863-0009

John Dougherty

WBZ, TV-4, Boston

1170 Soldiers Field Road

Brighton, MA 02134

(617) 787-7145
Lawrence Frail

Prosecuting Attorney

Raleigh County Courthouse Annex

PO Box 907

Beckley, WV 25801

(304) 255-9148

Chief William D.E. Fury

Spring Lakes Heights

Police Department

555 Brighton Avenue

Spring Lake Heights, NJ 07762 (201) 449-6161

James Garside

Inspector

Nassau County Police Department

c/o First Precinct

1490 Franklin Avenue

Mineola, NY 11501

(516) 223-1100 
Robert Halpin

Chief - Operator Council

Rhode Island Division of

Motor Vehicles, Safety

and Regulations

345 Harris Avenue

Providence, RI 02909

(401) 277-2994

Jacqueline A. Ryles-Harris

Chief, Community Corrections

Prince Georges County DWI Facility

13401 Dille Drive

Upper Marlboro, MD 20772

(301) 952-7201

Howard B. Horowitz

Chief, Law Enforcement Section

Corporation Counsel's Office

District of Columbia

451 Indiana Avenue, NW, Room 323

Washington, DC 20001

(202) $727-9813$

William Lyons

Assistant Attomey General

New Hampshire Attorney General's Office

25 Capitol Street

Concord, NH 03301

(603) 271-3671

George R. McCarthy

Chairman

Massachusetts Alcoholic Beverages

Control Commission

100 Cambridge Street, Room 2204

Boston, MA 02202

(617) $727-3040$
John B. McDuffee

Coordinator

New Hampshire Highway Safety

Agency

117 Manchester Street

Concord, $\mathrm{NH} 03301$

(603) $271: 2131$

John Mancke

Attorney

Mancke and Wagner

2233 N. Front Street

Harrisburg, PA 17110

(717) 234-7051

Frank Matthews

Executive Director

Services to Overcome Drug

Abuse Among Teenagers-

Delaware, Inc.

625 Orange Street

Wilmington, DE 19801

(302) 656-4044

Edith Prague

State Representative

Legislative Office Building

Room 4047

Hartford, CT 06106

(203) $240-8487$

Nancy Ricci

State President

Citizen's Project to RID

17 Fritz Place

Wallingford, CT 06492

(203) 284-9879 
Joseph J. Strojnowski

Deputy Superintendent

New York State Police

Building $\$ 22$, State Campus

Albany, NY 12226

(518) 457-5936

Robert Suthard

Office of Public Safety

Commonwealth of Virginia

613 9th Street Office Building

Richmond, VA 23219

(804) 786-5351 
San Francisco, California April 18, 1990

Ken B. Anderson

Assistant Commissioner

California Highway Patrol

PO Box 942898

Sacramento, CA 94298-0001

(916) 445-5265

Shirley Anderson

Snowomish County MADD

8126 N.E. 142nd Place

Bothell, WA 98011

(206) 296-3667

Richard E. Erwin

Attorney

PO Box 203

Carpinteria, CA 93013

(805) 684-7335

Robert P. Fahrendorf

Attomey

$316 \mathrm{~S}$. Arlington Avenue

PO Box 3677

Reno, NV 89505

(702) 348-7775
Lynn Pace Blake

Executive Director

Business Council for Alcohol

Education

PO Box 3406

Phoenix, AZ 85030

(602) 256-2660

Roy A. Ferguson

State Representative

Washington State House of

Representatives

418 John L. O'Brien Building

Olympia, WA 98504

(206) 786-7936

Kay Glazer

MADD of Clachama County

1175 Westward Ho Road

Lake Oswego, OR 97034

(503) 656-4805

Jerry G. Landau

Chief

Controlled Substances Division

Maricopa County Attomey's

Office

$111 \mathrm{~W}$. Monroe, Suite 800

Phoenix, AZ 85003

(602) 495-8484 


\author{
D. Ronald Hyde \\ Judge \\ Livermore-Pleasanton-Dublin \\ Municipal Court District \\ 5672 Stoneridge Drive \\ Pleasanton, CA 94566 \\ (415) 463-0595
}

Patricia A. Lynch

City Attorney

PO Box 1900

Reno, NV 89505

(702) $785-2050$

Julie Kawahara - Holl

Prevention/DUI Coordinator

Community Substance Abuse

Services

San Francisco Department of

Public Health

1380 Howard Street, 4th Floor

San Francisco, CA 94103

(415) 255-3528

Karen Mills

State Representative

Arizona Legislature

1700 West Washington

Phoenix, AZ 85007

(602) $542-3376$

Ford W. Kiene

General Manager

City Beverages Distributors, Inc.

PO Box 1357

Kent, WA 98035-1357

(206) $852-4010$
Randy Oaks

Lieutenant

Las Vegas Metropolitan

Police Department

400 East Stewart Avenue

Las Vegas, NV 89101

(702) $386-3394$

Brad Patten

Medical Writer

The Phoenix Gazette

120 E. Van Buren Street

Phoenix, AZ 85004

(602) 271-8634
A. A. Pierce
Director
Califormia Department of Motor
Vehicles
2415 First Avenue
Sacramento, CA 95818
(916) $732-0251$

\section{Rollie T. Pean \\ Chief}

Department of Public Safety

500 Central Avenue

Coos Bay, OR 97420

(503) 269-8914

Wayne R. Teglia

Director

Nevada Department of Motor

Vehicles and Public Safety

555 Wright Way

Carson City, NV 89711-0900

(702) 687-5375 


\section{W. Dan Phillips}

Judge

Kitsap County District Court

614 Division Street

Port Orchard, WA 98366

(206) 895-3769

\section{Scott Wise}

Executive Director

Safety Consultant Services, Inc.

9928 Flower Street, Suite 101

Bellflower, CA 90706

(213) $920-7689$

\section{Donna Pickering}

MADD of Arizona

5150 N. 16th Street

Building B, Suite 146

Phoenix, AZ 85064

(602) 279-2043

\section{Lynden Woodmansee}

Major

Washington State Patrol

General Administration Building

AX-12

Olympia, WA 98504-0612

(206) 753-5159 
Kansas City, Missouri

April 25, 1990

Rodney Burke

Lieutenant

Springfield Police Department

312 E. Chestnut Street

Springfield, MO 65802

(417) 864-1789

Joseph Cambiano

Municipal Judge

City of Grandview, Missouri

1005 Grand, Suite 438

Kansas City, MO 64106

(816) 221-2737

Larry A. Davis

Defense Attomey

9239 Gross Point Road

Suite 300-302

Skokie, IL 60077

(708) 677-5202

Sharon F. Faville

Director

Alcohol Countermeasures

Probation

$226 \mathrm{~W}$. Wallace Street

Fort Wayne, IN 46802

(219) 428-7523
William Grismer

Kragie/Newell Advertising

2633 Fleur Drive

Des Moines, IA 50321

(515) 288-7910

Richard J. Hackett

Chief of Traffic

State's Attomey's Office -

Cook County

Chicago Traffic Center, Room 4

$321 \mathrm{~N}$. LaSalle Street

Chicago, Il 60610

(312) $822-3520$

James Hood

Speaker Pro Tem

South Dakota House of

Representative

Box 611

Spearfish, SD 57783-0611

(605) 642-2757

Harold W. LeGrande

Superintendent

Nebraska State Patrol

PO Box 94907

Lincoln, NE 68509-4907

(402) 471-4545 
Patricia Libbert

Assistant Administrator

Department of Revenue

Drivers License Bureau

301 W. High Street

Jefferson City, MO 65102

(314) 751-3103

Don Paulin

Administrative Assistant to the Governor-Iowa

State Capitol Building

Des Moines, IA 50319

(515) 281-8318

James E. Peters

President

Responsible Hospitality Institute 4340 Scotts Valley Drive

Suite I

Scotts Valley, CA 95066

(408) 438-1404

Winn L. Richards

Senator

Utah State Senate

3955 Harrison Blvd.

Odgen, UT 84403

(801) 399-1050

S. Duane Richens

Superintendent

Utah Highway Patrol

4501 South 2700 West

Salt Lake City, UT 84119

(801) $965-4379$
William J. Ritter

Program Director

Drivers Educational

Alternative Program

3663 Glenmere Drive

Youngstown, $\mathrm{OH} 44511$

(216) $743-9975$

Bill Sammon

President

MADD, Polk County Chapter

1111 Ashworth Road

West Des Moines, IA 50265

(515) 225-5233

John W. Smith

Vehicle Administrator

Department of Revenue

Division of Vehicles

Docking State Office Building

Topeka, KS 66612-2021

(913) 296-2013

Jerry L. Soucie

Defense Attorney

Nebraska Association of Criminal

Defense Attorneys

927 East Sage Road

West Chester, PA 19382

(215) 430-6682

Charles Taylor

State Director

Tavern League of Wisconsin

636 State Street

Madison, WI 53703

(608) $257-3330$ 
John A. Topolnicki, Jr.

Chief Deputy District Attorney

District Attorney's Office

18th Judicial District

5606 S. Court Place

Littleton, CO 80120-1205

(303) 794-4484

James M. Vukelic

Chief Deputy Attomey General

North Dakota Attomey General's Office

600 East Blvd.

Bismarck, ND 58505

(701) 224-2210
Daniel G. Welter

Judge

Circuit Court of Cook County

9951 S. Damen

Chicago, IL 60643

(708) $974-6320$

Terry L. Witkowski

Executive Director

Milwaukee Safety Commission

Safety Academy, Room 151

6680 North Teutonia Avenue

Milwaukee, WI 53209

(414) $935-7191$ 
Atlanta, Georgia

April 27, 1990

John H. Adams

Judge

Ninth Judicial Circuit

Orange County Courthouse

46 East Robinson, Room 217

Orlando, FL 32801

(407) 836-2281

Donald Hansen

Executive Vice President

Texas Hotel and Motel

Association

900 Congress Avenue, Suite 310

Austin, TX 78701

(512) 474-2996

Kate Cunningham

Assistant Solicitor

Solicitor's Office

9th Circuit Court

PO Box 70100

North Charleston, SC 29415

(803) $740-5850$

John L. Howell

Lieutenant

Legislative Liaison Officer

Georgia State Patrol

PO Box 1456

Atlanta, GA 30371

(404) 624-7423

Ray Elliott

Assistant District Attomey

320 Robert S. Kerr Avenue

Room 505

Oklahoma City, OK 73102

(405) 278-1663

Donald J. Larson

Region IV Administrator

MADD

PO Box 66494

Baton Rouge, LA 70896

(504) $383-3000$

Robert K. Gill

Assistant Criminal District

Michael L. Lightsey

Operations Coordinator

Attorney

Tarrant County District

Attomey's Office

Mississippi Alcohol Safety

Education Program

PO Box 5287

200 West Bellonap

Fort Worth, TX 76196-0201

(817) 334-1819

Mississippi State, MS 39762

(601) 325-3423 
Norman MeNickle

Chief of Police

Stillwater Police Department

PO Box 1725

Stillwater, OK 74076

(405) $372-4171$

Fernando R. Macias

State Senator

New Mexico State Senate

118 S. Downtown Mall, Suite A

Las Cruces, NM 88001

(505) 524-7809

Don Pendleton

Captain

Kentucky State Police

Post 7

Eastern Bypass

Richmond, KY 40475

(606) 623-24:04 
F. T. Ratchford, Jr. Attomey

Merritt \& Ratchford.

Attorneys at Law

PO Box 12544

Pensacola, FL 32573-2544

(904) $432-7661$

William D. Teem

Colonel

North Carolina State

Highway Patrol

PO Box 27687

Raleigh, NC 27611

(919) 733-7952

William W. Watt

Municipal Court Judge

City of Little Rock

600 West Markham Street

Little Rock, AR 72201

(501) 371-4733 


\section{APPENDDX G \\ RESULTS BASED ON BREATH MEASURES}

To determine whether breath and/or blood testing is being used in low BAC research studies, and whether a particular testing method is associated with specific BAC levels, we reviewed 36 research studies on low BAC levels and performance decrement selected from the Transportation Research Board's Zero Alcohol and Other Options report and NHTSA's "Alcohol and Highway Safety 1989: A Review of the State of Knowledge." Target BAC levels in the studies ranged from 0.00 to 0.15 .

Twenty-two of the studies measured the subjects' BAC levels with breath testing devices, 10 used blood samples, 1 study measured BAC in both breath and blood, and BAC level was not measured in 3 studies (subjects were given a standard amount of alcohol in order to reach a target BAC level). The testing method chosen for each study did not appear to be related to the target BAC levels. 


\section{APPENDIX H \\ RELATIONSHIP OF OBSERVABLE (BEHAVIORAL) SIGNS OF INTOXICATION AND DRIVING IMPAIRMENT AND INCREASED CRASH RISK}

Presumptive BAC laws create a rebuttable legal presumption that a driver is presumed impaired (or intoxicated) if the driver's BAC is at or above a specified level (e.g., .10). This kind of law shifts the burden of proof regarding impairment from the prosecution to the defendant once the defendants BAC is established. The defendant is entitled to introduce evidence to raise a reasonable doubt that they were impaired, regardless of their BAC level. When a presumptive BAC limit is part of the case against a driver, the defendant's attorney will seek to introduce evidence that their client was not impaired. To this end, they try to show that the defendant did not exhibit obvious signs of impairment. They were not weaving down the road, they did not appear drunk, with disheveled clothes, hair, slurred speech, staggering, etc.

The prosecution presumes the defendant is impaired based on the BAC reading and the defense argues that the defendant was not impaired based on the lack of the appearance of impairment. The defense position implies that people whose driving ability is impaired will always appear drunk or obviously impaired by alcohol. The unstated assumption is that if the person does not appear impaired then their driving was not impaired. This situation raises an interesting question regarding which is a better indicator of driving impairment, BAC, or appearance.

Virtually all of the extensive research that has been done on the relationship between alcohol and impaired driving ability and increased crash risk has sought to establish the relationship between BAC level and driving ability, not the appearance of alcohol intoxication and driving ability. In order to see if any published research had examined the relationship between the appearance of impairment and driving ability, a computerized literature search of this topic was conducted for this report. Three data bases were covered: TRIS (Transportation Research Information Services), PsychInfo (Psychological Abstracts Information Service), and Dissertation Abstracts Online. The search produced over three hundred citations, however, after screening and reviewing abstracts, no studies were found that had examined the relationship between observable or behavioral signs of impairment and impaired performance on driving related skills.

Thus, while there is a good scientific basis for relating alcohol use as measured by BAC to impaired performance, there is no basis for relating the appearance of intoxication or impairment to impaired performance or driving related skill. 
DOT HS 807692

February 1991

NRD-40 